NBSIR 73-418

\title{
Test Methods for Determining Coaxial Cable Response to Bending Strain, Bulk Compression (Hydrostatic Pressure), Axial Strain, and Torsional Strain
}

J. F. Mayo Wells, S. Edelman, and J. Jacobs

Electronic Technology Division Institute for Applied Technology

National Bureau of Standards

Washington. D. C. 20234

July 1973

Final

\section{Prepared for}

Defense Special Projects Group, Department of Defense Sponsoring Agency was dissolved in June of 1972 

NBSIR $73-418$

\section{TEST METHODS FOR DETERMINING COAXIAL \\ CABLE RESPONSE TO BENDING STRAIN, BULK COMPRESSION (HYDROSTATIC PRESSURE), AXIAL STRAIN, AND TORSIONAL STRAIN}

J. F. Mayo-Wells, S. Edelman, and J. Jacobs

Electronic Technology Division Institute for Applied Technology National Bureau of Standards

Washington, D. C. 20234

July 1973

Final

Prepared for

Defense Special Projects Group, Department of Defense Sponsoring Agency was dissolved in June of 1972

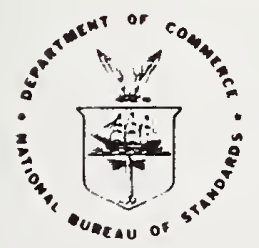

U. S. DEPARTMENT OF COMMERCE, Frederick B. Dent, Secretary 

TEST METHODS FOR DETERMINING COAXIAL CABLE RESPONSE TO BENDING STRAIN, BULK COMPRESSION (HYDROSTATIC PRESSURE), AXIAL STRAIN, AND TORSIONAL STRAIN

\author{
Final Report \\ to the \\ Defense Special Projects Group \\ Tasking Message UN CLAS/711A2167 \\ NBS Project 4253445 \\ Prepared by \\ J. F. Mayo-Wells, S. Edelman, and J. Jacobs
}

\title{
ABSTRACT
}

Test methods have been developed for measuring the response to specimen one-meter lengths of coaxial cables, considered as sensing elements, to four separate types of strain: bending strain, bulk compression, axial strain, and torsional strain. Measurements were made on commercially available coaxial cables and on coaxial cables made in the laboratory from insulated wire and wire braid. Cable dielectric materials investigated include polytetrafluoroethylene (TFE), fluorinated ethylene propylene polymer (FEP), cellular FEP, polyethylene, cellular polyethylene, and polyvinyl chloride (PVC). Data from the measurements are included in an appendix. 



\section{TA B LE OF C O NTENTS}

TEST METHODS FOR DETERMINING COAXIAL CABLE RESPONSE TO BENDING STRAIN, BULK COMPRESSION (HYDROSTATIC PRESSURE), AXIAL STRAIN, AND TORSIONAL

STRAIN

Introduction .............. l

1. Task 1 - Development of Measurement Methods and Equipment . 2

2. Task 11 - Measurement of Cable Response to Strain . . . . . 14

3. Task 111 - Criteria for Cable Evaluation . . . . . . . . . 20

4. Task IV - Poling Methods . . . . . . . . . . . . . . . . . 21

5. Results and Conclusions . . . . . . . . . . . . . . 24

6. Recommendations . . . . . . . . . . . . . . . 27

7. References... . . . . . . . . . . . . . . . 29

Appendix A - Tabulation of Travel, Consultation, and Presentations for Project 4253445 . . . . . . . . . 30

Appendix B - Measurements for Bending Strain Test Development. 31

Appendix C - Evaluation of Tests . . . . . . . . . . . 34

Appendix D - Criteria for Cable Evaluation . . . . . . . . 38

Appendix E - Cable Response Data . . . . . . . . . . . 47

Appendix F - Figure 17. Bending-Strain Response of an Unpoled Specimen of Cable Type D-250-4214 as a Function of Beam Displacement, for Two Driving Frequencies. . 115 



\section{INTRODUCTION}

This document reports work done as part of NBS Project 4253445 , established in response to the Dutch Door Tasking Message UN CLAS/711A2167 from the Defense Special Projects Group (DSPG) addressed to N. T. Larsen and T. M. Rizzi of the National Bureau of Standards (NBS). At the initiation of the project, various objectives were identified pertaining to the overall goal of providing an approximate characterization of the response of selected coaxial cables to mechanical strain. The intent was to make a limited number of measurements on one or two specimens of each cable type of interest to determine the order of magnitude of cable response to given values of mechanical strain. The small number of measurements entailed could not be expected to provide statistically valid levels of cable response, but were intended to provide guidance in planning the focus of attention for future work. In addition, several objectives were identified in connection with poling experiments to enhance such response. Because it might not be possible to achieve all of these objectives within available resources, it was recognized at the outset that priorities would need to be established for the component tasks and, further, that these priorities would need to be modified in the course of the work in the light of intermediate results. The component tasks are listed below. Task 1 was identified intially as the principal task; priorities of the other subordinate tasks were left to be established later.

1. Develop test methods to measure the response to specimen lengths of coaxial cables, considered as sensing elements, to four separately applied strains: (a) bending strain, (b) hydrostatic pressure (bulk compression), (c) axial strain, and (d) torsional strain.

11. Measure stability of the cable-generated signal as a function of: (a) time, (b) bias voltage, and (c) environmental parameters such as temperature, pressure, and relative humidity.

111. Evaluate four cable dielectric materials available in commercial coaxial cables for various features including: (a) cost, (b) mechanical ruggedness, (c) life, (d) stability of signal-generating elements, (e) uniformity of manufacture, (f) uniformity of response along length, and (g) linearity of hydrostatic-pressure response.

IV. Evaluate at least two methods of poling as a means of increasing cable sensitivity. Possible poling methods to be considered include: (a) application of heat together with ac and/or dc electric fields, (b) cold working, (c) direct injection of charge, and (d) irradiation (exposure to hard radiation). 
Elimination of task elements judged to be unlikely to produce useful information, substitution of other tasks as appropriate, and the like would be made by consultation between DSPG and NBS. Task elements found to require too great an expenditure of time or funds would be particularly subject to critical review. (An example of changes that were made is the agreement to limit consideration in Task IV of poling by either direct charge injection or by exposure to hard radiation to measurements on poled samples to be supplied by the sponsor. Also, at times during the project, the sponsor requested that minor tasks be carried out to provide a quick answer to a question that had been raised. An example is the request to prepare and measure a cable maintained for several days at an elevated temperature and with no electric poling field applied.)

In addition it was stipulated that the NBS group would maintain liaison with a group in the U. S. Army Mobility Equipment Research and Development Center who were concerned with applications, under contract to DSPG, and that representatives of the DSPG would be kept informed of progress at all stages. Major contacts are listed in Appendix A. In the following, the individual tasks are discussed in the order in which they appeared in the work statement.

\section{TaSk 1 - DEVELOPMENT OF MEASUREMENT METHODS AND EQUIPMENT}

In connection with Task I, a key question discussed with DSPG at the beginning of the project related to identification of levels of the four strains that would be representative of the envisioned application. Little information on this point was available, and it was agreed that the sponsor would have an outside agency supply pertinent data early enough in the course of the work to permit at least some measurements for each type of cable dielectric to be made at realistic levels. It was agreed further that work on this first-priority task should not be deferred while awaiting these data, but that experiments would proceed on the basis of "best guesses" of levels of strain that might yield useful information.

One such guess was the expectation that response to hydrostatic pressure would be the most significant signal mode. Accordingly, the hydrostatic pressure apparatus was scheduled to be constructed first. It was agreed to consider first the feasibility of developing an apparatus to simulate some of the conditions of the envisioned application, specifically by immersion of the cable sample in a particulate medium. This approach was abandoned after further consultation with the sponsor because of the mathematical complexity of the analysis of pressure wave propagation and because of the severity of the problem of interpretation of the results. Therefore, and at the expense of being unable to vary (and hence simulate) environmental parameters, an apparatus was designed in which the cable specimen would be immersed in water; the experimental arrangement is described under 1.2. 
Experts in the noise behavior of coaxial cables who were consulted were of the opinion that the response to bending strain was likely to be the second most significant signal mode after hydrostatic pressure. Hence, the bending strain experimental arrangement was scheduled next. It was designed while details of the pressure apparatus were still being discussed and was, in fact, the first apparatus completed.

Results from the axial strain and torsional strain arrangements showed these modes to generate much larger cable outputs at the strain levels applied than pressure and bending. The proviso "at the strain levels applied" emphasizes the continuing lack of guideline information.

\subsection{Bending Strain Test}

The bending strain test was designed to subject a specimen cable to bending strain, alone, or with a minimum contribution from other strain modes, especially axial strain. To accomplish this, the cable is positioned along the neutral plane of a cantilevered beam. The neutral plane is defined as the plane over the extent of which an infinitely thin sheet would experience no axial strain when the driven end of the beam is deflected. The beam is a sandwich of two halves bolted together, having matching machined grooves in the two mating surfaces. The grooves are partially filled with resilient material, such as polyurethane foam, so that any axial strains will be relieved while the bending of the beam will be transmitted to the cable. The beam is triangular in planform so that the bending curvature is constant along the long axis of the beam when the free (in this case, driven) end of the beam is deflected by a force acting in a direction perpendicular to the broad surfaces of the beam. Figure 1 shows the beam geometry and dimensions. The beam, made from 6061-T6 aluminum alloy, can accommodate a cable specimen one meter long.

The force for beam deflection is provided by a shaker acting through a vertical rod that is sufficiently flexible to minimize side loading of the shaker armature resulting from small misalinements between the armature axis and the hole in the beam into which the rod fits.

Measurements were made using two shaker systems: one providing up to $1500 \mathrm{~N}$ with a lower frequency limit between $\mathrm{I}$ and $5 \mathrm{~Hz}$, and the other rated at $275 \mathrm{~N}$ from $5 \mathrm{~Hz}$ to $9 \mathrm{kHz}$ and with reduced force available to be low $0.02 \mathrm{~Hz}$. Test frequencies ranged primarily from 0.02 to $70 \mathrm{~Hz}$. The larger shaker system had an accelerometer mounted in the shaker head used to monitor shaker acceleration. For this purpose, the output of the accelerometer was supplied to a charge-sensitive amplifier set for the accelerometer sensitivity of $12.08 \mathrm{pC} / \mathrm{g}_{n}$, and the output of the amplifier was displayed by a digital voltmeter $\left(g_{n}=9.807 \mathrm{~m} / \mathrm{s}^{2}\right)$. 

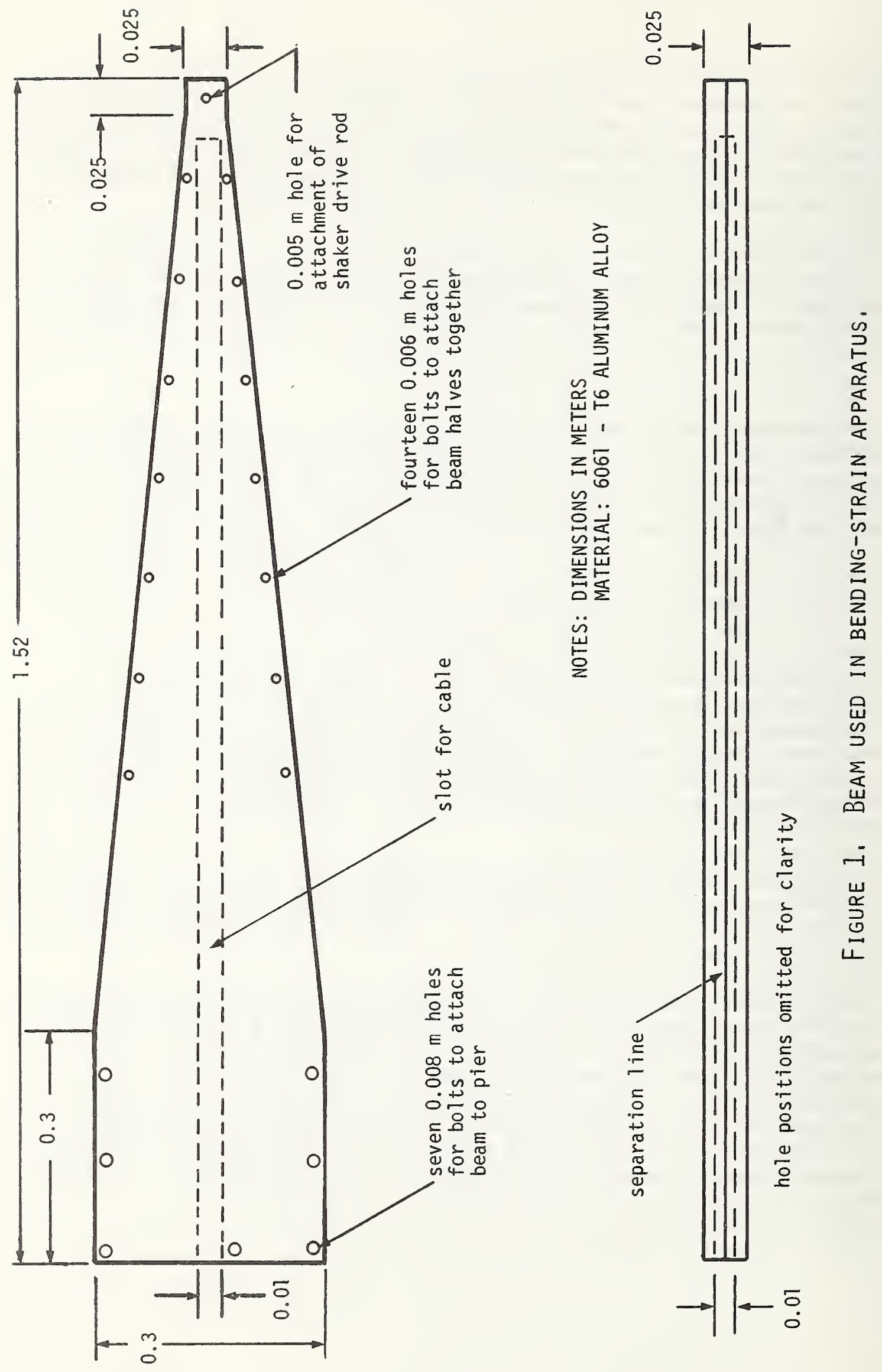


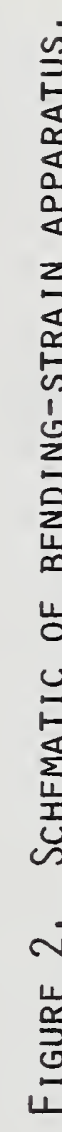

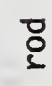

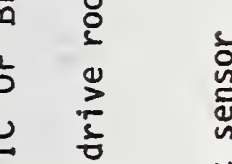

$+$

छ

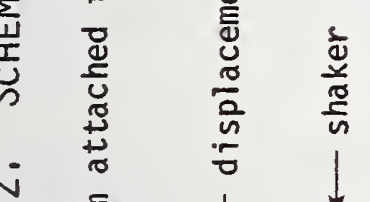

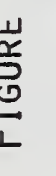

.

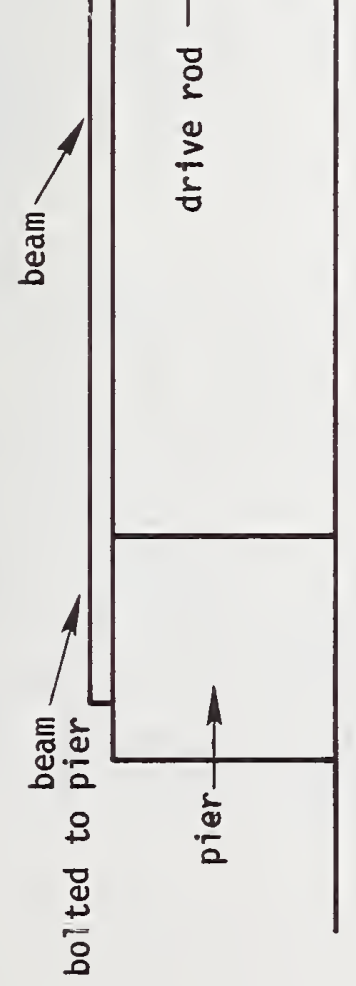

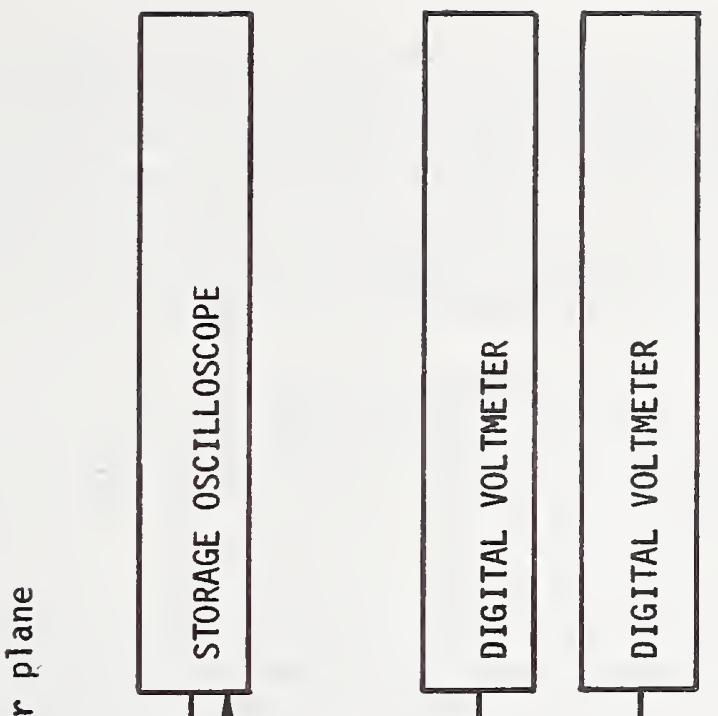
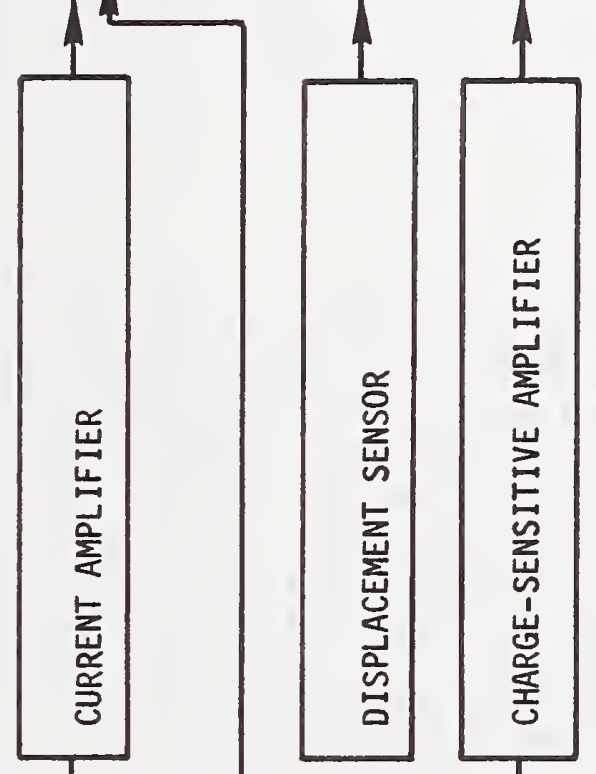

눈

뭄

禾

$z_{n}$

뜬

崖
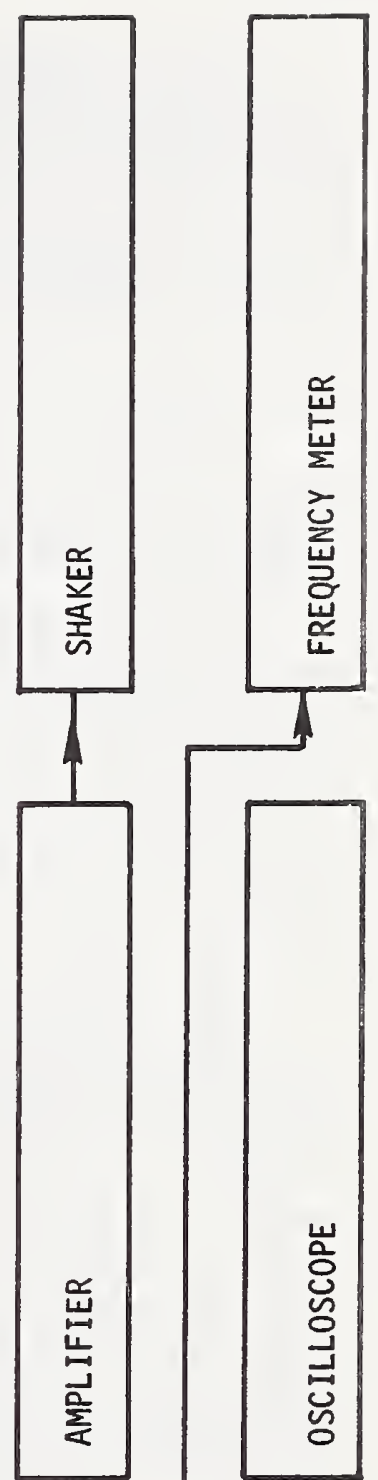

兽 
Displacement of the beam is measured with an eddy-current displacement measuring system. Figure 2 shows a schematic of the bending strain test apparatus. Over the range of interest, the system provides a displacement indication with a least count corresponding to $2.5 \times 10^{-6} \mathrm{~m}$. A dc-responding digital voltmeter included in the system provides a readout usable to about $10 \mathrm{~Hz}$; above this 1 imit an rms digital voltmeter is used. The radius of curvature $R$ is given by the relation:

$$
R=\frac{1}{2}\left(\frac{L^{2}}{y}+y\right),
$$

where $L$ is the length of the beam and $y$ is the displacement of the driven end of the beam.

Acceleration at the driven end of the beam is monitored using an accelerometer with a sensitivity of $6.3 \mathrm{mV} / \mathrm{g}_{\mathrm{n}}$. The output is displayed on one channel of a dual-beam, dual-channel storage oscilloscope. (The possibility of deviation from a monotonic increase in measured acceleration along the long axis of the beam from the fixed end to the driven end was examined at $10-\mathrm{cm}$ intervals using an accelerometer with a sensitivity of $21 \mathrm{mV} / \mathrm{g}_{n}$. Up to $70 \mathrm{~Hz}$ no such deviation was detected. Typical data for $33.9 \mathrm{~Hz}$ are given in Appendix B, 1.)

The length of cable under test is connected to a current amplifier, and the output of this instrument is displayed on the other channel of the storage oscilloscope. The current amplifier used has independent settings for gain and rise time. The gain adjustment is available in decade steps and is calibrated in units of V/A; the output of the instrument is a voltage proportional to the input current multiplied by the gain setting. The rise time control is an adjustable low-pass filter with a rolloff of $12 \mathrm{~dB}$ per octave. The filter accepts the signal from the input amplifier; the rise time is the time in milliseconds for this signal to rise from $10 \%$ to $90 \%$ of its peak value. Ultimate sensitivity of the instrument is $3 \times 10^{-15} \mathrm{~A}$, but this sensitivity is limited by various settings of rise time and gain.

The displacement sensor is calibrated by direct optical measurement. The driven end of the beam is observed through a long-working-distance microscope equipped with a micrometer eyepiece. Two distinct images representing the maximum excursion of the beam are observed for driving frequencies of $20 \mathrm{~Hz}$ and above. These images appear and may be identified because the beam spends more time near the ends of its excursion where the velocity momentarily becomes zero than elsewhere. The lower frequency limit referred to is a function of illumination of the beam, beam vibration amplitude, and the observer. A strobe lamp, triggered by the same oscillator that provides input for the shaker amplifier, and set to slash at twice the trigger frequency with adjustable phasing, provides additional illumination of the beam end. With practice an operator was consistently able to make measurements with a resolution better than 
$1.8 \times 10^{-\kappa} \mathrm{m}$. Typical data from one five-trial set of measurements are presented in Appendix B, 2. A comparison of measurements made with the displacement sensor and with the microscope for five vibration amplitudes is presented in Appendix B, 3 .

\subsection{Bulk Compression Test}

Figure 3 shows a schematic of the apparatus developed for the bilk compression test. This test is designed to subject a specimen length of cable to hydrostatic pressure with a minimum of other strain modes

present. In the apparatus, the cable is loosely constrained to lie along the long axis of a water-filled pipe by fastening the cable to a piece of methylmethacrylate with strips of masking tape spaced at approximately 15-cm intervals. Approximately a meter of cable is subjected to pressure in the test. The cable passes through seals in the pipe end caps and the cable ends are accessible. The seals are simple packing glands with vacuum wax as the packing. The seal is made after the cable is in place in such a manner that little or no torsional strain is applied to the cable. This arrangement also permits testing the response of meterlength sections of longer cables.

Pressure pulses are applied to the water through an air-water interface in a narrow-diameter standpipe. A silicon strain gage pressure transducer is used to measure the water pressure at the center of the main pipe. Output from the specimen under test is applied to the current amplifier described in the preceding section and the amplifier output is displayed on a storage oscilloscope.

The pressure pulses are derived from a fast-acting solenoid valve which is in turn controlled by switches actuated by a cam wheel. The cam is driven by a synchronous motor slaved to an adjustable-frequency oscillator signal. Figure 4 is a schematic of the arrangement. Adjustable restrictions in the form of needle valves mounted in the output and exhaust lines close to the valve permit some shaping of the pressure pulses from the solenoid valve. Repetition rates of $0.1,0.2,0.5,1.0$, 1.5 , and $2.0 \mathrm{~Hz}$ are used.

The air supply is laboratory compressed air supplied at either $10^{5} \mathrm{~Pa}$ or $7 \times 10^{5} \mathrm{~Pa}$ and regulated to a pressure appropriate for the particular test. A bourdon-tube element air pressure gage is used to measure regulator output pressure. An operator setting a given pressure uses this gage and, as a check, the stored oscilloscope display for several cycles of the pressure transducer output. Pressure transducers of this type are likely to drift no more than one percent of the full-scale value over a period of one year, assuming that they are not subjected to misuse. Assuming a worst-case drift of $\pm 1 \%$ over the range of interest (corresponding to two-thirds of the range of the transducer), it is estimated that an experienced operator can set the pressure to within $\pm 5 \%$, e.g., to within $\pm 4 \times 10^{3} \mathrm{~Pa}$ of the desired $8 \times 10^{4} \mathrm{~Pa}$. 

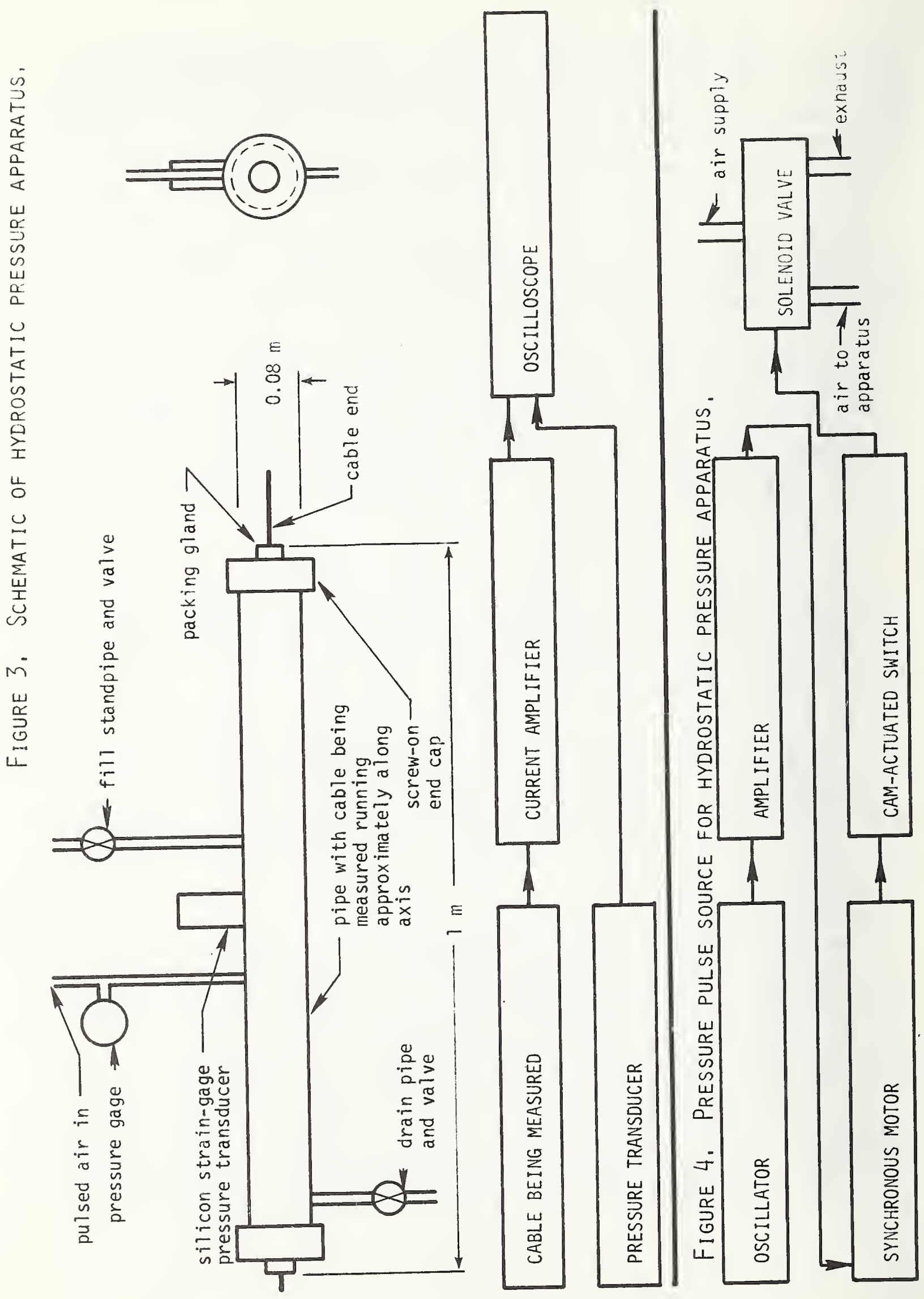


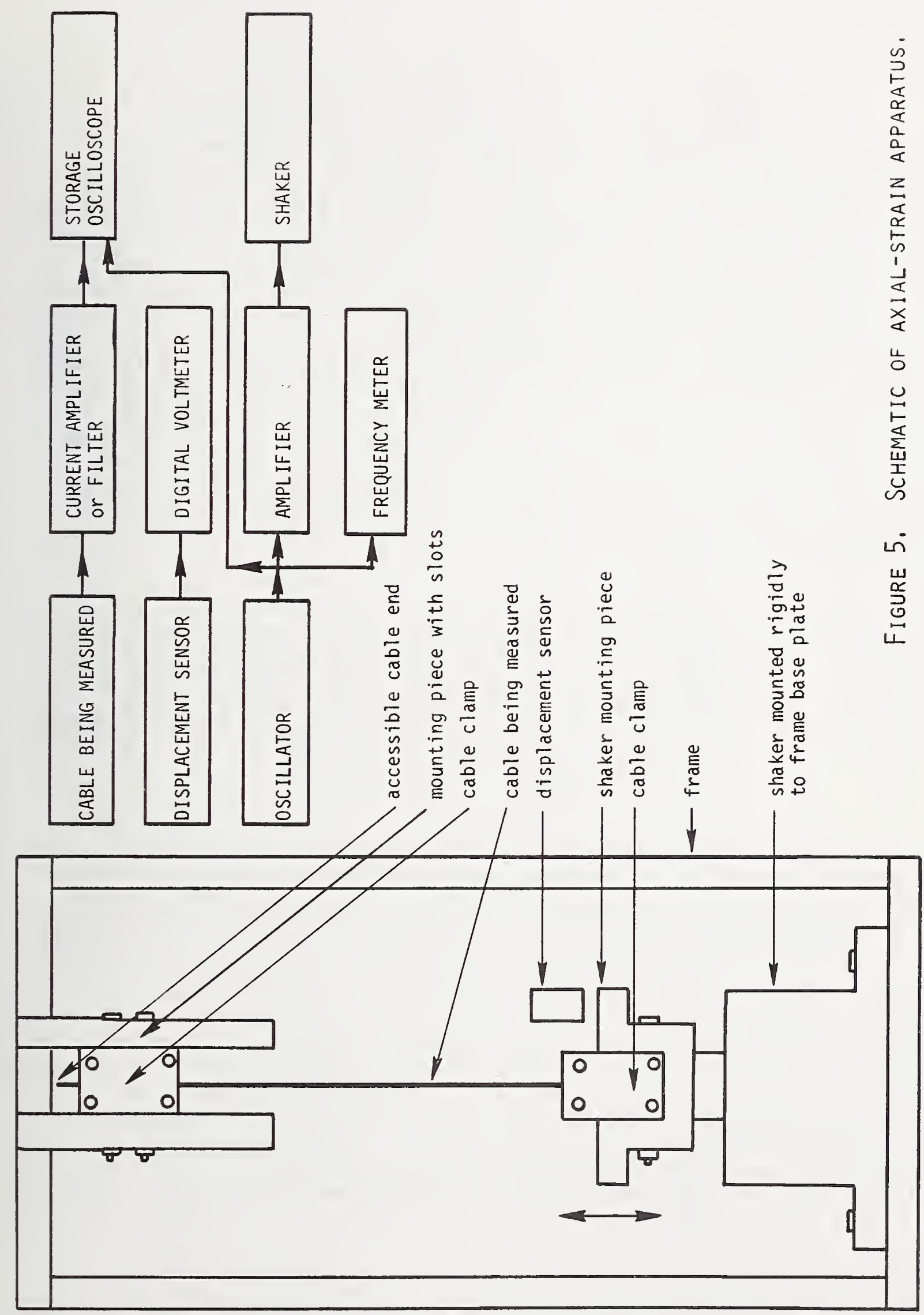




\subsection{Axial Strain Test}

Figures 5 and 7 are diagrams of the axial strain apparatus, equipment for a test which is designed to subject a specimen length of cable to axial strain with a minimum of other strain modes present. The cable is held vertically between foam-padded clamps, one mounted on a rigid frame and the other mounted on a shaker head so that the long axis of the cable is in the direction of motion of the shaker. The shaker is mounted to the frame so that relative motion between the two clamps is confined to that produced by the shaker. The output of the cable is fed to either the current amplifier or a band-pass filter. The output of either the current amplifier or the filter is displayed on one channel of a dualbeam, dual-channel storage oscilloscope. (Outputs of cables in this mode have for some dielectrics been large enough to permit use of the filter without amplification other than that provided by the oscilloscope preamplifier.) The shaker is driven by a power amplifier excited by an oscillator; the oscillator waveform is displayed, for comparison, on the other channel of the oscilloscope. To monitor displacement, the motion of an extension piece mounted on the shaker head is measured with the eddy current displacement sensors. The typical frequency range is from 0.05 to $100 \mathrm{~Hz}$.

Some cables had a tendency to vibrate in a lateral mode at certain frequencies. To restrain this mode, very soft foam material was brought to bear lightly on two oppostite sides of the cable for approximately three-fourths of the one-meter length. Measurements taken at frequencies at which this mode is not excited were found to show no significant differences with or without the foam damping. The restraints are to be used whenever a cable exhibits lateral motion.

\subsection{Torsional Strain Test}

Figures 6 and 7 are diagrams of the torsional strain apparatus, equipment for a test which is designed to subject a specimen length of cable to torsional strain with a minimum of other strain modes present. The cable is held vertically between padded clamps. One clamp is mounted to a rigid frame and the other to a moving member rotatably mounted to the frame. The configuration is such that the cable is held fixed at its top end. The lower end of the cable, the clamp, and the moving member can rotate about the long axis of the cable. The moving member is provided with an arm so that the long axis of the arm moves in a plane perpendicular to the long axis of the cable. A small shaker is mounted so that its direction of motion is in the plane of movement of the arm and perpendicular to the long axis of the arm. A short extension from the shaker head bears against one side of the arm, and the arm is spring-loaded lightly against the shaker head extension. Movement of the shaker thus pivots the arm and applies torsional strain to the cable. Shaker drive, typical 


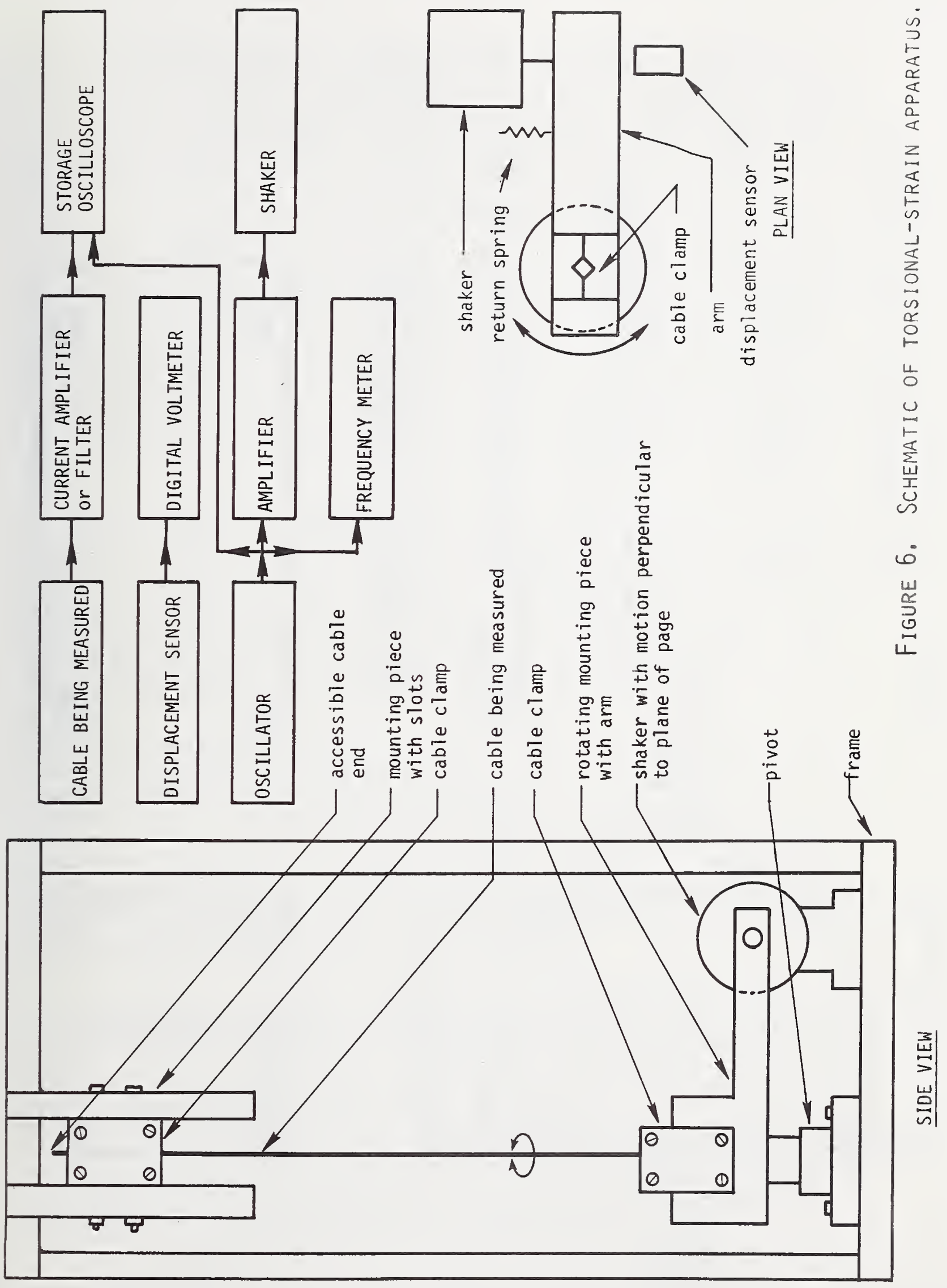




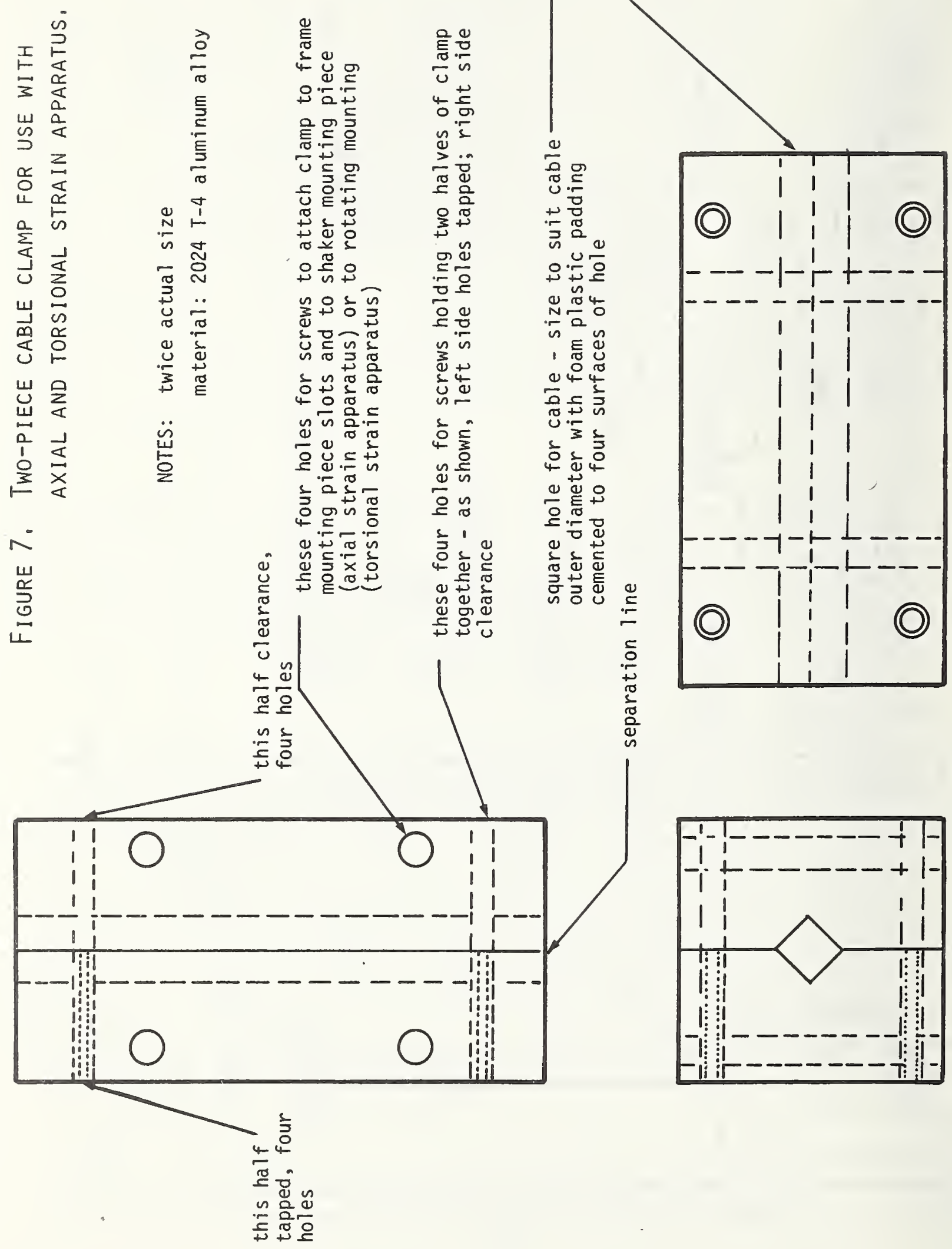


range of frequencies used, and cable output measurement procedures are as for the axial strain arrangement. Displacement of the arm was measured $12.7 \mathrm{~cm}$ (5.0 in.) from the pivot with the displacement sensor. The lateral motion referred to in the description of the axial strain arrangement also occurred in some of the torsional strain measurements and was dealt with in the same manner.

\subsection{General Measurement Considerations}

Noise. Coaxial cables used to connect cables under test to measuring instruments will themselves generate noise in response to mechanical strain induced by movement. This together with ambient electromagnetic fields determined a threshold of sensitivity for each measurement run. The impedance of the cable under test is typically $10^{11}$ to $10^{14}$ ohms. This high impedance necessitates careful shielding and attention to the avoidance of ground loops. An effort was made to select "quiet" cables for connecting the specimen cable to the current amplifier and to keep these connecting cables as free from mechanical movement as possible.

Amplification for Display. For the bending, axial, and torsional strain experimental arrangements, the output from the cable under test is fed to a current amplifier. If the cable exhibits a large output in repsonse to a particular test, the current amplifier is removed and an adjustable band-pass filter inserted in its place between the cable and oscilloscope. For the hydrostatic test, measurements are first made without the current amplifier. If the signal measured is small, the measurements for that cable are made with the current amplifier between cable and oscilloscope.

The current amplifier used to amplify specimen cable outputs for display is briefly described at the end of 1.1. Selection of the specific instrument was dictated by considerations of availability and of the filtering feature. Other types of amplifier can be used, for example, a charge-sensitive amplifier. This type is relatively insensitive to input shunt capacitance and hence can readily be used with cables long enough so that capacitance becomes a signficant factor in the other instruments. As the measurements in this investigation are of cable specimen lengths of one meter, the consideration of shunt capacitance, at least as a first-order effect, does not apply.

In developing the measurement method, measurements were made on the same cable with both a charge-sensitive amplifier and the current amplifier so that these two alternatives could be compared. For a given measurement, the output waveform from each type of amplifier was displayed on one channel of a dual-beam, dual-channel oscilloscope. This was done for a number of signal levels and at different frequencies. With suitable adjustment of the respective amplifier gain controls, the output waveforms were virtually identical for signals with a low enough noise level for the measurement to be meaningful, that is, any observed differences were of the same order of magnitude as the noise. 
Monitoring of Specimen and Connecting Cable dc Resistance. It is important that appropriately high dc resistance be maintained between center. conductor and shield. This is especially true in the case of cable specimens to be poled, where relatively low resistance paths can lead to destructive arcing when the poling field is applied. As a check that cable connections are properly made (several different types of BNC connectors are used depending on cable size) and that there are no local low-resistance paths in the dielectric, both low-resistance continuity measurements with a common multimeter and high-resistance measurements with a megohmmeter are made on each specimen cable. Resistances of $\leq 0.5$ ohm indicate acceptable continuity. Cables with a center conductor-to-shield resistance of less than $10^{10}$ ohms are rejected. Poling experience indicates that if a current of about $10^{-5} \mathrm{~A}$ develops through a weak spot in the dielectric, the current will rapidly increase and a hole will be formed in the dielectric between center conductor and shield, destroying the cable. For a poling potential of $10 \mathrm{kV}$, a current of $10^{-\zeta}$ A corresponds to a resistance of $10^{9}$ ohms. Since the highest poling potential used is $20 \mathrm{kV}$, a minimum resistance of $10^{10}$ ohms results in a current of $2 \times 10^{-6} \mathrm{~A}$. Cable center conductor-to-shield resistances for cables without weak spots are greater than $10^{11}$ ohms.

Daily resistance measurements are made on connecting cables carrying low-level signals to identify cables with poor end-to-end continuity (center conductor-center conductor or shield-shield) or shorts between center conductor and shield.

Use of Storage 0scilloscopes. The low-frequency measurements are greatly facilitated by the use of storage oscilloscopes. With the instruments used, a trace representing a signal duration of $50 \mathrm{~s}$ is obtainable. The preamplifiers provide a maximum sensitivity of $10 \mu V$ per division.

Under certain circumstances the storage oscilloscope permits determination of a signal amplitude nearly buried in noise. The technique used has been to provide the oscilloscope with an external synchronizing signal from the oscillator and to permit several traces to superimpose. Instead of the ordinary narrow-line trace, a widened trace will appear in which the signal is displayed as a periodic variation of amplitude at the signal frequency. It is convenient to display the signal frequency at the same time for reference.

Evaluation of Methods. Performance of the four tests developed was evaluated in the course of measurements on representative cables as part of Task 11, described in the following section.

\section{TaSK II - MEASUREMENT OF CABLE-RESPONSE TO STRAIN}

\subsection{Cable Specimens}

Commercially available coaxial cables with dielectrics of tetrafluorethylene, fluorinated ethylene propylene, cellular fluorinated 
Table 1. Construction information for various commerclally avallable coaxlal cables *

\begin{tabular}{|c|c|c|c|c|c|c|}
\hline $\begin{array}{l}\text { Menuf. } \\
\text { code }\end{array}$ & $\begin{array}{l}\text { Manuf. model } \\
\text { number }\end{array}$ & $\begin{array}{l}\text { Center conductor } \\
\text { materlal and slze }\end{array}$ & $\begin{array}{l}\text { Dlelectrlc } \\
\text { materlal }\end{array}$ & $\begin{array}{l}\text { Shield } \\
\text { materlal }\end{array}$ & $\begin{array}{l}\text { Jacket } \\
\text { materlal }\end{array}$ & $\begin{array}{l}\text { Jacket } \\
\text { color }\end{array}$ \\
\hline$A$ & $\begin{array}{l}8219 \\
(R G 58 \mathrm{~A} / \mathrm{U})\end{array}$ & $\begin{array}{l}\text { tInned copper } \\
\text { I } 9 \times 32 \text { AWG } \\
(20 \text { AWG dia.) }\end{array}$ & cellular polyethylene & tInned copper & $v \operatorname{lnyl} * t$ & black \\
\hline A & $\begin{array}{l}8263 \\
\text { (RG } 59 \mathrm{~B} / \mathrm{U})\end{array}$ & $\begin{array}{l}\text { copper-coated } \\
\text { steel }\left(0.023^{\prime \prime}\right)\end{array}$ & polyethylene & bare copper & $\begin{array}{l}v \mid n y l \text { (non- } \\
\text { contamlnatIng) } * * \text {. }\end{array}$ & black \\
\hline A & 8739 & $\begin{array}{l}\text { twln tinned } \\
\text { copper } 22 \text { AWG } \\
\text { conductors - } \\
\text { cabled }\end{array}$ & $\begin{array}{l}\text { vinyl (separate } \\
\text { Insulation on two } \\
\text { conductors) } \star \star\end{array}$ & $\begin{array}{l}\text { t Inned copper, } \\
\text { splral-wrapped }\end{array}$ & $v \operatorname{lny} \mid * \pi$ & $\begin{array}{l}\text { sllver-grey } \\
\text { ("chrome") }\end{array}$ \\
\hline A & 83269 & $\begin{array}{l}\text { sllver-coated } \\
\text { copper-coated } \\
\text { steel } 7 \times 0.0067^{\prime \prime} \\
\text { (26 AWG dla.) }\end{array}$ & $\begin{array}{l}\text { polytetrafluoro- } \\
\text { ethylene (TFE) }\end{array}$ & $\begin{array}{l}\text { silver-coated } \\
\text { copper }\end{array}$ & $\begin{array}{l}\text { polytetrafluoro- } \\
\text { ethylene tape }\end{array}$ & whlte \\
\hline 8 & $\begin{array}{l}\text { RG } 58 / U \\
\text { low nolse }\end{array}$ & $\begin{array}{l}\text { not avallable } \\
\text { from manuf. }\end{array}$ & polyethyl ene & $\begin{array}{l}\text { copper lubrlcated } \\
\text { wlth suspension of } \\
\text { colloldal carbon In } \\
\text { water }\end{array}$ & $\begin{array}{l}\text { not avallable } \\
\text { from manuf. }\end{array}$ & black \\
\hline C & RG $59 / 0$ & $\begin{array}{l}\text { bare copper } \\
20 \text { AWG }\end{array}$ & foamed polyethylene & & polyvinyl chlorlde & black \\
\hline C & 8450 & $\begin{array}{l}\text { twin t Inned copper } \\
20 \text { AWG conductors } \\
+ \text { t lnned copper } \\
\text { ground wlre }\end{array}$ & $\begin{array}{l}\text { polypropylene } \\
\text { (separate Insula- } \\
\text { tion on two con- } \\
\text { ductors) }\end{array}$ & $\begin{array}{l}\text { a luminlzed } \\
\text { polyethylene } \\
\text { terephthalate }\end{array}$ & polyvinyl chlorlde & grey \\
\hline C & 8403 & $\begin{array}{l}\text { quad } t \text { Inned } \\
\text { copper } 20 \text { AWG } \\
\text { conductors }\end{array}$ & $\begin{array}{l}\text { polyethylene } \\
\text { (separate Insulation } \\
\text { on four conductors, } \\
\text { rayon braid) }\end{array}$ & tInned copper & polyvinyl chlorlde & grey \\
\hline 0 & $250-3804$ & $\begin{array}{l}40 \% \text { conduct IvIty } \\
\text { sIIver-plated } \\
\text { copper-covered } \\
\text { steel } 29 \text { AWG } \\
\left(0.011^{\prime \prime} \text { dla.) }\right.\end{array}$ & polyethylene & t Inned copper & polyvinyl chlorlde & orange \\
\hline 0 & $250-3808$ & same as $250-3804$ & $\begin{array}{l}\text { polytetrafluoro- } \\
\text { ethylene (TFE) }\end{array}$ & $\begin{array}{l}\text { sllver-plated } \\
\text { copper }\end{array}$ & $\begin{array}{l}\text { polytetrafluoro- } \\
\text { ethylene tape }\end{array}$ & yellow \\
\hline 0 & $250-3866$ & same as $250-3804$ & $\begin{array}{l}\text { polytetrafluoro- } \\
\text { ethylene (TFE) }\end{array}$ & $\begin{array}{l}\text { sllver-plated } \\
\text { copper }\end{array}$ & $\begin{array}{l}\text { polytetrafluoro- } \\
\text { ethylene tape }\end{array}$ & red \\
\hline 0 & $\begin{array}{l}250-4021- \\
00008,250- \\
4214\end{array}$ & $\begin{array}{l}40 \% \text { conductivity } \\
\text { sllver-plated } \\
\text { copper-covered } \\
\text { steel } 7 \times 0.0067^{\prime \prime} \\
\left(0.020^{\prime \prime} \text { dia.) }\right.\end{array}$ & $\begin{array}{l}\text { polytetrafluoro- } \\
\text { ethylene (TFE) }\end{array}$ & $\begin{array}{l}\text { sllver-plated } \\
\text { copper }\end{array}$ & $\begin{array}{l}\text { polytetrafluoro- } \\
\text { ethylene tape } \\
\text { plus outer jacket of } \\
\text { polyvinyl chlorlde }\end{array}$ & black \\
\hline 0 & $260-3905$ & $\begin{array}{l}\text { sllver-plated } \\
\text { copper } 4 \times 38 \text { AWG } \\
(0.008 " \text { dla.) }\end{array}$ & $\begin{array}{l}\text { polyvinyl } \\
\text { chloride (PVC) }\end{array}$ & $\begin{array}{l}\text { sllver-plated } \\
\text { copper }\end{array}$ & Nylon & black \\
\hline 0 & $270-3953$ & $\begin{array}{l}40 \% \text { conductlvi- } \\
\text { ty sllver-plated } \\
\text { copper-covered } \\
\text { steel } 7 \times 38 \text { AWG } \\
\left(0.012^{\prime \prime} \text { dla.) }\right.\end{array}$ & $\begin{array}{l}\text { fluorlnated } \\
\text { ethylene } \\
\text { propylene polymer } \\
\text { (FEP) }\end{array}$ & tInned copper & $\begin{array}{l}\text { fluor Inated ethylene } \\
\text { propylene polymer }\end{array}$ & whl te \\
\hline 0 & $275-3933$ & $\begin{array}{l}\text { sIlver-plated } \\
\text { copper 19×36AWG } \\
\left(0.025^{\prime \prime} \text { dla.) }\right.\end{array}$ & $\begin{array}{l}\text { cellular fluorl- } \\
\text { nated ethylene- } \\
\text { propylene polymer } \\
\text { (cellular FEP) }\end{array}$ & $\begin{array}{l}\text { silver-plated } \\
\text { copper }\end{array}$ & polyvinyl chloride & whl te \\
\hline$E$ & RG $187 \mathrm{~A} / \mathrm{U}$ & $\begin{array}{l}\text { not avallable } \\
\text { from manuf. }\end{array}$ & $\begin{array}{l}\text { polytetrafluoro- } \\
\text { ethylene (TFE) }\end{array}$ & $\begin{array}{l}\text { not aval lable } \\
\text { from manuf. }\end{array}$ & $\begin{array}{l}\text { polytetrafluoro- } \\
\text { ethylene }\end{array}$ & clear \\
\hline
\end{tabular}

- Information IIsted as supplled by manufacturers

* As Identifled by manufacturer - probably polyvinyl chiloride 
ethylene propylene polymer, polyethylene, cellular polyethylene, and polyvinyl chloride were procured. Table 1 indicates the construction data and manufacturers' designation for various cables.

Cable specimens are prepared by cutting a 1 -meter length from the parent cable and attaching a BNC connector to one end. The other end is left as cut if a check indicates there is a resistance of at least $10^{10}$ ohms between center conductor and shield. Cables to be poled are cut longer initially, as a special connector has to be attached to one end and the shield has to be stripped back from the other for poling. After poling, the special connector is replaced with a BNC connector and the unshielded length of center conductor is cut off.

The range of readily available commercial coaxial cables does not encompass all dielectrics of interest. Further, some materials are available as coaxial cable dielectrics only in very small diameter cables, with dielectric thicknesses of a few tenths of a millimeter. Such cables present severe mechanical problems in terms of making connections and in handling and are in addition very difficult to pole (probably because the percentage variation in dielectric thickness is greater than that for larger cables). Accordingly, some coaxial cables were prepared from insulated wire and wire braid. It was not possible to obtain a tight fit between the wire braid shield and the dielectric insultation, even using such techniques as clamping the braid shield in place with an outer jacket of shrink-fit tubing. Attempts were also made to construct a coaxial cable with a painted-on shield of conductive rubber; continuity problems have so far made this method unreliable. Table? Iists the various insulated wires available.

Table 2. List of insulation materials available in the form of insulated wires.

Crosslinked polyalkene

Fluorinated ethylene propylene polymer (FEP)

Polyvinylidene fluoride $\left(P_{2} F_{2}\right)$

Polyethylene terephthalate

Polyvinyl chloride (PVC)

Rubber

Silicone rubber

Ethylene-tetrafluoroethyl ene copolymer

Polytetrafluoroethylene (TFE) 
Table 3. Strain measurements made for each type of cable.

An " $X$ " in the appropriate column indicates that at least one data run was made for that strain mode for the given cable type. $P=$ hydrostatic pressure (bulk compression); $B=$ bending strain; $A=$ axial strain; $T=$ torsional strain.

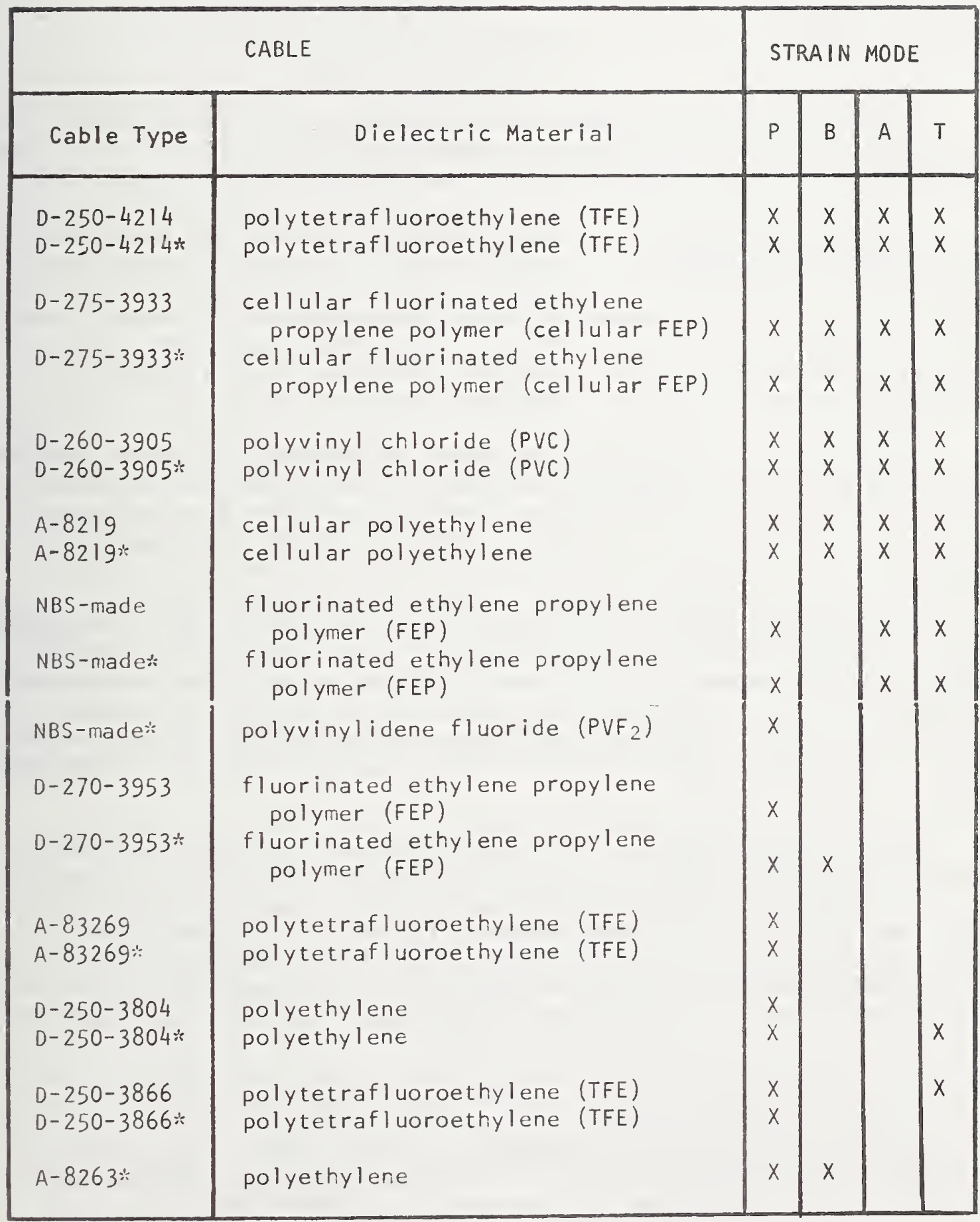

* indicates unpoled; if no asterisk, cable was poled. 
Cable specimens were initially stored in envelopes in loose coils of a few turns. Representatives of the DSPG pointed out that uncoiling specimens for tests and re-coiling them for storage might influence the test results. Specimens were thereafter stored by hanging vertically downwards suspended by the BNC connector.

Table 3 identifies strain measurements made for each type of cable.

\subsection{Evaluation of Tests}

As no fully characterized standard cables exist, the four tests described under Task I can only be evaluated in terms of the scatter of the test results, for each test, when the same cable specimen is measured.

Bending Strain Test. The chief source of variability appeared in the mounting of the cables, presumably caused by changes brought about in the cable by mounting and unmounting. When the cable was left in the beam between trials, there was no significant variation in results among trials. Results from several sets of trials showed a maximum deviation from the mean measured value less than 8 percent. Typical data for two frequencies are presented in Appendix $C, 1$.

Hydrostatic Pressure Test. The chief source of variability appeared to be the effects of installing the cable in the apparatus. Results from several sets of trials showed a maximum deviation from the mean measured value less than 9 percent. Typical data for two frequencies are presented in Appendix $\mathrm{C}, 2$.

Axial Strain Test. The chief source of variability was associated with the mounting of the cable. In this test, a clamp is at tached at each end of the cable, and the clamps are then mounted into the apparatus. Care must be taken not to load the cable, yet it should not be slack. Results from several sets of trials showed a maximum deviation from the mean measured value less than 12 percent. Typical data for two frequencies are presented in Appendix $\mathrm{C}, 3$.

Torsional Strain Test. The remarks for Axial Tension Test apply. The same clamps are used to mount the cable in this test and in fact the clamps are ordinarily not removed from the cable specimen until both tests are completed. For evaluation of the test, the clamps were removed and re-attached for each trial. Results from several sets of trials showed a maximum deviation from the mean measured value less than 13 percent. Typical data for two frequencies are presented in Appendix C, 4 .

\subsection{Stability of Response as a Function of Time}

Six selected cables were measured throughout the project period, starting as soon as the individual tests were developed. Cables used in poling experiments were measured before and after poling. Typical 
results for $0-250-4214$ (polytetrafluoroethylene dielectric cable) are given in Appendix D, I for response to hydrostatic pressure (Figure 8 ) and to bending strain (Figure 9).

\subsection{Stability of Response as a Function of Bias Voltage}

DSPG and NBS agreed that the measurement of cable response to strain in the presence of bias dc voltage was not a high-priority item. Accordingly, when noise problems proved to be severe, no further work was done with bias voltages. For the measurement attempted, bias dc voltages derived from batteries were applied to a cable specimen (D-275-3933 U-1, an unpoled cellular fluorinated ethylene propylene polymer dielectric) in the hydrostatic pressure apparatus during measurement. Voltages from 1 to $150 \mathrm{~V}$ were used. Capacitors were used to protect the current amplifier.

\subsection{Stability of Response as a Function of Environmental Parameters}

At the time this task was formulated, it was envisaged that the simulation referred to in section 1 would be carried out and that the effects of varying environmental parameters such as pressure, temperature, and relative humidity would be investigated. However, the simulation attempt was dropped from the work for reasons given in the referenced section.

DSPG and NBS agreed that project resources and time would not permit a systematic investigation of environmental parameters. It was further agreed that only a few experiments would be attempted. Since DSPG evinced an interest in the effects of low temperature on D-250-4214, one of these experiments involved measuring the response of an unpoled specimen (U-1) of D-250-4214 to bending strain with both cable and beam cooled to approximately $5^{\circ} \mathrm{C}$. The results are compared with room-temperature measurements of the same cable in Appendix D, 2 (Figure 10).

There was also some interest in the effects of immersion in water on a cellular dielectric, although with the outer jacket left on. The hydrostatic pressure test offered a ready means of exposing a cable to several days'immersion. Accordingly, an unpoled specimen (U-l) of D-275-3933 (cellular fluorinated ethylene propylene dielectric) was inserted into the hydrostatic pressure apparatus for 48 hours and measured at insertion, 24 hours later, and 48 hours later. For comparison, an unpoled specimen (U-1) of D-270-3953 (fluorinated ethylene propylene polymer dielectric) was inserted into the apparatus for 24 hours and measured at insertion and 24 hours later. It was suggested that a poled cable might behave differently and D-270-3953 P-1 was inserted into the apparatus for 120 hours and measured at insertion, 24 hours later, and 120 hours later. The results for these three experiments are in Appendix E under the respective cable type (pp 86, 87, 88, 90, 91, 97, 98, and 99). 


\section{TaSK III - CRITERIA FOR CABLE EVALUATION}

of the criteria for cable evaluation listed in this task, only three are concerned with results obtained in the course of the laboratory work of this project. These three are: temporal stability of signalgenerating elements, uniformity of response along length, and linearity of hydrostatic pressure response. The first of these has already been covered under Task II.

At an early stage of this investigation, DSPG identified a strong interest in one type of commercially available cable. Specimens from several different 300-meter reels were supplied for measurement. For other types of commercial cable, sample lengths of about 16 meters were obtained. Most of these samples were obtained during joint visits to cable manufacturers by DSPG, MERDC, and NBS, and it was agreed that unless there were significant variations in response among specimens of the selected cable no further work need be done on the uniformity of response along length. The results for five lengths of the selected cable, D-250-4214, are given in Appendix D, 3 for response to hydrostatic pressure (Figure 11) and bending strain (Figure 12). The cable samples were selected as follows:

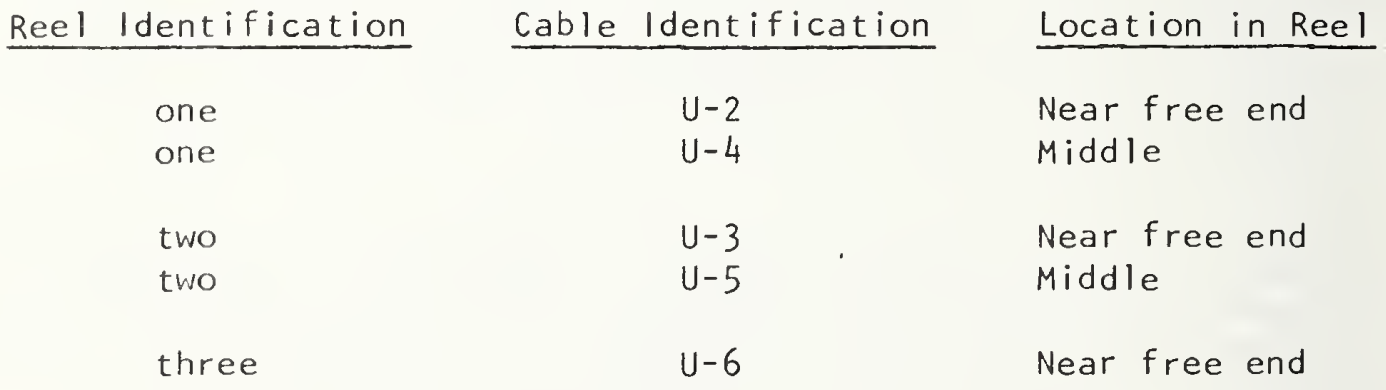

In order to examine the degree of linearity of cable response to hydrostatic pressure, measurements were made of the response of poled and unpoled samples of four selected cable types to eight levels of pressure at the lowest repetition frequency used, which was $0.1 \mathrm{~Hz}$. The levels of pressure ranged from $1.6 \times 10^{4} \mathrm{~Pa}$ to $8.3 \times 10^{4} \mathrm{~Pa}$. The upper limit is determined by the laboratory air supply; in the absence of information concerning the levels of pressure to be encountered in the envisaged application, DSPG and NBS agreed that there was no reason to explore cable response to higher levels of pressure. Plots of cable response as a function of pressure are given in Appendix D, 4 for those cables with a response greater than 10-12 A (Figures 13, 14, 15, and 16).

Information concerning cable cost, mechanical ruggedness, life, and uniformity of manufacture was obtained by personnel of DSPG and MERDC during the joint visits to manufacturers and from other sources. 


\subsection{Poling with Electric Field}

Mechanical deformation of a material containing partially oriented electric dipoles will result in a charge being developed across the material. If such a mechanism, occurring in the dielectric, is responsible for even part of the output of a coaxial cable subjected to mechanical strain, it may be possible to improve the sensitivity, that is, increase the output for a given type of strain and strain level, by changing the dipole orientation distribution so that more dipoles are alined in a preferred orientation. An electric field applied across the dielectric tends to orient dipoles along the field and a net polarization of the material should result. The polarization may be in a sense "frozen" if the dielectric material is heated from room temperature to a temperature near its softening temperature and then cooled to room temperature with the field applied. Attempts to improve cable sensitivity by poling were carried out in a thermostatically controlled oven.

For coaxial cables, it is convenient to produce the field by applying high voltage dc to the center conductor and grounding the shield.

The particular voltage-temperature combination is determined empirically for each cable type as follows. A short specimen of cable is prepared so that the poling field may be applied across the dielectric. The voltage supplied to the center conductor is increased until the potential difference to ground (the shield) is approximately $2.5 \times 10^{7} \mathrm{~V}$ per meter of dielectric thickness (this is not electric field strength, as the field is radial and non-uniform from center conductor to shield). This value represents a starting point suggested by other experimental work on poling carried out by NBS. If the cable breaks down before the $2.5 \times 10^{7} \mathrm{~V}$ per meter level is reached, a second short specimen is prepared and tested with a slightly lower voltage. With an approximate poling voltage determined, the next step is to test the specimen at elevated temperature. The temperature used is $5^{\circ}-10^{\circ} \mathrm{C}$ below the softening temperature of the dielectric. If the specimen survives without breakdown elevation to the selected temperature, thirty minutes of exposure at this temperature, and cooling to room temperature (the poling potential is applied throughout), the poling temperature and potential are considered to have been determined for that particular cable type, subject to modification on the basis of continuing experience.

If breakdown occurs before the specimen has reached the selected temperature, but within $10^{\circ} \mathrm{C}$ of it, another specimen is prepared, the potential applied, and the specimen elevated to a temperature approximately $5^{\circ} \mathrm{C}$ lower than that at which the previous specimen broke down. If the new specimen survives the heating-exposure-cooling cycle, the poling temperature and potential are considered to have been determined, as before. 
If breakdown occurs $10^{\circ} \mathrm{C}$ or more before the specimen has reached the selected temperature, the potential is reduced by about 10 percent and the process repeated. Voltages and temperatures used are shown in Table 4.

Because of oven size limitations, the cables were partially coiled (looped is a more descriptive term) when poling attempts were made. For the higher poling voltages, it was necessary to remove the shield for several centimeters so that arc-over between the center conductor and shield would not dccur. During poling, current was monitored with a panel-type microammeter. Based on experience, safe currents for cables were considered to be less than $10 \mu \mathrm{A}$. Most of the current was from corona. Incipient breakdowns in the cable insultation tended to manifest themselves as sudden, irreversible increases in current.

In a polymer material, at least two factors may hinder the desired dipole alinement. Double bonds tend to inhibit rotation about the bond and the mass of long-chain molecules jumbled together in a loose tangle imposes on individual molecules what may be termed a mutual mechanical interference. An ac jitter field superimposed on the dc field may tend to promote initial movement despite the steric hindrance and permit a greater percentage of dipole orientation than otherwise. An experimental poling attempt using the secondary coil of a high-voltage transformer in series with the dc power supply did not give conclusive results.

Table 4. Poling voltage in kilovolts and poling temperature in degrees $C$ for various cables.

\begin{tabular}{|c|c|c|}
\hline Cable Identification & $\begin{array}{l}\text { Vol tage } \\
\quad(\mathrm{kV})\end{array}$ & $\begin{array}{c}\text { Temperature } \\
\left({ }^{\circ} \mathrm{C}\right)\end{array}$ \\
\hline$A-8219$ & 1.5 & 60 \\
\hline$A-8739$ & 10 & 60 \\
\hline$A-83269$ & 10 & 200 \\
\hline$D-250-3804$ & 10 & 65 \\
\hline$D-250-3866$ & 7. & 155 \\
\hline$D-250-4214$ & 9. & 200 \\
\hline & & (outer jacket removed) \\
\hline$D-260-3905$ & 5. & 60 \\
\hline$D-270-3953$ & 20. & 200 \\
\hline$D-275-3933$ & 10 & 200 \\
\hline $\begin{array}{l}\text { NBS-made fluorinated } \\
\text { ethylene propylene } \\
\text { polymer }\end{array}$ & 8. & 200 \\
\hline
\end{tabular}


Table 5. Summarized cable response to hydrostatic pressure (bulk compression), bending strain, axial strain, and torsional strain.

\begin{tabular}{|c|c|c|c|c|c|}
\hline \multicolumn{2}{|r|}{ CABLE } & \multicolumn{4}{|c|}{ RESPONSE* } \\
\hline Cable Type & Dielectric Material & P & B & A & $T$ \\
\hline $0-250-4214$ & polytetrafluoroethylene (TFE) poled & 2 & 2 & 6 & 5 \\
\hline $0-250-4214$ & polytetrafluoroethylene (TFE) unpoled & 2 & 2 & 6 & 5 \\
\hline$D-275-3933$ & cellular fluorinated ethylene propylene polymer (FEP) poled & 3 & 3 & 6 & 5 \\
\hline$D-275-3933$ & cellular fluorinated ethylene propylene polymer (FEP) unpoled & 2 & 2 & 6 & 1 \\
\hline$D-260-3905$ & polyvinyl chloride (PVC) poled & 2 & 3 & 5 & 4 \\
\hline$D-260-3905$ & polyvinyl chloride (PVC) unpoled & 2 & 2 & 1 & 3 \\
\hline$A-83269$ & polytetrafluoroethylene (TFE) poled & 2 & & & \\
\hline$A-83269$ & polytetrafluoroethylene (TFE) unpoled & 2 & & & \\
\hline$D-250-3804$ & polyethylene poled & 1 & & & \\
\hline$D-250-3804$ & polyethylene unpoled & 1 & & & 2 \\
\hline$D-250-3866$ & polytetrafluoroethylene (TFE) poled & 1 & & & 2 \\
\hline$D-250-3866$ & polytetrafluoroethylene (TFE) unpoled & 1 & & & \\
\hline$A-8219$ & cellular polyethylene poled & 1 & 2 & 4 & 2 \\
\hline$A-8219$ & cellular polyethylene unpoled & 1 & 2 & 4 & 2 \\
\hline NBS-made & fluorlnated ethylene propylene polymer (FEP) poled & 3 & & 6 & 4 \\
\hline NBS-made & fluorinated ethylene propylene polymer (FEP) unpoled & 2 & & 6 & 3 \\
\hline NBS-made & polyvinylidene fluoride unpoled & 1 & & & \\
\hline$D-270-3953$ & fluorlnated ethylene propylene polymer (FEP) poled & 3 & & & \\
\hline $0-270-3953$ & fluorinated ethylene propylene polymer (FEP) unpoled & 2 & 2 & & \\
\hline$A-8263$ & polyethylene unpoled & 2 & 3 & & \\
\hline
\end{tabular}

* P indicates cable response to hydrostatic pressure (bulk compression); $B$, to bending strain;

$A$, to axial strain; and $T$, to torsional strain. The numbers indicate the magnitude of the respective response, according to the following scale:

$$
\begin{aligned}
& 1=1 \text { ittle or no response } \\
& 2=\text { above noise to } 5 \times 10^{-11} \mathrm{~A} \\
& 3=5 \times 10^{-11} \mathrm{~A} \text { to } 5 \times 10^{-10} \mathrm{~A} \\
& 4=5 \times 10^{-10} \mathrm{~A} \text { to } 10^{-9} \mathrm{~A} \\
& 5=10^{-9} \mathrm{~A} \text { to } 5 \times 10^{-8} \mathrm{~A} \\
& 6=5 \times 10^{-8} \mathrm{~A} \text { to } 5 \times 10^{-7} \mathrm{~A} .
\end{aligned}
$$


Task IV calls for evaluation of at least one additional method of poling to include direct injection of charge, irradiation (exposure to hard radiation), and cold working.

Available facilities limited the scope of evaluation of direct injection of charge and irradiation as poling techniques to testing of previously treated cable samples. The sponsor planned to supply such samples. No samples were supplied, and the evaluation was therefore dropped from the work program.

The practical difficulties of poling coaxial cable by the cold working technique without destroying the cable led to abandonment of plans to evaluate this technique. However, it should be noted that cold working of certain materials has been reported [1] to be an effective poling means, especially in combination with subsequent electrical poling [2].

\section{RESULTS AND CONCLUSIONS}

\subsection{Task 1}

Test methods have been developed for measuring the response of specimen lengths of coaxial cables considered as sensing elements to four separately applied strains: bending strain, bulk compression, axial strain, and torsional strain. Estimates of the precision of the measurement methods are given in 2.2; the response data constitute Appendix E.

\subsection{Task II}

The large dispersion of measured response among samples of different cable types as compared to the dispersion observed in repeated measurements of the same cable type indicates large structural differences among the cable samples. In general, cable response is not linear with applied strain. Moreover, cable response for a given type of strain and strain level may or may not be a monotonic function of frequency, as mechanical resonance behavior frequently appears.

For the bending, axial, and torsional modes, response below about 1 $\mathrm{Hz}$ was not significant. Hydrostatically excited response was relatively independent of the pulse repetition rate.

Table 5 indicates the range of response for the cables tested. The current amplifier with a gain setting of $10^{10} \mathrm{~V} / \mathrm{A}$ was used for all hydrostatic pressure measurements; the same amplifier was used with a gain of $10^{9} \mathrm{~V} / \mathrm{A}$ for all bending measurements. Axial measurements were made with a filter with a measured insertion loss factor no greater than three to one.

Figures in brackets indicate the literature references at the end of this report. 
Table 5 shows that, at the strain levels used, the axial and torsional modes can result in response very much larger than for the other two modes.

Levels of Strain Applied. The levels of strain to be applied were to be recommended by representatives of the DSPG on the basis of results of investigations being carried out in another laboratory. These were not forthcoming. In the absence of these specific recommendations, the levels of strain applied in each mode were chosen by reasonable guess.

Typical levels applied were as follows:

hydrostatic pressure: from $2.5 \times 10^{4} \mathrm{~Pa}$ to $8.3 \times 10^{4} \mathrm{~Pa}$ above a tmospheric

bending strain: radius of curvature from $8.2 \times 10^{3}$ meter to $2.7 \times 10^{3}$ meter

axial strain: from $5 \times 10^{-5}$ meter per meter to $2 \times 10^{-4}$ meter per meter torsional strain: from $8 \times 10^{-8}$ radian per meter to $8 \times 10^{-6}$ radian per meter.

Stability of Response as a Function of Time. There was no indication for any of the six cables measured of a variation of cable response with time greater than the estimated error of the measurement, over a period of up to 18 weeks. In addition, six other cables were measured twice with intervals between measurements of from one to 18 weeks; again there was no indication of a variation of cable response with time greater than the estimated error of the measurement. These statements are true for poled cables that were not first measured immediately after the poling field was removed. Anomalous results were obtained with some cable specimens when measurements were attempted within the first 15 to 30 minutes after the field was removed. These measurements frequently indicated the presence of a dc offset of up to 2 volts. The effects described are probably caused by temporary surface charges induced during poling. In Appendix D, I are given plots of the response of cable type D-250-4214 (polytetrafluoroethylene dielectric cable) to hydrostatic pressure and to bending strain as a function of time.

Stability of Response as a Function of Bias Voltage. Noise levels increased greatly and monotonically with increase in bias voltage in the experiment with cable D-275-3933 U-1 (cellular fluorinated ethylene propylene polymer dielectric cable) in the hydrostatic apparatus. As a result, no useful measurement of cable response with bias was possible. Since this was not a high-priority item, no further work with bias voltages was done. 
Stability of Response as a Function of Environmental Parameters. For the single trial attempted, cooling the cable and beam of the bending test did not result in a significant difference in cable response compared with measurement of the same cable specimen at room temperature, as is shown in the graph constituting Appendix D, 2. The cable type used in this experiment was D-250-4214 (polytetrafluoroethylene dielectric cable).

The rationale for the water soak experiment using the hydrostatic pressure apparatus is given in section 2.5. An unpoled specimen of cable type D-270-3953 (fluorinated ethylene propylene polymer dielectric cable) was measured immediately after insertion into the apparatus and after a 24-hour soak. At all repetition rates and pressures the response of the cable after soak was approximately twice that of the cable before soak. An unpoled specimen of cable type D-275-3933 (cellular fluorinated ethylene propylene dielectric cable) was measured immediately after insertion into the apparatus, after a 24-hour soak, and again after a further 24hour soak. Although the re was variation in the percentage loss of response at all repetition rates and pressures response after 24 hours of soak was less than response before soak. After 48 hours of soak, cable response was reduced still more, for some rates and pressures by as much as a factor of three. A poled specimen of cable type D-275-3933 was measured immediately after insertion into the apparatus, after a 24-hour soak, and again after a further 96 hours. As with the unpoled specimen of the same cable type, there was variation in the percentage loss of response, but at all repetition rates and pressures response after 24 hours of soak was less than response before soak. After 120 hours of soak, cable response was either the same as at 24 hours of soak or greater. The results for these experiments are in Appendix $E$ under the respective cable type (pp 86, 87, 88, 90, 91, 97, 98, and 99).

\subsection{Task III}

Uniformity of Response along Length. The response of cable specimens taken from three 300-meter reels of cable type D-250-4214 (polytetrafluornethylene dielectric cable) to hydrostatic pressure and bending strain was measured. The measurements were carried out in as consistent a manner as possible and within two days. The results are plotted in Appendix D, 3. No differences in response greater than the measurement error were detected among the five samples.

Linearity of Hydrostatic Pressure Response. The response to eight levels of hydrostatic pressure was measured for poled and unpoled specimens of four cable types. The results are plotted in Appendix D, 4. The response of cable type A-8219 (cellular polyethylene dielectric cable) was less than $10^{-12} \mathrm{~A}$ and is not plotted. Other cable types are $\mathrm{D}-250$ 4214 (polytetrafluoroethylene dielectric cable, Figure 13); D-275-3933 (cellular fluorinated ethylene propylene dielectric cable, Figure 14); and D-260-3905 (polyvinyl chloride dielectric cable, Figures 15, 16). 
Linearity of Cable Response to Strain Modes other than Hydrostatic Pressure. This type of response was not stressed by DSPG because information on the actual values of strain levels to be encountered in the envisaged application was not provided to DSPG for transmittal to NBS as had been anticipated. A plot of the response of unpoled cable type D-250-4214 (polytetrafluoroethylene dielectric cable) to bending strain for 25 and $42 \mathrm{~Hz}$ constitutes Appendix F (Figure 17).

\subsection{Task IV}

Compared with the as-received cables, there were slight improvements in the outputs from poled cables for all dielectrics except cellular polyethylene and polytetrafluorethylene. As part of the manufacturing process, most coaxial cable undergoes a voltage test for breakdown. Immediately after the dielectric is extruded or wrapped around the center conductor, the cable passes through lengths of bead chain with typically $5 \mathrm{kV} d c$ on the chain and with the center conductor at ground potential. A current drain on the dc supply indicates a fault, and the offending section of cable is cut out. It is not known if the voltage applied, the duration that the voltage is applied, the temperature of the dielectric (after extrusion), and other similar parameters have such values that poling of the dielectric occurs.

At the request of $D S P G$, an as-received length of several meters of one cable, D-250-4214-5, was annealed by maintaining it at a temperature of $200^{\circ} \mathrm{C}$ for 96 hours; the activity of a one-meter sample of this cable was reduced to nearly zero as measured in the bending and bulk compression tests. An attempt was made to pole a one-meter sample of the annealed cable with the result that about $80 \%$ of the original activity was restored. DSPG agreed that further investigation would be left to future work.

\section{RECOMMENDATIONS}

The primary emphasis of the project tasks was on the development of test methods and on measuring the activity of coaxial cables using these methods. In the course of the work possible lines along which future effort might be made became evident. The wide range of response observed among the various cable types also suggests further investigation.

Recommended is additional study of cable types of specific interest. For each type, cable response should be measured as a function of strain over the range of frequencies and strains that reflect intended use. The scatter in the measurements of the current work suggests the recommendation that in further work attention should be paid to the adequacy of sampling.

The wide range of responses from different types of cables also suggests the existence of a variety of mechanisms for the activity and 
emphasizes the need for futher work to elucidate these mechanisms. It is recommended that consideration be given to an investigation to separate the effects of different mechanisms using a more simple geometry than that of coaxial cable. The correlation of response with cable geometry is not possible in the absence of knowledge of the mechanisms responsible for the activity of coaxial cables. If these mechanisms become better understood, it will be desirable to produce a series of experimental cable lengths with varying center conductor diameter, dielectric thickness, etc. and to measure their characteristics with the methods that have been developed.

The testing of dielectrics that required fabrication of cable in the laboratory is not comparable to the testing of dielectrics in commercial cables. Dielectrics of special interest should be investigated by procuring experimental cables made with commercial machinery.

An examination of the open literature does not reveal any definitive description of the mechanisms involved in poling. The preliminary investigation carried out as Task IV of this project indicated that a tendency exists for cables with certain dielectrics to be rendered more active following poling with an electric field and at elevated temperature. Parameters that need to be investigated for various dielectrics of interest include optimum poling field, temperature, and duration. The effects of temperature cycling while the field is applied and the effects of applying the field repetitively over a range of periods from days to milliseconds also need investigation. Particularly useful would be the development of means to monitor activity while the poling process is taking place. 


\section{REFERENCES}

[1] Cohen, J., and Edelman, S., Piezoelectric effect in oriented polyvinylchloride and polyvinylfluoride, J. Appl. Phys. 42, No. 8, 3072-3074 (July 1971).

[2] Edelman, S., Grisham, L. R., Roth, S. C., and Cohen, J., Improved piezoelectric effect in polymers, J. Acoust. Soc. Am. 48, No. 5, 10401043 (November 1970). 
TABULATION OF TRAVEL, CONSULTATIONS, AND PRESENTATIONS FOR PROJECT 4253445.

\section{Activity}

Travel to cable manufacturer to discuss coaxial cable construction and to observe cable production

Travel to agency serving as consultants to DSPG (Defense Special Projects Group)

Consultations with DSPG

Consultations with MERDC (U. S. Army Mobility Equipment Research and Devlopment Center)

Presentation (including demonstration of apparatus) for DSPG
Number of Occurrences 
APPENDIX B
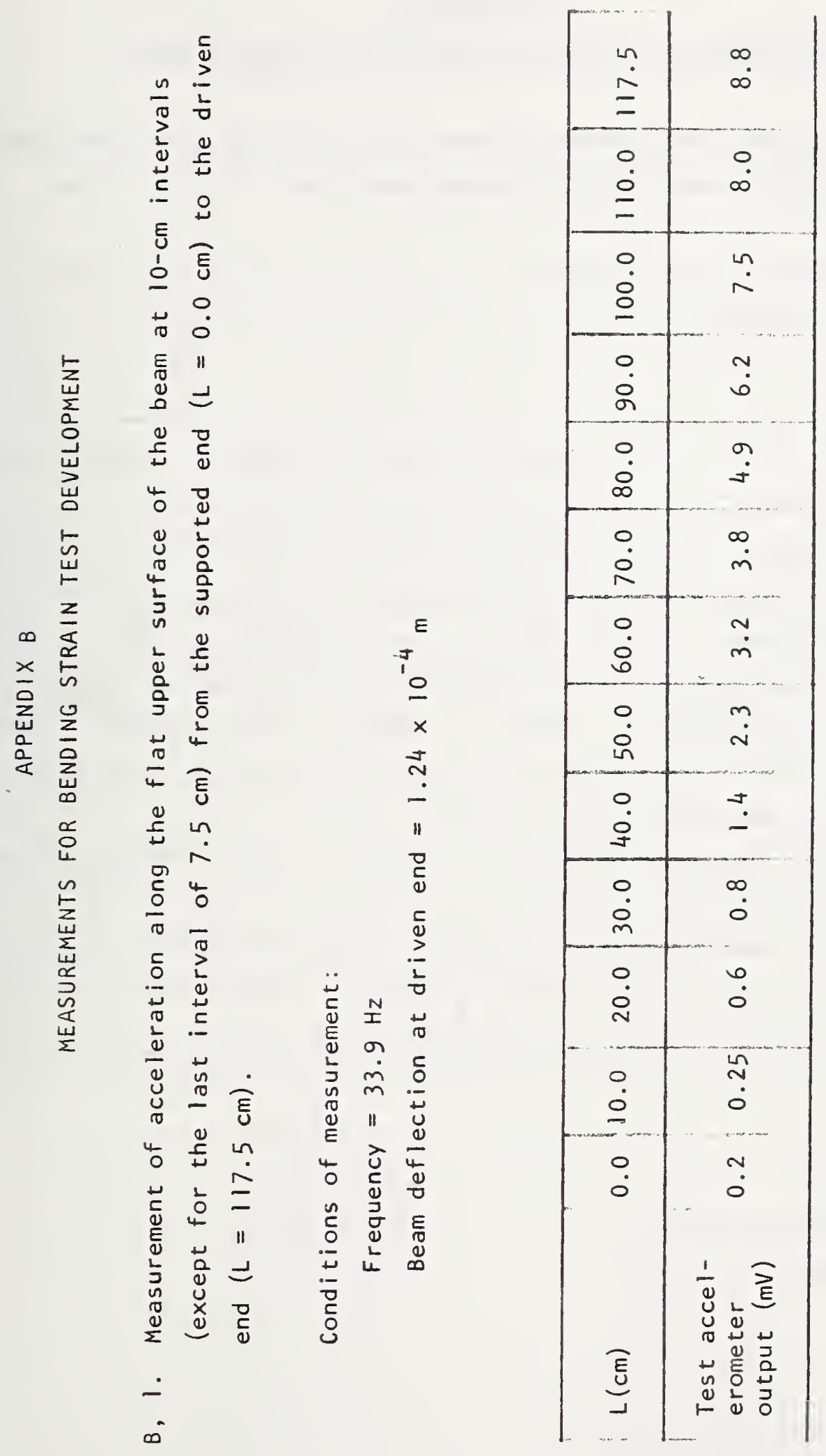
APPEND IX B

MEASUREMENTS FOR BENDING STRAIN TEST DEVELOPMENT

B, 2. Measurements of the displacement of the driven end of the beam using microscope with micrometer eyepiece.

Condition of measurement:

Frequency - $33.9 \mathrm{~Hz}$

\begin{tabular}{|c|c|c|c|c|c|c|}
\hline \multicolumn{2}{|c|}{ Trial } & One & Two & Three & Four & Five \\
\hline \multirow{3}{*}{$\begin{array}{l}\text { Eyepiece } \\
\text { Readings }\end{array}$} & Upper & 3632 & 3636 & 3631 & 3631 & 3632 \\
\hline & Lower & 3138 & 3146 & 3136 & 3138 & 3140 \\
\hline & Difference & 494 & 490 & 495 & 493 & 492 \\
\hline \multicolumn{2}{|c|}{$\begin{array}{l}\text { Difference times eye- } \\
\text { piece factor of } \\
9.84 \times 10^{-6}=\text { displace- } \\
\text { ment (in. } \times 10^{-3} \text { ) }\end{array}$} & 4.86 & 4.82 & 4.87 & 4.85 & 4.84 \\
\hline \multicolumn{2}{|c|}{ Displacement $\left(m \times 10^{-4}\right)$} & 1.24 & 1.22 & 1.24 & 1.23 & 1.23 \\
\hline
\end{tabular}

Mean

Range

Average deviation

Standard deviation
$1.23 \times 10^{-4} \mathrm{~m}$

$0.02 \times 10^{-4} \mathrm{~m}$

$0.01 \times 10^{-4} \mathrm{~m}$

$7.4 \times 10^{-7} \mathrm{~m}$ 
B, 3. Comparison of eddy-current displacement sensor and microscope measurements of the displacement of the driven end of the beam.

Condition of measurement:

Frequency $=25 \mathrm{~Hz}$

\begin{tabular}{|l|l|l|l|l|l|}
\hline \multicolumn{1}{|c|}{ Trial } & One & Two & Three & Four & Five \\
\hline $\begin{array}{l}\text { Eddy-current } \\
\text { sensor reading } \\
\text { (inch) }\end{array}$ & 0.0031 & 0.0033 & 0.0036 & 0.0040 & 0.0046 \\
\hline $\begin{array}{l}\text { Converted to } \\
\begin{array}{l}\text { m } \times 10^{-5} \text { (first } \\
\text { row times } \\
\left.2.54 \times 10^{-2}\right)\end{array}\end{array}$ & 7.9 & 8.4 & 9.1 & 10.2 & 11.7 \\
\hline $\begin{array}{l}\text { Mean of 5 micro- } \\
\text { scope readings } \\
\left(\mathrm{m} \times 10^{-5}\right)\end{array}$ & 7.8 & 8.4 & 9.2 & 10.0 & 11.4 \\
\hline $\begin{array}{l}\text { Difference } \\
\left(\mathrm{m} \times 10^{-5}\right)\end{array}$ & 0.1 & 0.0 & 0.1 & 0.2 & 0.3 \\
\hline
\end{tabular}


APPENDIX C

EVALUATION OF TESTS

C, 1. Cable response in the bending strain test for five trials.

Cable $0-250-4214-P-3$

Conditions of measurement:

Frequency $=10 \mathrm{~Hz}$

Radius of curvature $=2.699 \times 10^{3} \mathrm{~m}$

\begin{tabular}{|c|c|c|c|c|c|}
\hline Trial & One & Two & Three & Four & Five \\
\hline $\begin{array}{c}\text { Cable response } \\
\left(\text { A } \times 10^{-12}\right)\end{array}$ & 5.1 & 5.2 & 5.4 & 5.0 & 5.5 \\
\hline
\end{tabular}

Mean

Range

Average deviation

Standard deviation
$5.2 \times 10^{-12} \mathrm{~A}$

$0.5 \times 10^{-12} \mathrm{~A}$

$0.2 \times 10^{-12} \mathrm{~A}$

$0.2 \times 10^{-12} \mathrm{~A}$

Conditions of measurement:

Frequency $=40 \mathrm{~Hz}$

Radius of curvature $=2.699 \times 10^{3} \mathrm{~m}$

\begin{tabular}{|c|c|c|c|c|c|}
\hline Trial & One & Two & Three & Four & Five \\
\hline $\begin{array}{c}\text { Cable response } \\
\left(\text { A } \times 10^{-12}\right)\end{array}$ & 8.3 & 8.1 & 8.6 & 7.9 & 8.2 \\
\hline
\end{tabular}

Mean

Range

Average deviation

Standard deviation
$8.2 \times 10^{-12} \mathrm{~A}$

$0.7 \times 10^{-12} \mathrm{~A}$

$0.2 \times 10^{-12} \mathrm{~A}$

$0.2 \times 10^{-12} \mathrm{~A}$ 


\section{APPENDIX C \\ EVALUATION OF TESTS}

C, 2. Cable response in the hydrostatic pressure test for five trials.

Cable $D-250-4214-P-3$

Conditions of measurement:

Repetition frequency $=0.1 \mathrm{~Hz}$

Pressure $=8.3 \times 10^{4} \mathrm{~Pa}$

\begin{tabular}{|cc|c|c|c|c|}
\hline Trial & One & Two & Three & Four & Five \\
\hline $\begin{array}{c}\text { Cable response } \\
\left(\mathrm{A} \times 10^{11}\right)\end{array}$ & 1.2 & 1.1 & 1.1 & 1.2 & 1.3 \\
\hline
\end{tabular}

Mean

$1.2 \times 10^{-11} \mathrm{~A}$

Range

$0.2 \times 10^{-11} \mathrm{~A}$

Average deviation

$0.1 \times 10^{-11} \mathrm{~A}$

Standard deviation

$0.8 \times 10^{-12} \mathrm{~A}$

Conditions of measurement:

Repetition frequency $=0.2 \mathrm{~Hz}$

Pressure $=2.5 \times 10^{4} \mathrm{~Pa}$

\begin{tabular}{|c|c|c|c|c|c|}
\hline Trial & One & Two & Three & Four & Five \\
\hline $\begin{array}{c}\text { Cable response } \\
\left(\text { A } \times 10^{-12}\right)\end{array}$ & 8.2 & 7.8 & 8.7 & 8.3 & 8.5 \\
\hline
\end{tabular}
Mean
$8.3 \times 10^{-11} \mathrm{~A}$
Range
$0.9 \times 10^{-12} \mathrm{~A}$
Average deviation
$0.2 \times 10^{-12} \mathrm{~A}$
Standard deviation
$0.3 \times 10^{-12} \mathrm{~A}$ 


\section{EVALUATION OF TESTS}

c, 3. Cable response in the axial strain test for five trials.

Cable: $D-250-4214-P-3$

Conditions of measurement:

Frequency $=1 \mathrm{~Hz}$

Axial motion $=1.5 \times 10^{-4} \mathrm{~m}$

\begin{tabular}{|c|c|c|c|c|c|}
\hline Trial & One & Two & Three & Four & Five \\
\hline $\begin{array}{c}\text { Cable response } \\
\left.\text { (A } \times 10^{-8}\right)\end{array}$ & 1.5 & 1.7 & 1.8 & 1.7 & 1.6 \\
\hline
\end{tabular}

Mean

Range

Average deviation

Standard deviation

Cable: $D-250-4214-P-2$
$1.7 \times 10^{-8} \mathrm{~A}$

$0.3 \times 10^{-8} \mathrm{~A}$

$0.1 \times 10^{-8} \mathrm{~A}$

$0.1 \times 10^{-8} \mathrm{~A}$

Conditions of measurement:

Frequency $=5 \mathrm{~Hz}$

Axial motion $=1.6 \times 10^{-4} \mathrm{~m}$

\begin{tabular}{|c|c|c|c|c|c|}
\hline \multicolumn{1}{|c|}{ Trial } & One & Two & Three & Four & Five \\
\hline $\begin{array}{l}\text { Cable response } \\
\left.\text { A } \times 10^{-8}\right)\end{array}$ & 6.6 & 6.9 & 6.2 & 7.3 & 7.0 \\
\hline
\end{tabular}

Mean

$6.8 \times 10^{-8} \mathrm{~A}$

Range

$1.1 \times 10^{-8} \mathrm{~A}$

Average deviation

$0.3 \times 10^{-8} \mathrm{~A}$

Standard deviation

$0.4 \times 10^{-8} \mathrm{~A}$ 


\section{APPENDIX C \\ EVALUATION OF TESTS}

C, 4. Cable response in the torsional strain test for five trials.

Cable: $0-250-4214-P-1$

Conditions of measurement:

Frequency $=5 \mathrm{~Hz}$

Angle $=8.4 \times 10^{-6} \mathrm{rad}$

\begin{tabular}{|c|c|c|c|c|c|}
\hline Trial & One & Two & Three & Four & Five \\
\hline $\begin{array}{l}\text { Cable response } \\
\left(\text { A } \times 10^{-11}\right)\end{array}$ & 5.7 & 5.2 & 4.6 & 4.8 & 5.1 \\
\hline
\end{tabular}

Mean

$5.1 \times 10^{-11 \mathrm{~A}}$

Range

$1.1 \times 10^{-11} \mathrm{~A}$

Average deviation

$0.4 \times 10^{-11} \mathrm{~A}$

Standard deviation

$0.4 \times 10^{-11} \mathrm{~A}$

Cable: $D-250-4214-P-2$

Conditions of measurement:

Frequency $=50 \mathrm{~Hz}$

Angle $=1.3 \times 10^{-6} \mathrm{rad}$

\begin{tabular}{|c|c|c|c|c|c|}
\hline \multicolumn{1}{|c|}{ Trial } & One & Two & Three & Four & Five \\
\hline $\begin{array}{l}\text { Cable response } \\
\left(\text { A } \times 10^{-9}\right)\end{array}$ & 1.28 & 1.42 & 1.16 & 1.37 & 1.20 \\
\hline
\end{tabular}

Mean

$1.25 \times 10^{-9} \mathrm{~A}$

Range

$0.26 \times 10^{-9} \mathrm{~A}$

Average deviation

$0.09 \times 10^{-9} \mathrm{~A}$

Standard deviation

$0.10 \times 10^{-9} \mathrm{~A}$ 
AFPENDIX D

D, 1. Figure 8

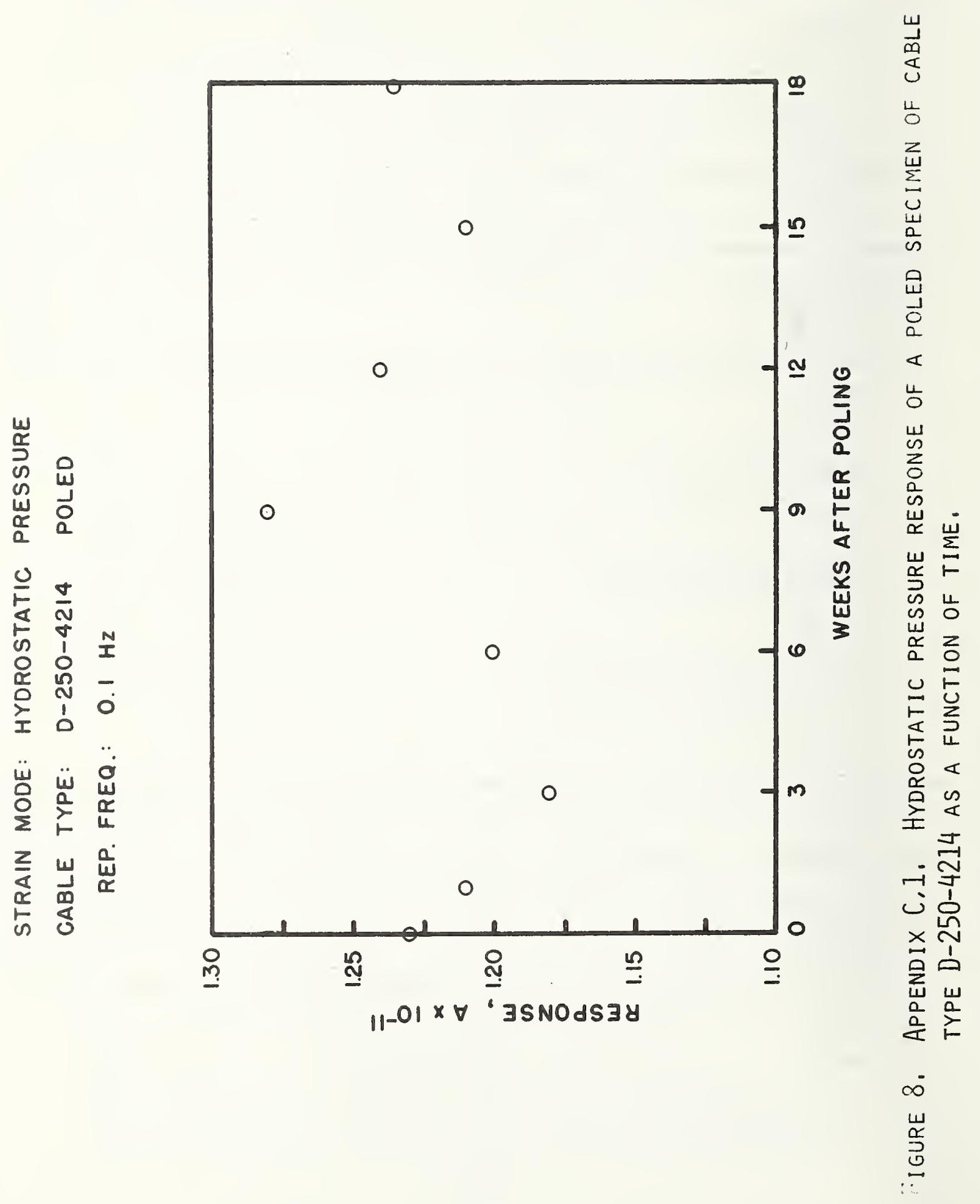


APPENOIX L

0,1 . Figure 9
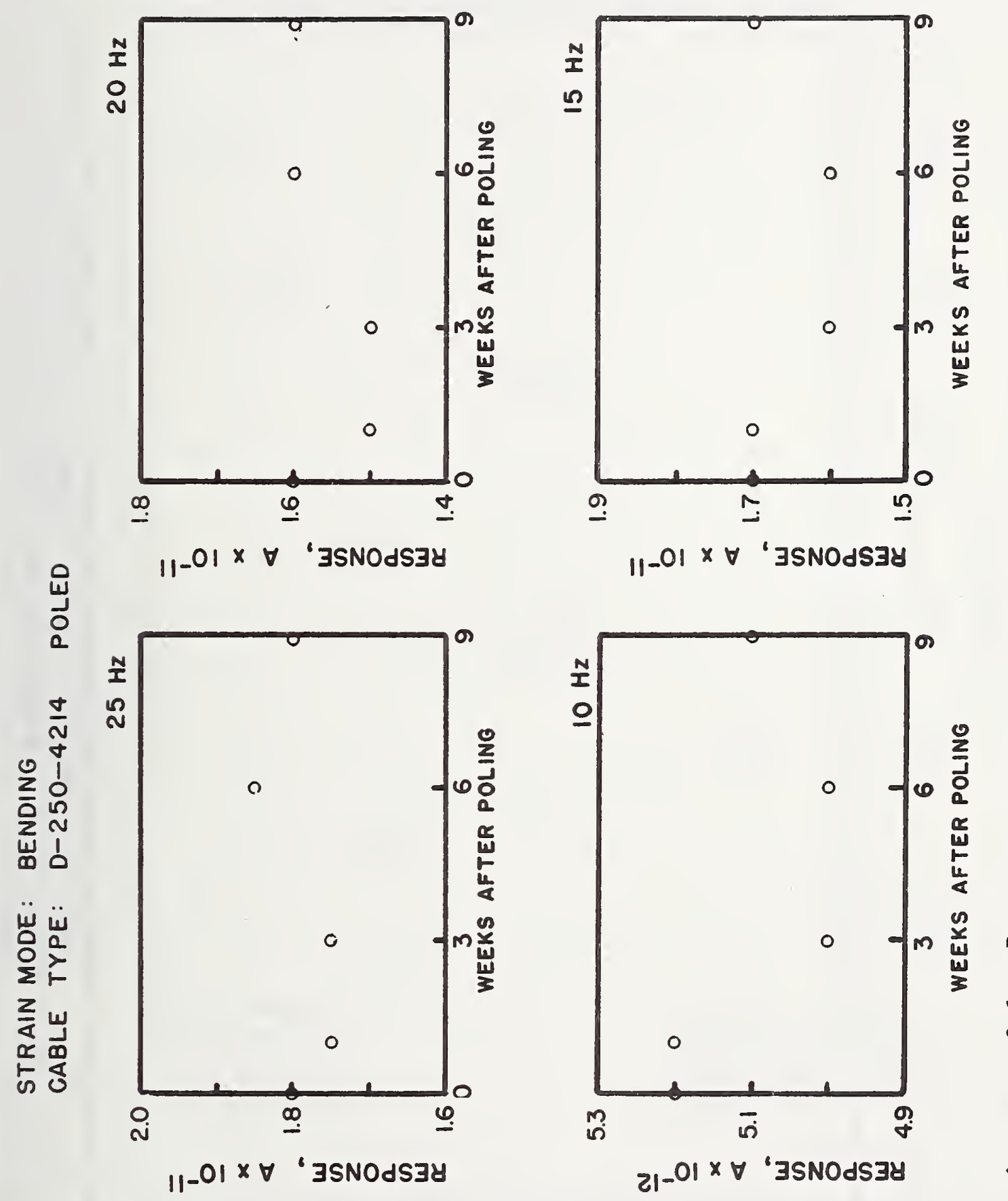

感

$\sum_{0} \sum$

山

$z z$ $\varangle 4$

능 웅

山

일

口 号

엉 号

눔

is

o

$\sum$

星

- ت

ن

$\times \sim$

مٌ

山

a

कi

崩 
APPENDIX D

0,2 . Figure 10

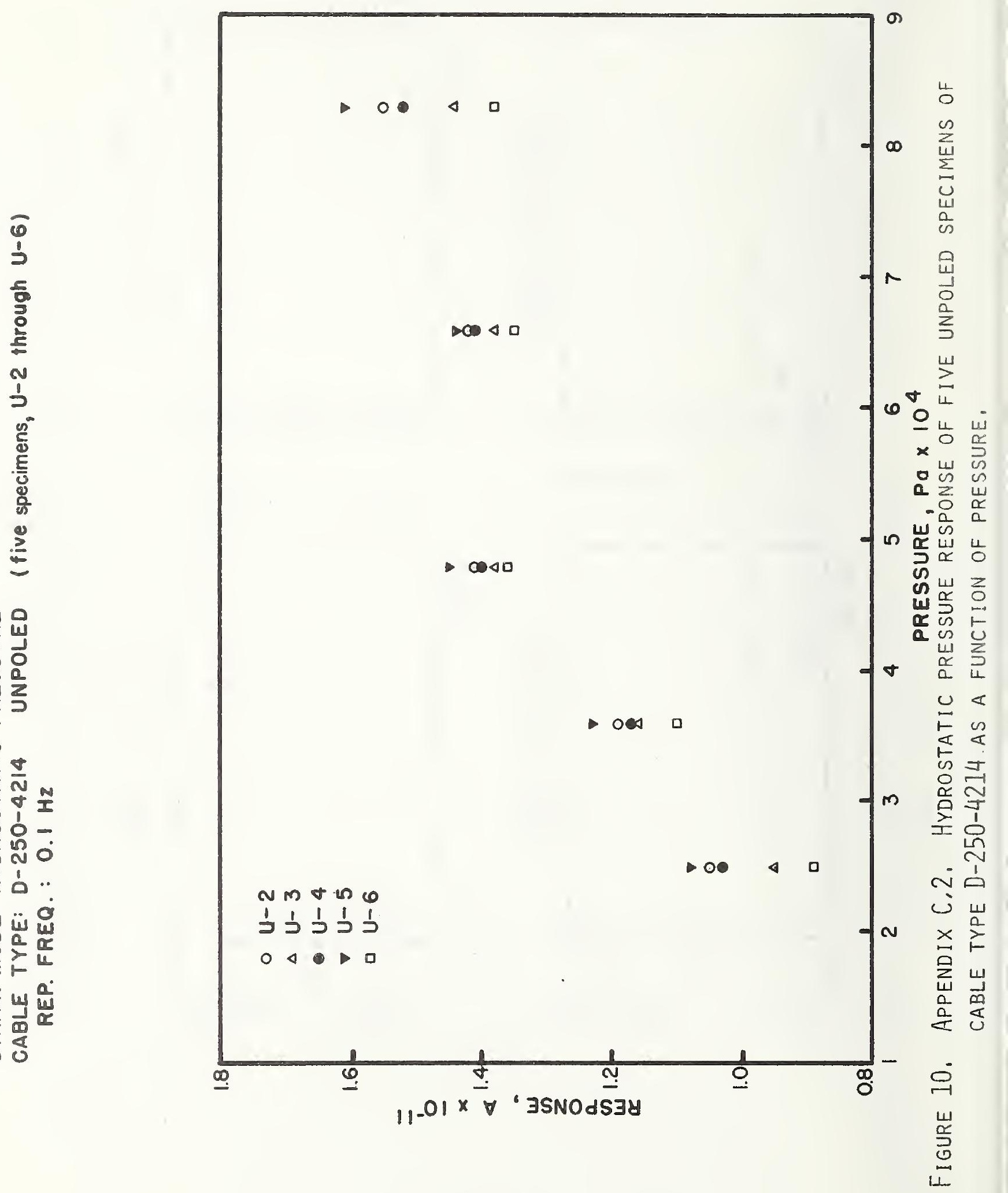


0,3 . Figure 11

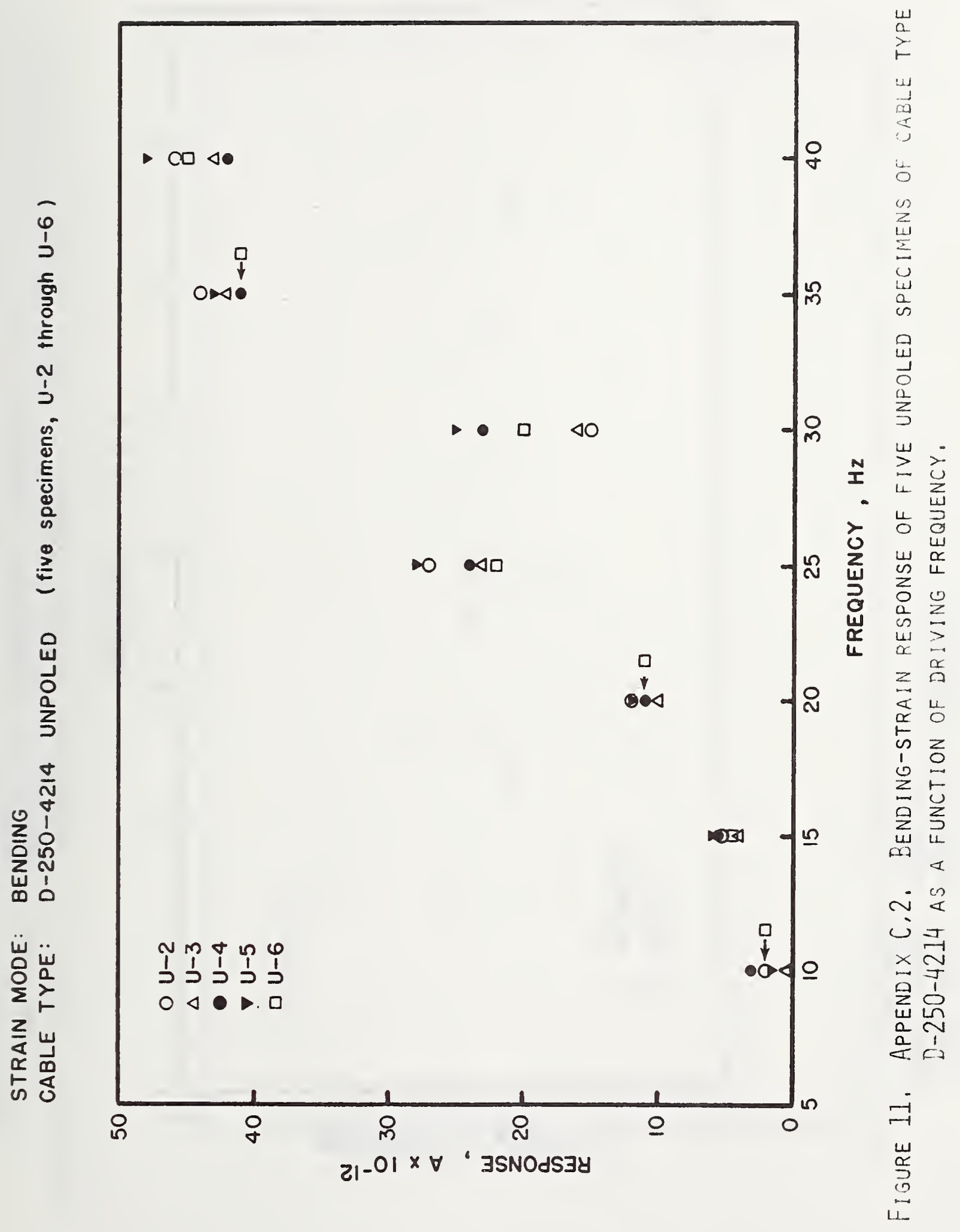


AFPi

i. 3. Figure 12

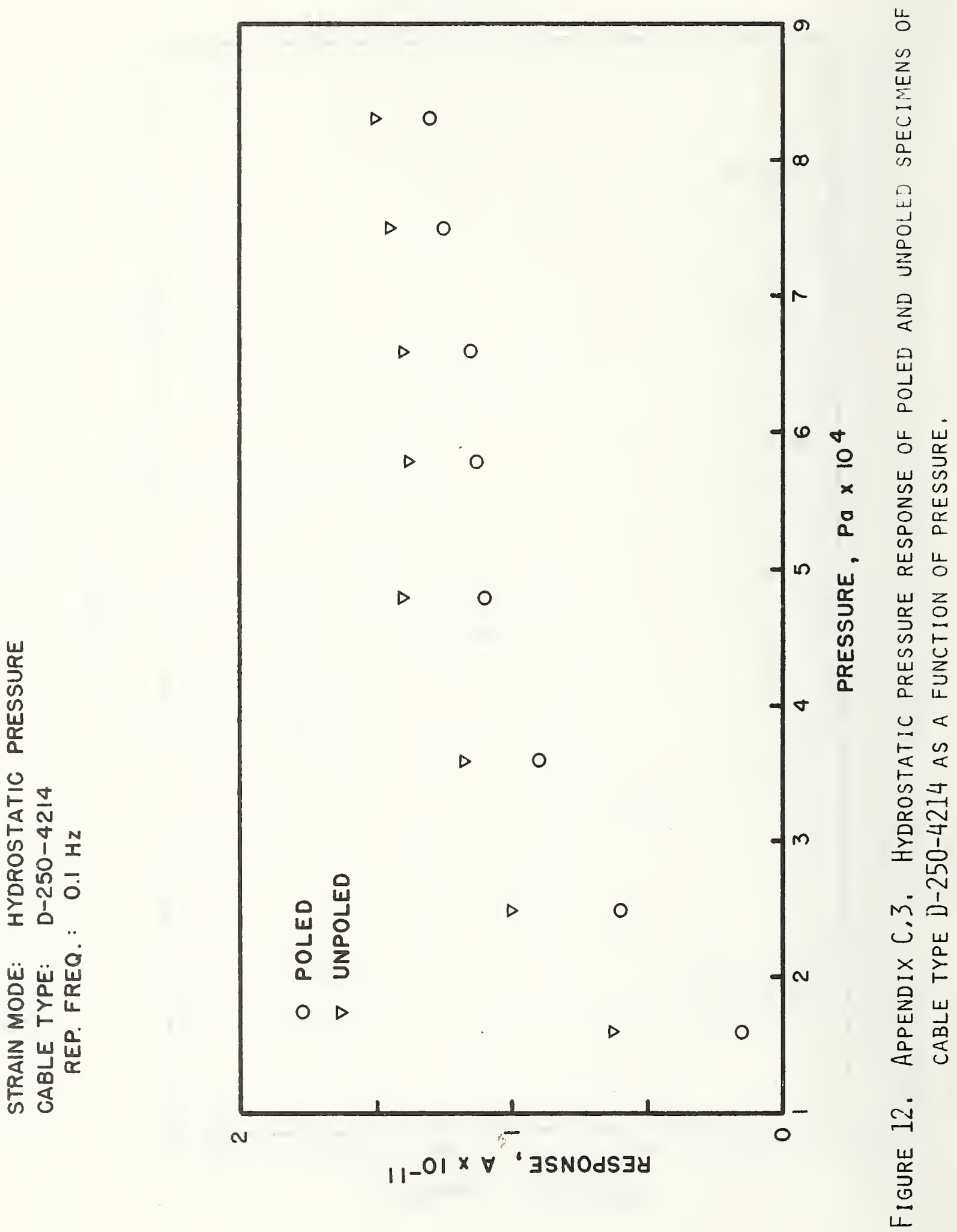




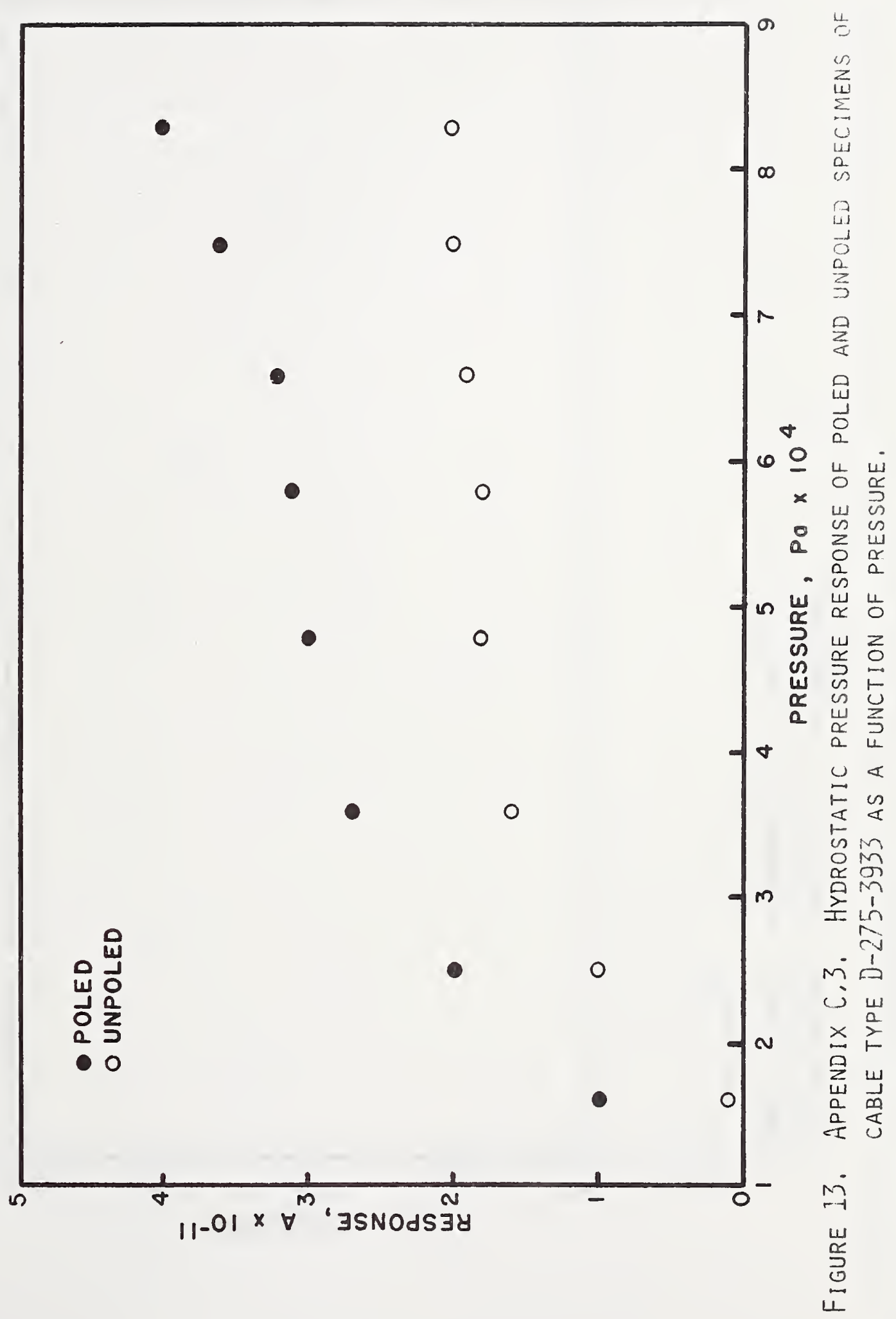




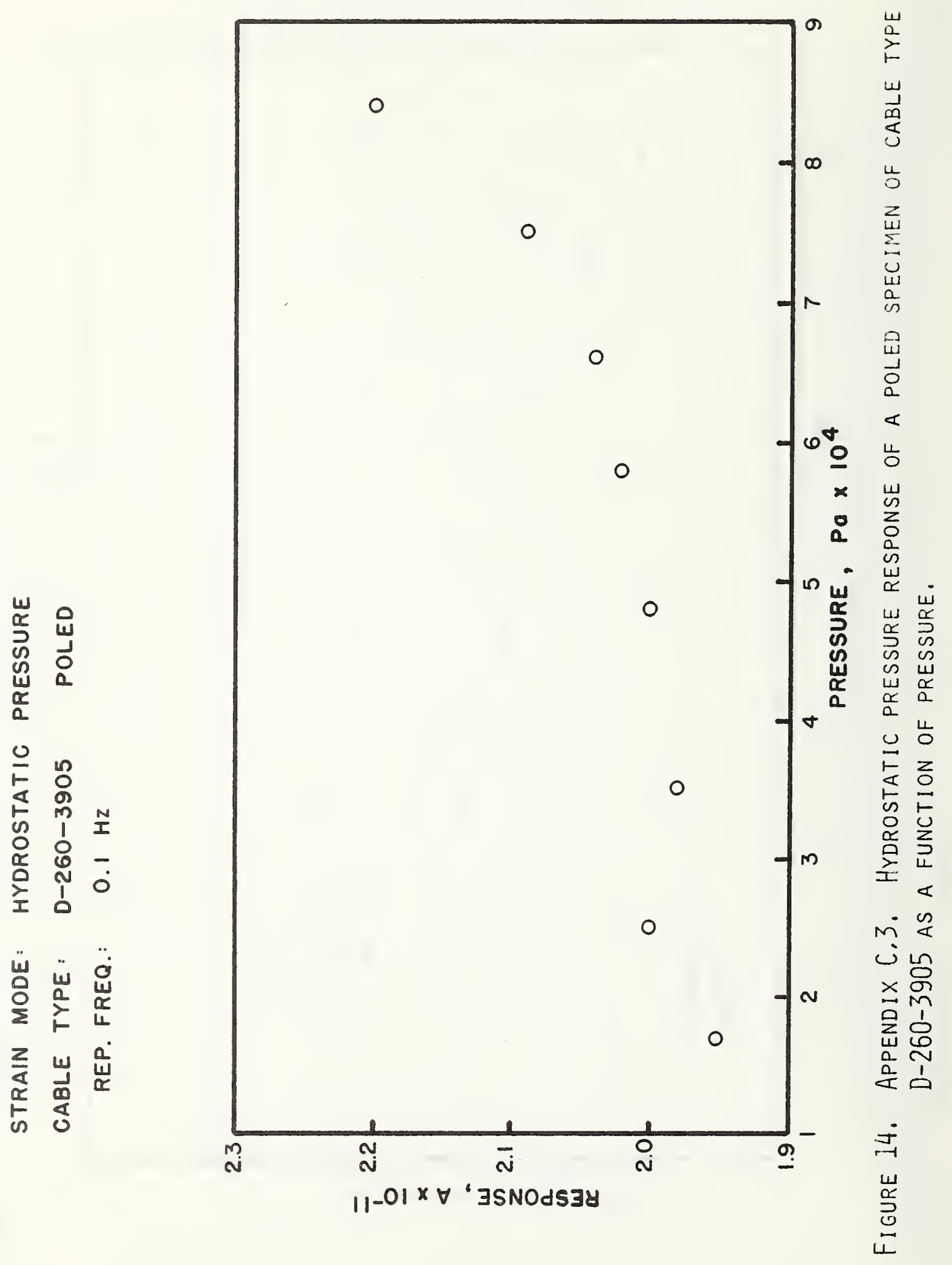




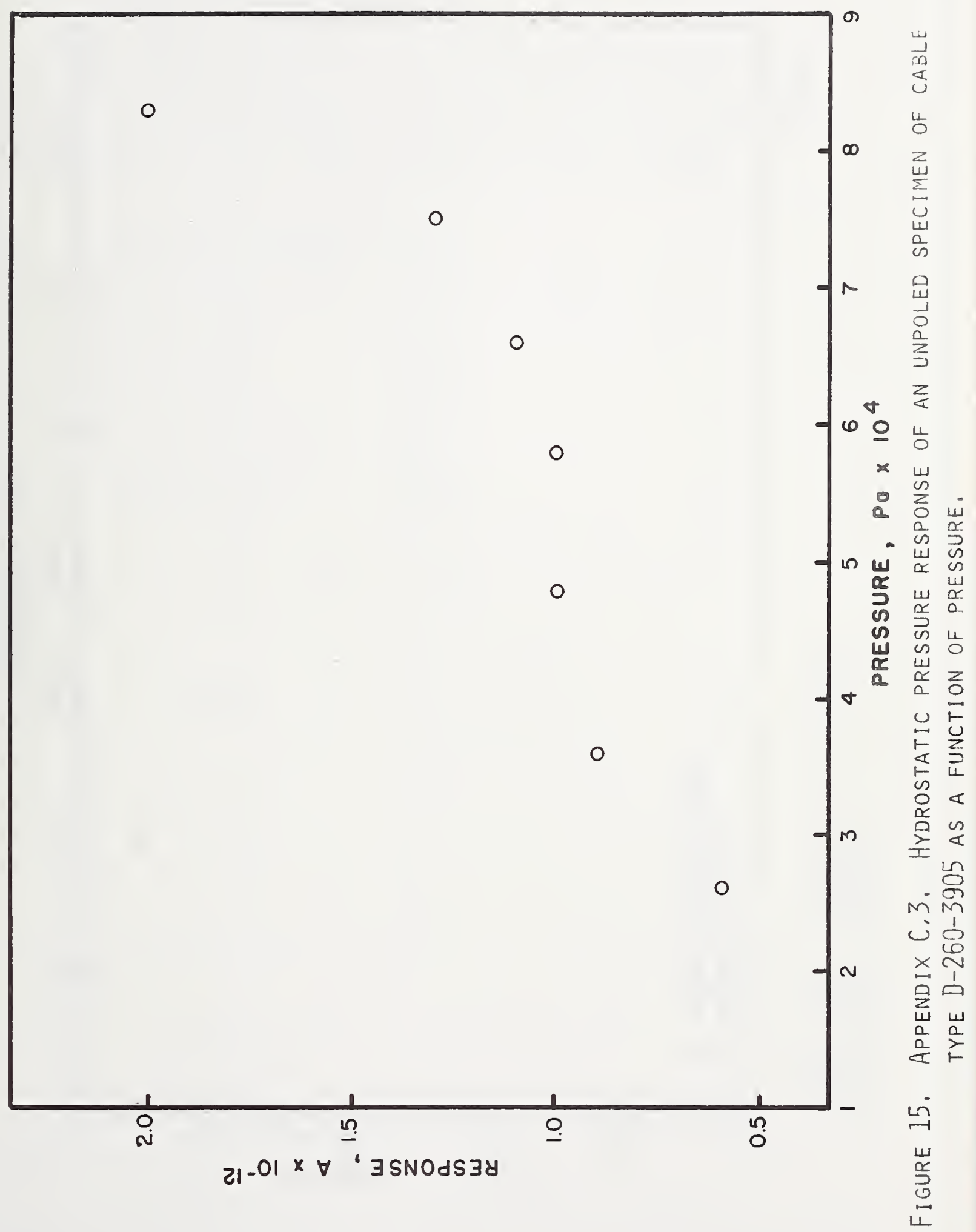




\section{0,4 . Figure 16}

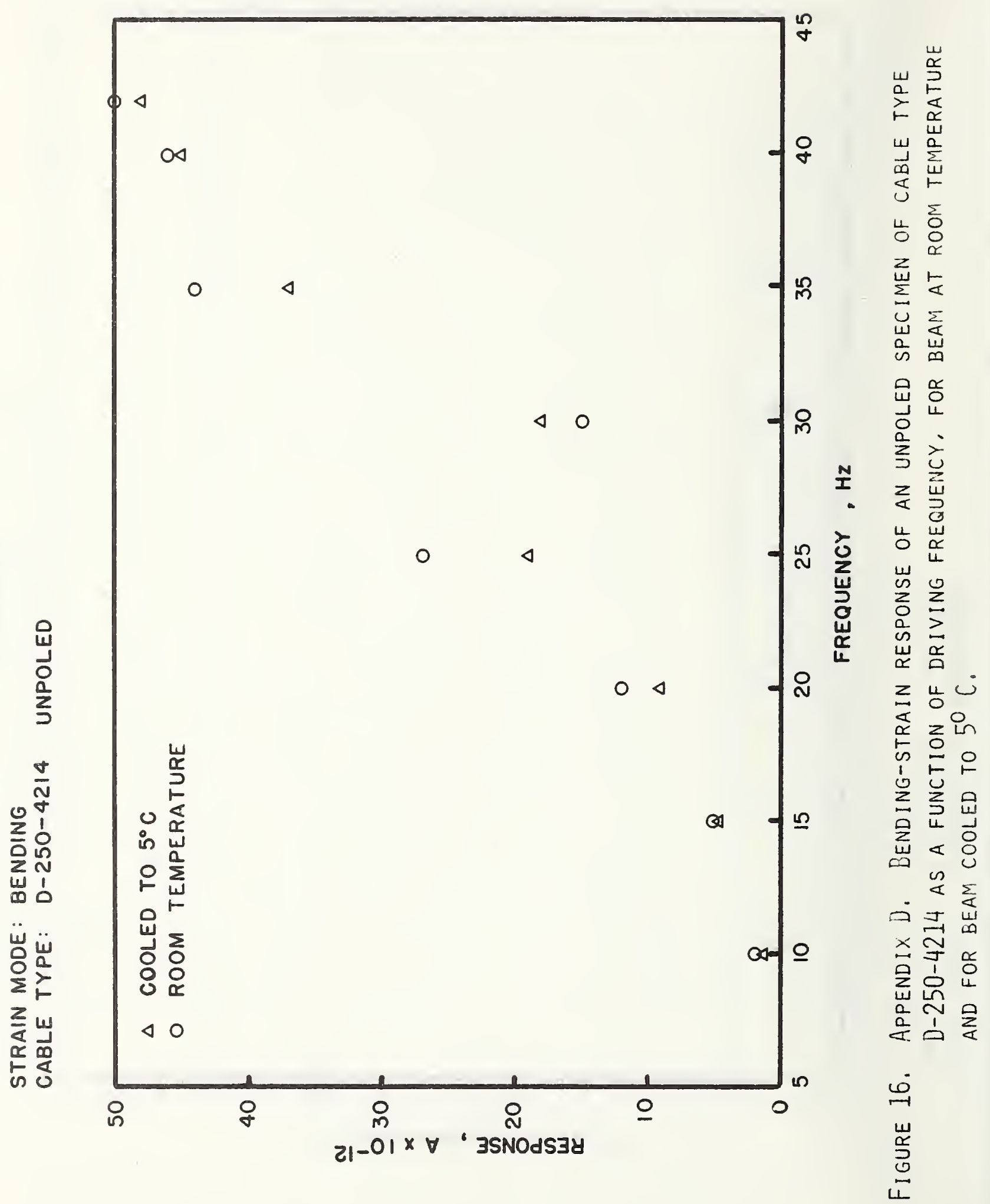




\section{APPENDIX E \\ CABLE RESPONSE DATA}

Data from cable measurements in response to hydrostatic pressure (bulk compression), bending strain, axial strain, and torsional strain. Data are presented for each cable type in the order (when given):
Hydrostatic pressure - poled
Hydrostatic pressure - unpoled
Bending strain - poled
Bending strain - unpoled
Axial strain - poled
Axial strain - unpoled
Torsional strain - poled
Torsional strain - unpoled 
Strain mode: Hydrostatic pressure (bulk compression)

Cable type: A8219 poled

\begin{tabular}{|c|c|c|}
\hline $\begin{array}{l}\text { Repetition Frequency } \\
\qquad(\mathrm{Hz})\end{array}$ & $\begin{array}{l}\text { Pressure } \\
\left(\mathrm{Pa} \times 10^{4}\right)\end{array}$ & $\begin{array}{l}\text { Cable Response } \\
\left(A \times 10^{-13}\right)\end{array}$ \\
\hline $\begin{array}{l}0.1 \\
0.1 \\
0.1 \\
0.2 \\
0.2 \\
0.2 \\
0.5 \\
0.5 \\
0.5 \\
1.0 \\
1.0 \\
1.0 \\
1.5 \\
1.5 \\
1.5 \\
2.0 \\
2.0 \\
2.0\end{array}$ & $\begin{array}{l}8.3 \\
4.8 \\
2.5 \\
8.3 \\
4.8 \\
2.5 \\
5.4 \\
3.5 \\
1.7 \\
3.1 \\
2.2 \\
1.2 \\
1.7 \\
1.4 \\
0.7 \\
1.7 \\
1.2 \\
0.6\end{array}$ & $\begin{array}{l}9.0 \\
6.0 \\
1.0 \\
7.6 \\
7.0 \\
1.0 \\
9.0 \\
6.0 \\
1.0 \\
4.0 \\
2.6 \\
1.3 \\
5.0 \\
4.0 \\
1.5 \\
5.0 \\
3.6 \\
1.5\end{array}$ \\
\hline \multicolumn{3}{|c|}{ Cable type: A-8219 unpoled } \\
\hline $\begin{array}{l}\text { Repetition Frezueney } \\
\left(\mathrm{Hz}_{\mathrm{Z}}\right)\end{array}$ & $\begin{array}{l}\text { Pressure } \\
\left(\mathrm{Pa} \times 10^{4}\right)\end{array}$ & $\begin{array}{c}\text { Cable Response } \\
\text { (A) }\end{array}$ \\
\hline $0.1 \div 2.0$ & $1.7-8.3$ & $\begin{array}{l}\text { This cable type pro- } \\
\text { duced no measurable re } \\
\text { sponse above noise to } \\
\text { hydrostatic pressure. }\end{array}$ \\
\hline
\end{tabular}




\section{Strain mode: Bending}

Cable type: A-8219 poled

\begin{tabular}{|c|c|c|}
\hline $\begin{array}{l}\text { Frequency } \\
\qquad(\mathrm{Hz})\end{array}$ & $\begin{array}{c}\text { Radius of Curvature } \\
\qquad\left(m \times 10^{3}\right)\end{array}$ & $\begin{array}{l}\text { Cable Response } \\
\text { (A) }\end{array}$ \\
\hline $\begin{array}{l}0.5,1.0,5.0,10 . \\
20 . \\
30 . \\
32 . \\
34 . \\
36 . \\
38 . \\
40 . \\
42 . \\
44 . \\
46 . \\
48 . \\
50 . \\
52 . \\
54 . \\
56 . \\
58 . \\
60 . \\
62 . \\
70 .\end{array}$ & $\begin{array}{l}2.699 \\
2.699 \\
2.699 \\
2.699 \\
2.699 \\
2.699 \\
2.699 \\
2.699 \\
2.699 \\
2.699 \\
2.699 \\
2.699 \\
2.699 \\
2.699 \\
2.699 \\
2.699 \\
2.699 \\
2.699 \\
2.699 \\
2.699\end{array}$ & $\begin{array}{l}\text { in noise } \\
\text { in noise } \\
4.0 \times 10^{-13} \\
8.0 \times 10^{-13} \\
2.6 \times 10^{-12} \\
2.0 \times 10^{-12} \\
1.6 \times 10^{-11} \\
1.4 \times 10^{-11} \\
1.6 \times 10^{-11} \\
1.2 \times 10^{-11} \\
1.4 \times 10^{-11} \\
1.3 \times 10^{-11} \\
1.4 \times 10^{-11} \\
1.2 \times 10^{-11} \\
1.0 \times 10^{-11} \\
8.0 \times 10^{-12} \\
9.0 \times 10^{-12} \\
2.2 \times 10^{-11} \\
3.6 \times 10^{-11} \\
7.0 \times 10^{-11}\end{array}$ \\
\hline
\end{tabular}


Strain mode: Bending

Cable type: A-8219 unpolled

\begin{tabular}{|c|c|c|}
\hline $\begin{array}{c}\text { Frequency } \\
(\mathrm{Hz})\end{array}$ & $\begin{array}{c}\text { Radius of Curvature } \\
\left(\mathrm{m} \times 10^{3}\right)\end{array}$ & $\begin{array}{c}\text { Cable Response } \\
(\mathrm{A})\end{array}$ \\
\hline $0.2,0.5,5.0,10$, & 2.699 & in noise \\
in noise \\
$70,30,35,40,50$
\end{tabular}

$-5 n$ 
Strain mode: Axial

Cable type: A-8219 poled

\begin{tabular}{|c|c|c|}
\hline $\begin{array}{c}\text { Frequency } \\
(\mathrm{Hz})\end{array}$ & $\begin{array}{c}\text { Axial Motion } \\
(\mathrm{m})\end{array}$ & $\begin{array}{c}\text { Cable Response } \\
(\mathrm{A})\end{array}$ \\
\hline $0.05-100$ & $2.16 \times 10^{-4}$ & $\begin{array}{l}\text { This cable type pro- } \\
\text { duced no measurable re- } \\
\text { sponse above noise to } \\
\text { axial strain. }\end{array}$ \\
\hline
\end{tabular}

Cable type: A-8219 unpoled

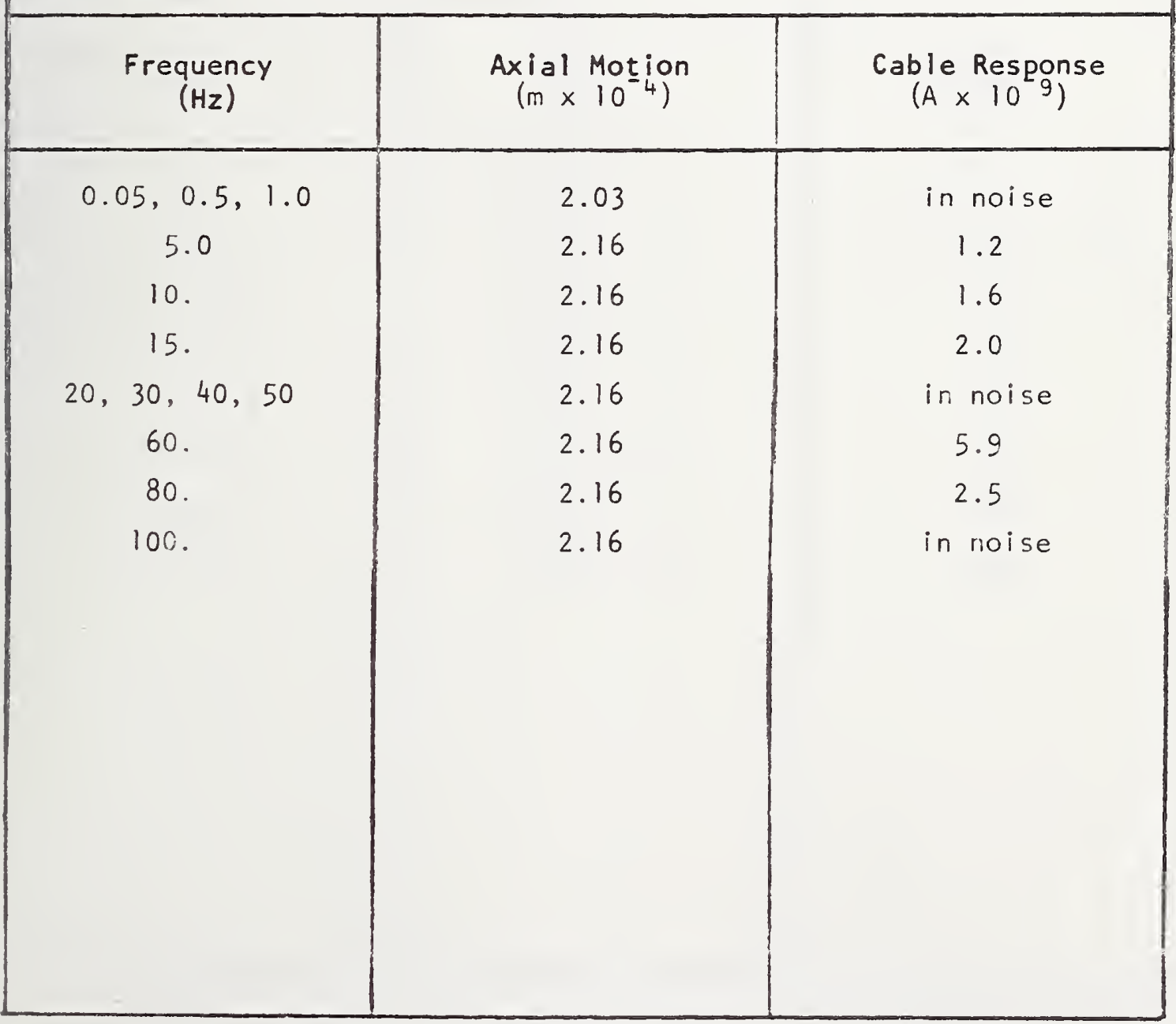


Cable type: A-8219 poled

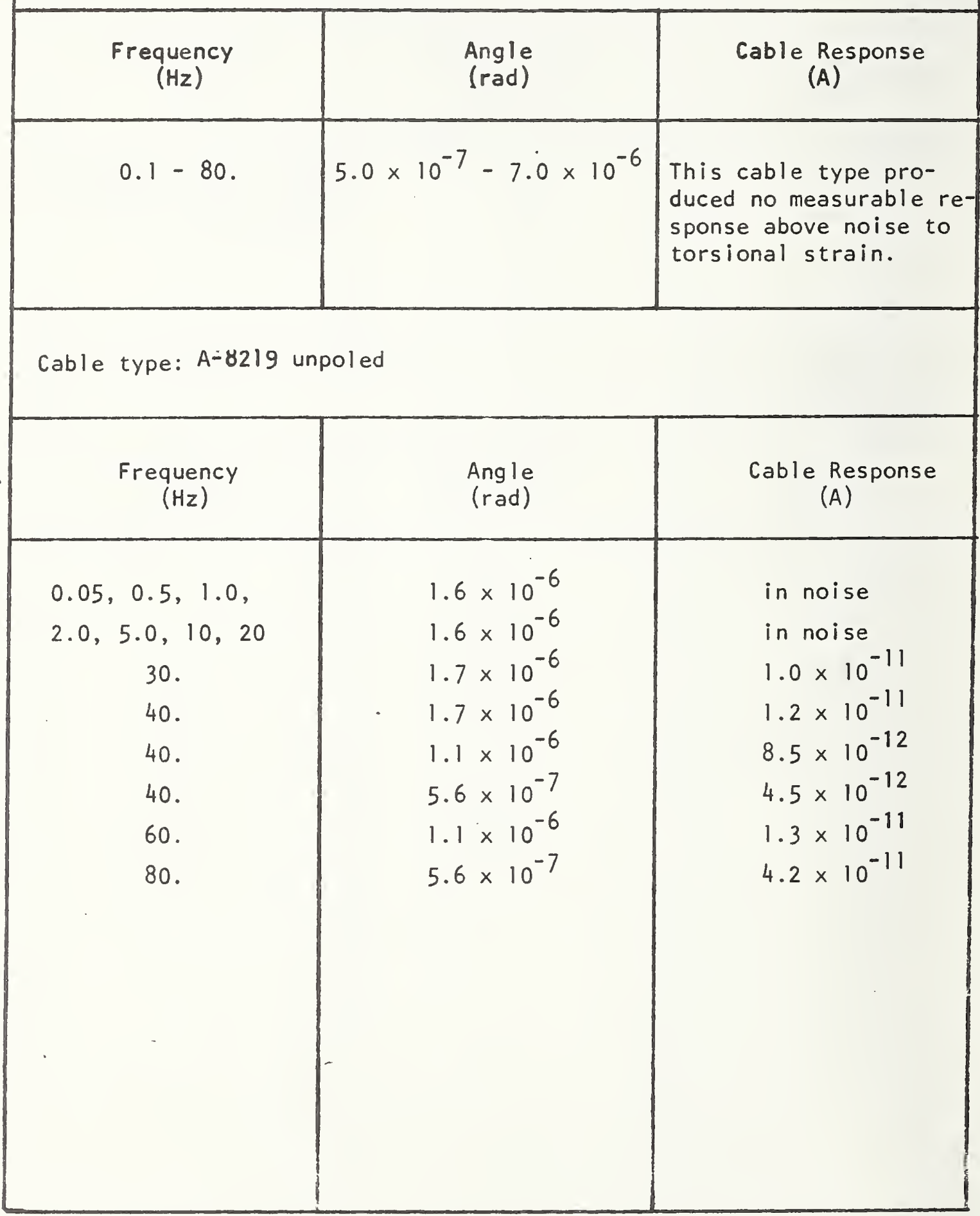


Strain mode: Hydrostatic pressure (bulk compression)

Cable type: A-8263 unpoled

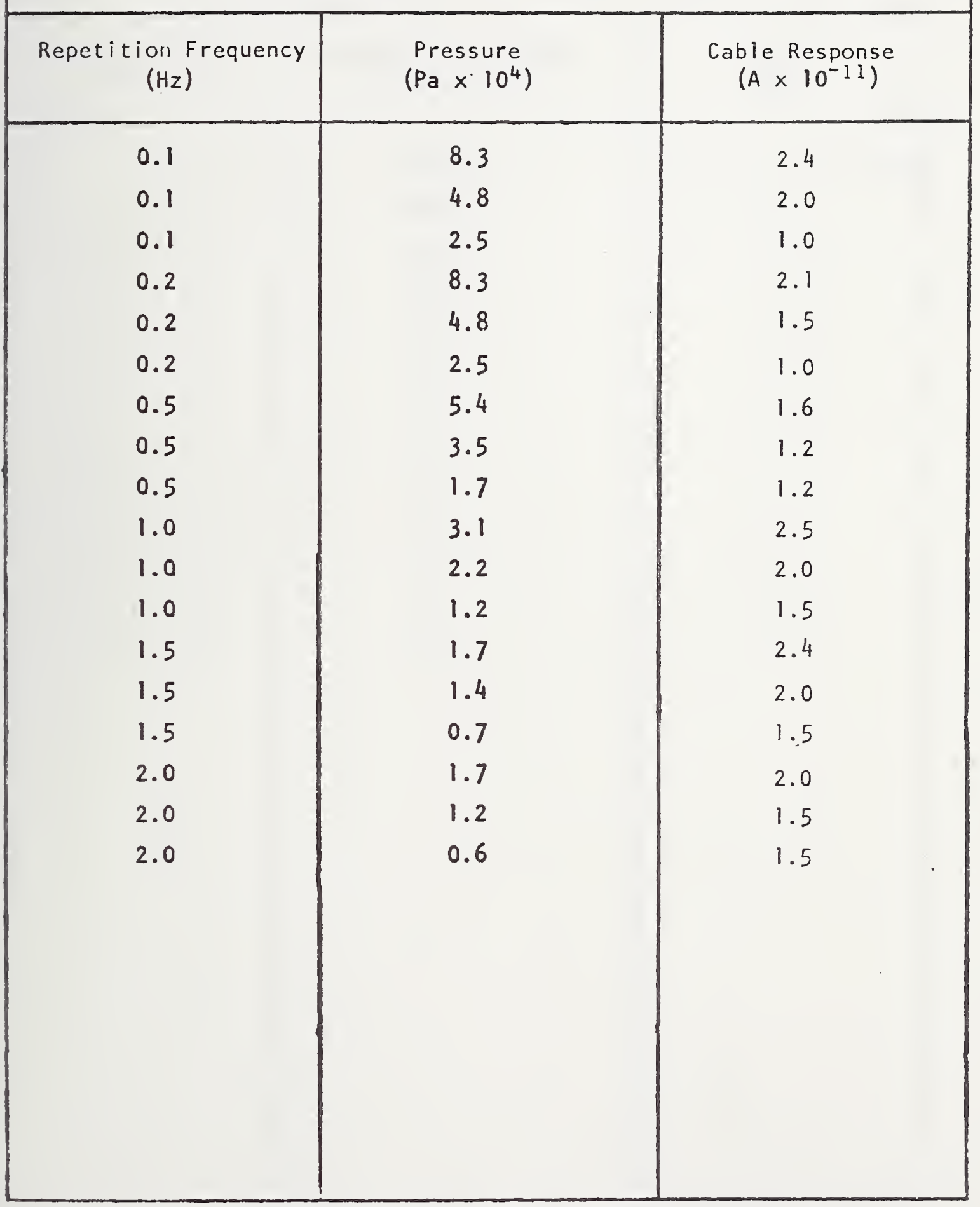




\section{Strain mode: Bending}

Cable type: A-8263 unpoled

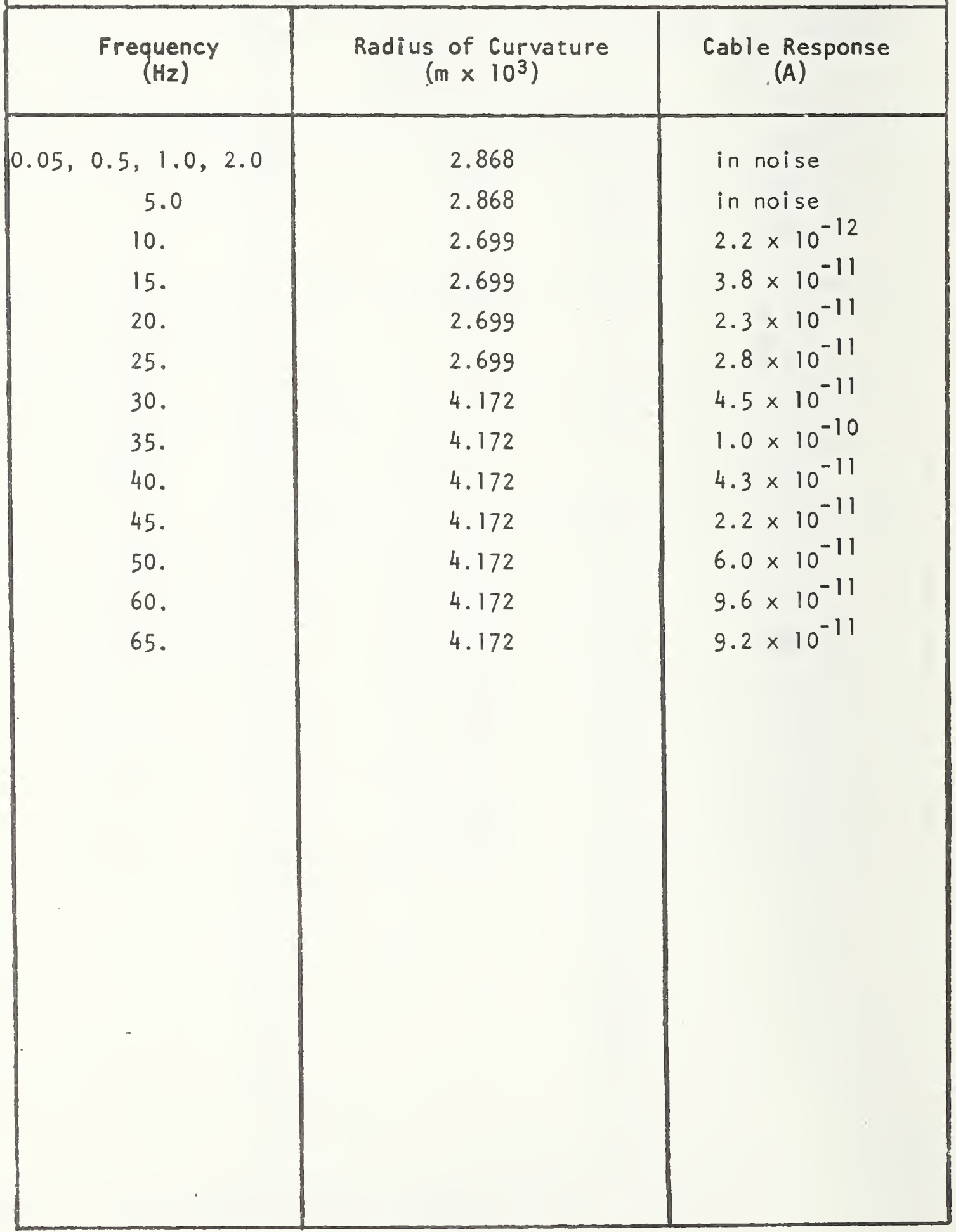


Strain mode: Hydrostatic pressure (bulk compression)

Cable type: A-83269 poled

\begin{tabular}{|c|c|c|}
\hline $\begin{array}{l}\text { Repetition Frequency } \\
\qquad(\mathrm{Hz})\end{array}$ & $\begin{array}{l}\text { Pressure } \\
\left(\mathrm{Pa} \times 10^{4}\right)\end{array}$ & $\begin{array}{c}\text { Cable Response } \\
\qquad\left(A \times 10^{-11}\right)\end{array}$ \\
\hline 0.1 & 8.3 & 1.5 \\
\hline 0.1 & 4.8 & 1.0 \\
\hline 0.1 & 2.5 & 1.0 \\
\hline 0.2 & 8.3 & 1.6 \\
\hline 0.2 & 4.8 & 1.5 \\
\hline 0.2 & 2.5 & 0.8 \\
\hline 0.5 & 5.4 & 2.0 \\
\hline 0.5 & 3.5 & 1.2 \\
\hline 0.5 & 1.7 & 1.0 \\
\hline 1.0 & 3.1 & 2.4 \\
\hline 1.0 & 2.2 & 2.0 \\
\hline 1.0 & 1.2 & 1.0 \\
\hline 1.5 & 1.7 & 2.0 \\
\hline 1.5 & 1.4 & 2.0 \\
\hline 1.5 & 0.7 & 1.0 \\
\hline 2.0 & 1.7 & 2.0 \\
\hline 2.0 & 1.2 & 1.8 \\
\hline 2.0 & 0.6 & 1.0 \\
\hline
\end{tabular}




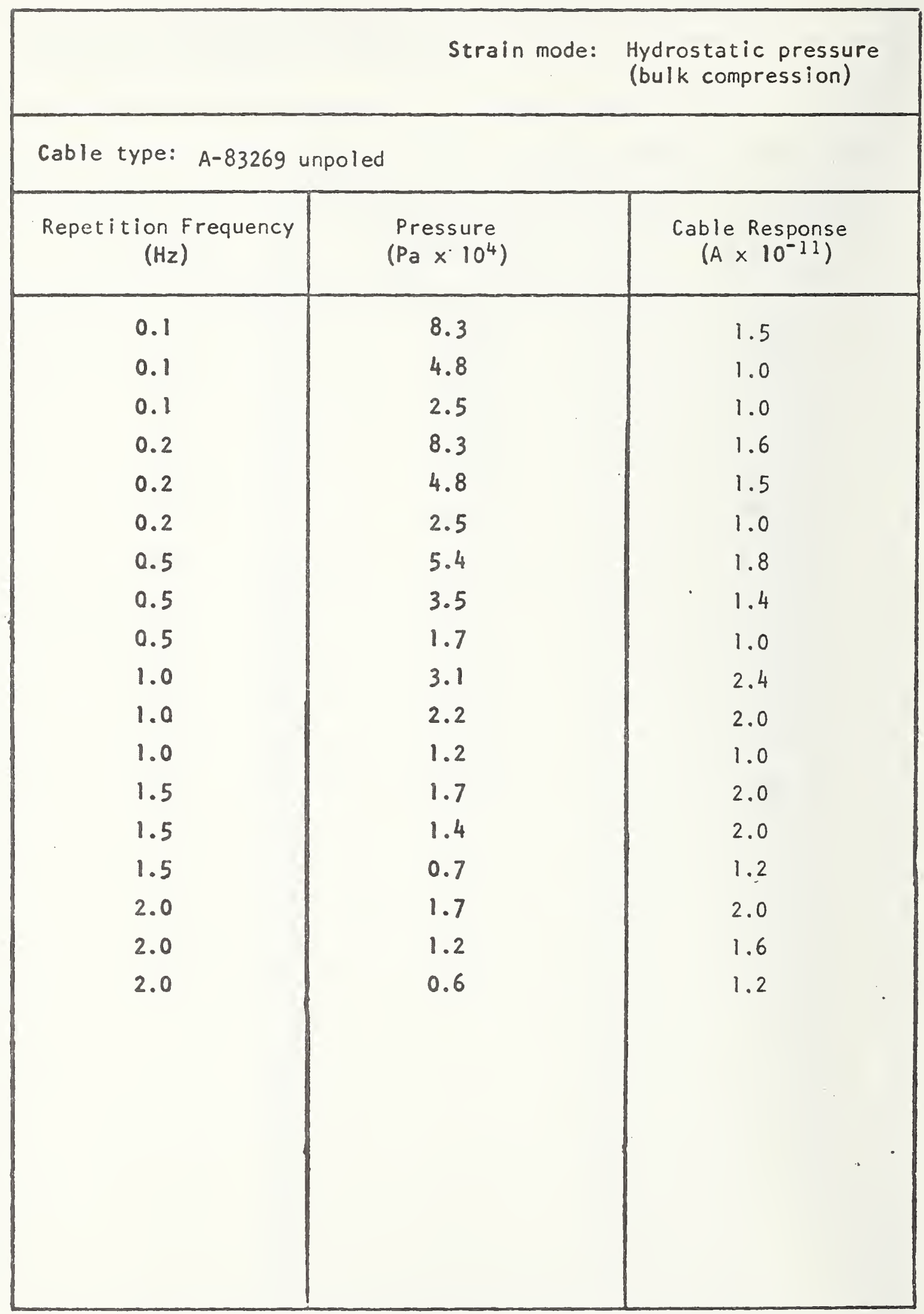


Strain mode: Hydrostatic pressure (bulk compression)

Cable types: D-250-3804 poled, D-250-3804 unpoled

\begin{tabular}{c|c|c}
\hline Redetition Frequency & Pressure & Cable Response \\
$(\mathrm{H} z \mathrm{z})$ & $\left(\mathrm{Pa} \times 10^{4}\right)$ & $(\mathrm{A})$
\end{tabular}

$0.1-2.0$

$1.7-8.3$

These cable types produced no measurable response above noise to hydrostatic pressure. 
Strain mode: Torsional

Cable type: D-250-3804 unpoled

\begin{tabular}{|c|c|c|}
\hline $\begin{array}{c}\text { Frequency } \\
\qquad(\mathrm{Hz})\end{array}$ & $\begin{array}{l}\text { Angle } \\
\text { (rad) }\end{array}$ & $\begin{array}{c}\text { Cable Response } \\
\text { (A) }\end{array}$ \\
\hline $\begin{array}{c}0.05,0.5,1.0 \\
10 \\
20 \\
25 \\
50 \\
60 \\
80 \\
90 \\
100\end{array}$ & $\begin{array}{l}7.0 \times 10^{-6} \\
7.0 \times 10^{-6} \\
7.0 \times 10^{-6} \\
4.5 \times 10^{-6} \\
5.4 \times 10^{-7} \\
3.4 \times 10^{-7} \\
4.5 \times 10^{-7} \\
5.0 \times 10^{-7} \\
2.0 \times 10^{-7}\end{array}$ & $\begin{array}{l}\text { in noise } \\
\text { in noise } \\
\text { in noise } \\
2.6 \times 10^{-11} \\
1.8 \times 10^{-11} \\
6.0 \times 10^{-11} \\
2.0 \times 10^{-11} \\
\text { in noise } \\
1.2 \times 10^{-11}\end{array}$ \\
\hline
\end{tabular}


Strain mode: Hydrostatic pressure (bulk compression)

Cable types: D-250-3866 poled, D-250-3866 unpoled

\begin{tabular}{c|c|c|}
\hline Renetition Frequency & Pressure & Cable Pesponse \\
$(\mathrm{Hz})$ & $\left(\mathrm{Pa} \times 10^{4}\right)$ & $(\mathrm{A})$ \\
\hline
\end{tabular}

\begin{tabular}{l|l}
$0.1-2.0$ & $1.7-8.3$
\end{tabular}

These cable types produced no measurable response above noise to hydrostatic pressure. 
Strain mode: Torsional

Cable type: D-250-3866 poled

\begin{tabular}{|c|c|c|}
\hline $\begin{array}{c}\text { Frequency } \\
(\mathrm{Hz})\end{array}$ & $\begin{array}{c}\text { Angle } \\
(\mathrm{rad})\end{array}$ & $\begin{array}{c}\text { Cable Response } \\
(\mathrm{A})\end{array}$ \\
\hline $0.05,0.5,1.0$ & $5.0 \times 10^{-6}$ & in noise \\
5.0 & $5.0 \times 10^{-6}$ & in noise \\
10. & $5.0 \times 10^{-6}$ & $1.6 \times 10^{-11}$ \\
20. & $4.8 \times 10^{-6}$ & in noise \\
30. & $3.1 \times 10^{-6}$ & $3.0 \times 10^{-11}$ \\
50. & $1.0 \times 10^{-6}$ & $2.6 \times 10^{-11}$ \\
60. & $5.6 \times 10^{-7}$ & $1.1 \times 10^{-10}$ \\
70. & $5.6 \times 10^{-7}$ & $2.8 \times 10^{-11}$ \\
80. & $3.6 \times 10^{-7}$ & $4.0 \times 10^{-11}$ \\
& $3.4 \times 10^{-7}$ & \\
& & \\
& &
\end{tabular}


Strain mode: Hydrostatic pressure (bulk compression)

Cable type: $0-250-4214$ poled

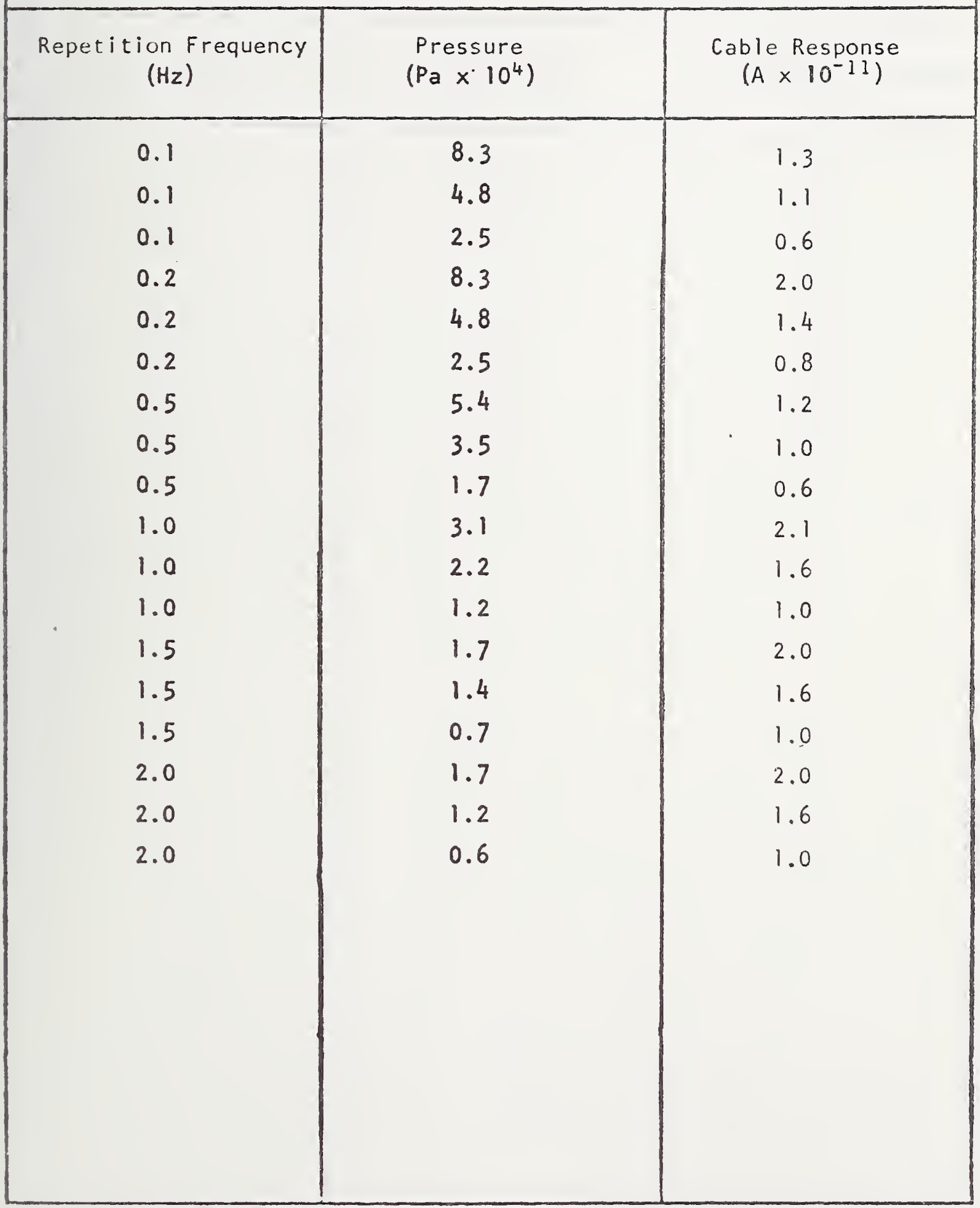




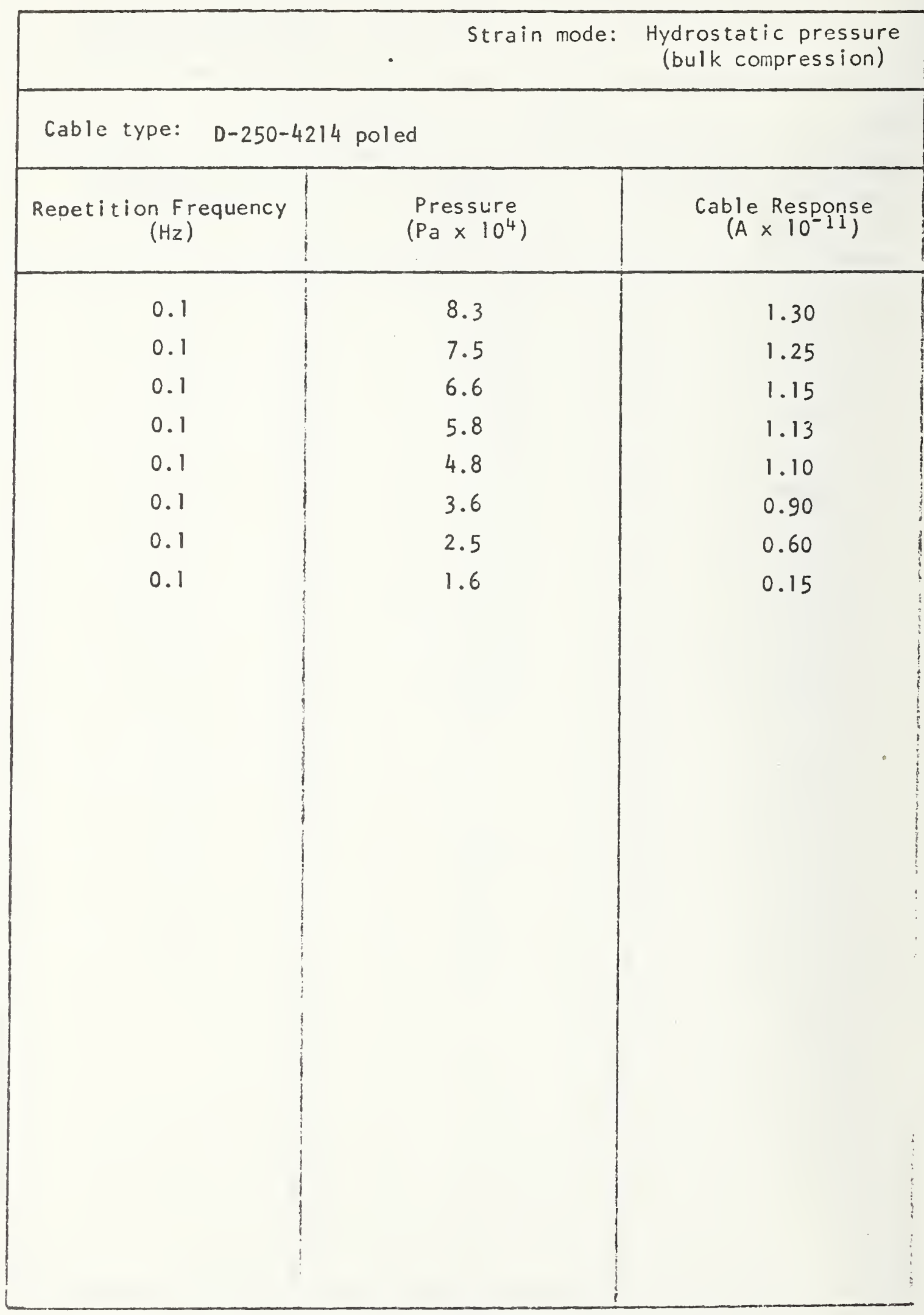


Strain mode: Hydrostatic pressure (bulk compression)

Cable type: D-250-4214 unpoled

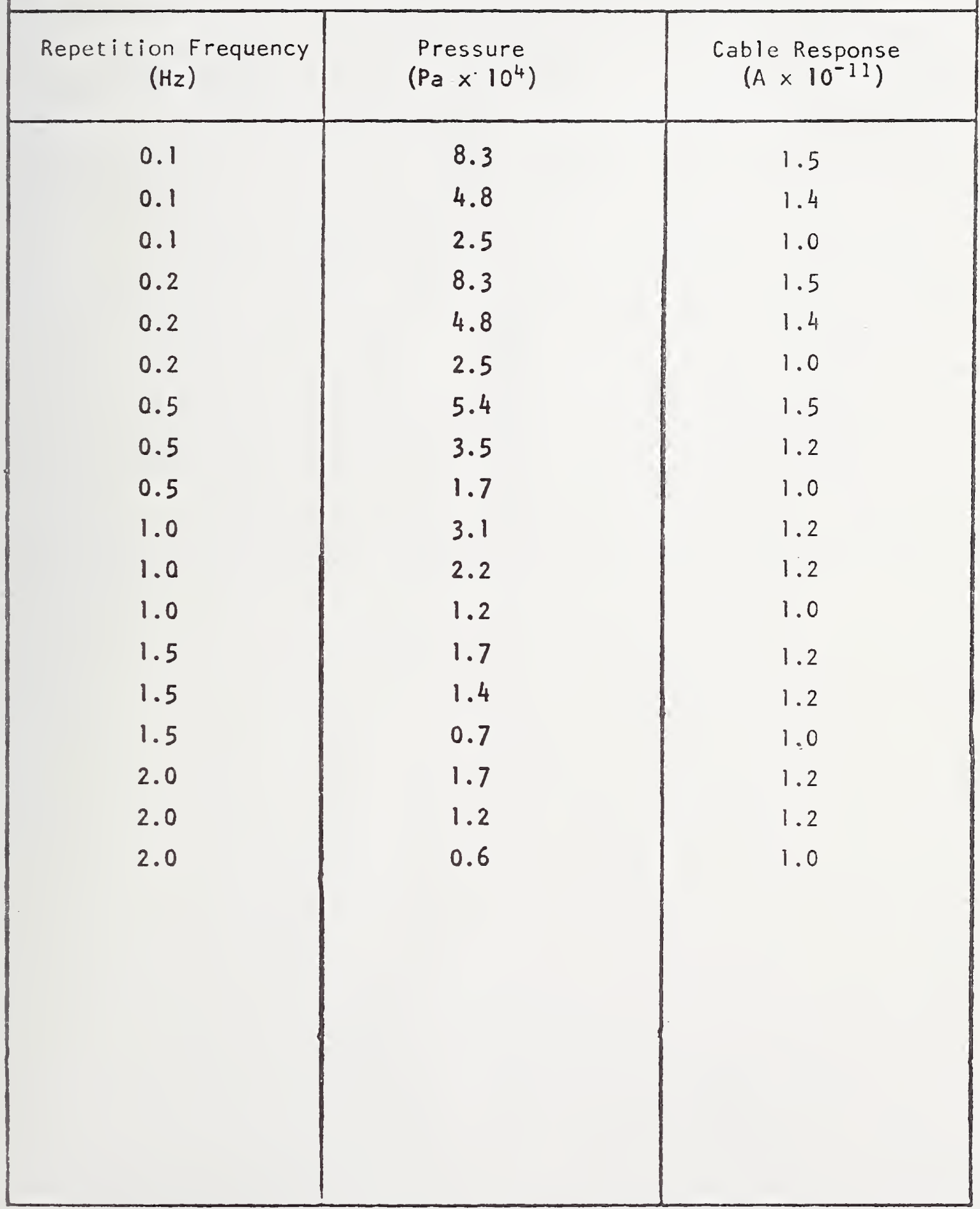




\section{Strain mode: Hydrostatic pressure}

(bulk compression)

Cable type: D-250-4214 unpoled

\begin{tabular}{|c|c|c|}
\hline $\begin{array}{c}\text { Redetition Frequency } \\
(\mathrm{Hz})\end{array}$ & $\begin{array}{c}\text { Pressure } \\
\left(\mathrm{Pa} \times 10^{4}\right)\end{array}$ & $\begin{array}{c}\text { Cable Response } \\
\left(\mathrm{A} \times 10^{-11}\right)\end{array}$ \\
\hline 0.1 & 8.3 & 1.50 \\
0.1 & 7.5 & 1.45 \\
0.1 & 6.6 & 1.40 \\
0.1 & 5.8 & 1.38 \\
0.1 & 4.8 & 1.40 \\
0.1 & 3.6 & 1.17 \\
0.1 & 2.5 & 1.00 \\
0.1 & 1.6 & 0.62 \\
\hline
\end{tabular}


Strain mode: Hydrostatic pressure (bulk compression)

Cable type: D-250-4214 unpoled (five samples, U-2 through U-6)

Repetition frequency: $0.1 \mathrm{~Hz}$

Pressure

$\left(\mathrm{Pa} \times 10^{4}\right)$

\begin{tabular}{|l|l|l|l|l|l|l|}
\cline { 2 - 6 } & $U-2$ & $U-3$ & $U-4$ & $U-5$ & $U-6$ & Average \\
\hline 8.3 & 1.55 & 1.44 & 1.52 & 1.61 & 1.38 & 1.50 \\
6.6 & 1.42 & 1.38 & 1.41 & 1.44 & 1.35 & 1.40 \\
4.8 & 1.41 & 1.38 & 1.40 & 1.45 & 1.36 & 1.40 \\
3.6 & 1.19 & 1.16 & 1.17 & 1.23 & 1.10 & 1.17 \\
2.5 & 1.05 & 0.95 & 1.03 & 1.08 & 0.89 & 1.00 \\
\hline
\end{tabular}


Strain mode: Bending

Cable type: D-250-4214 poled

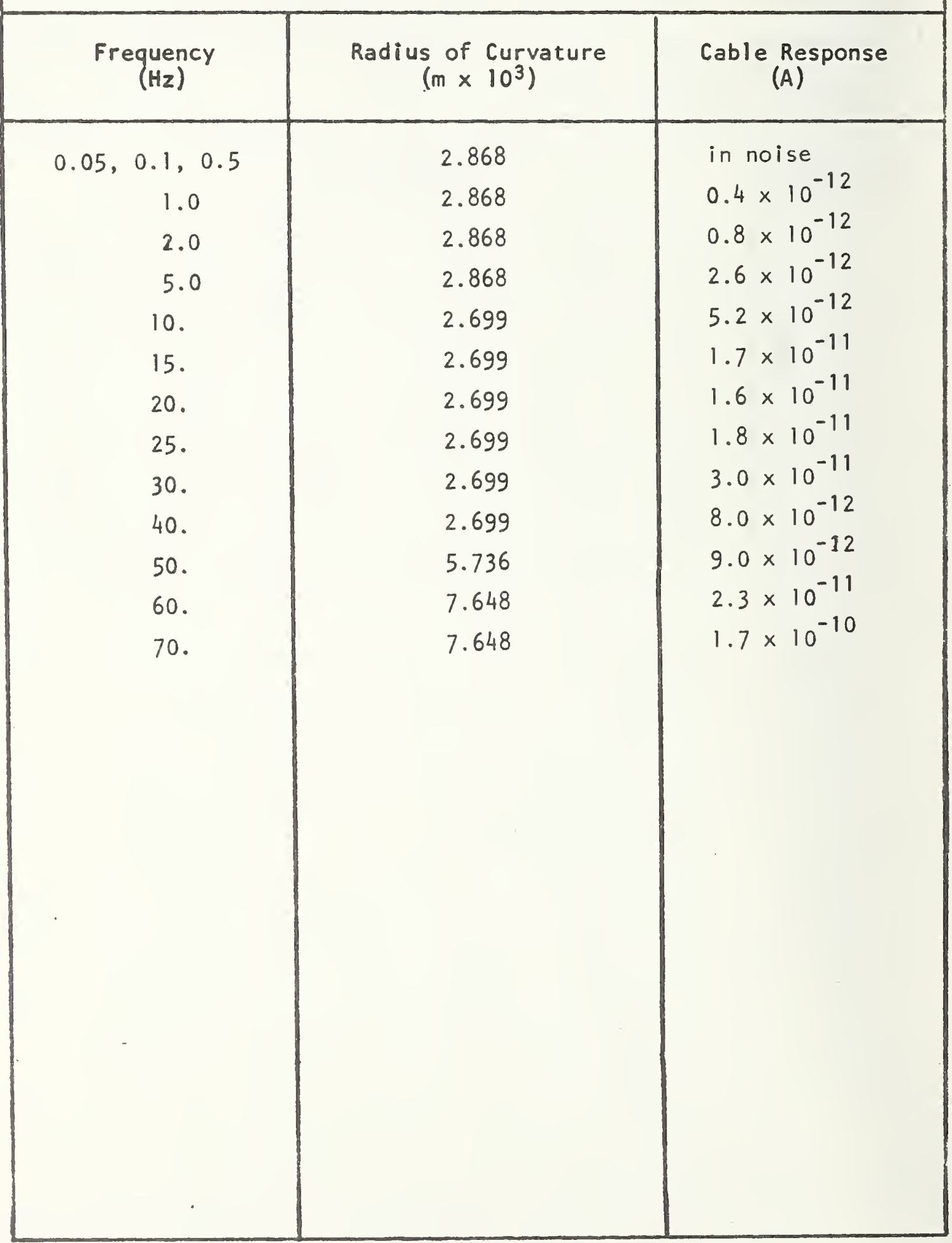


Strain mode: Bending

Cable type: D-250-4214 unpoled

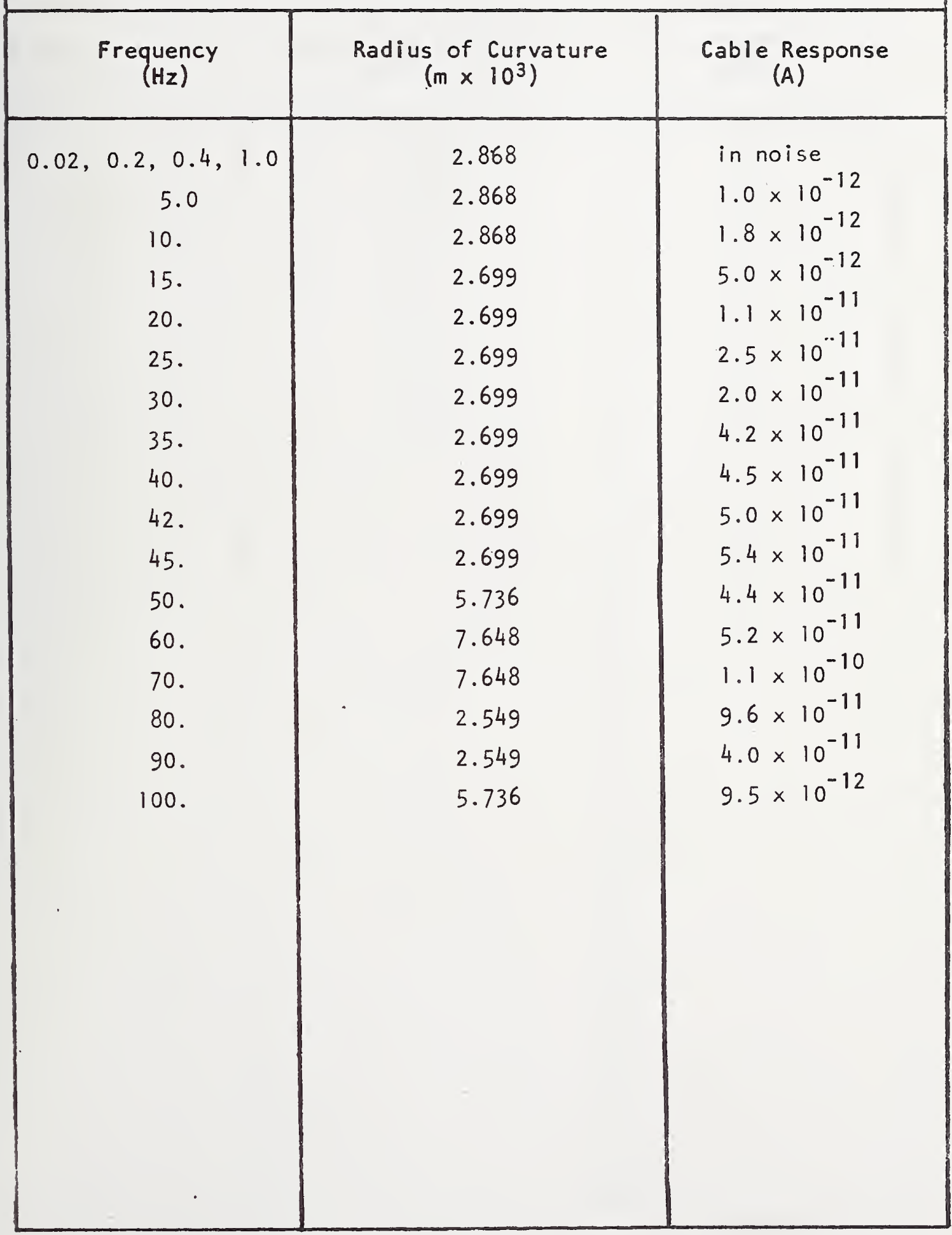


Strain mode: Bending

Cable type: D-250-4214-U-1 unpoled cooled to $5^{\circ} \mathrm{C}$

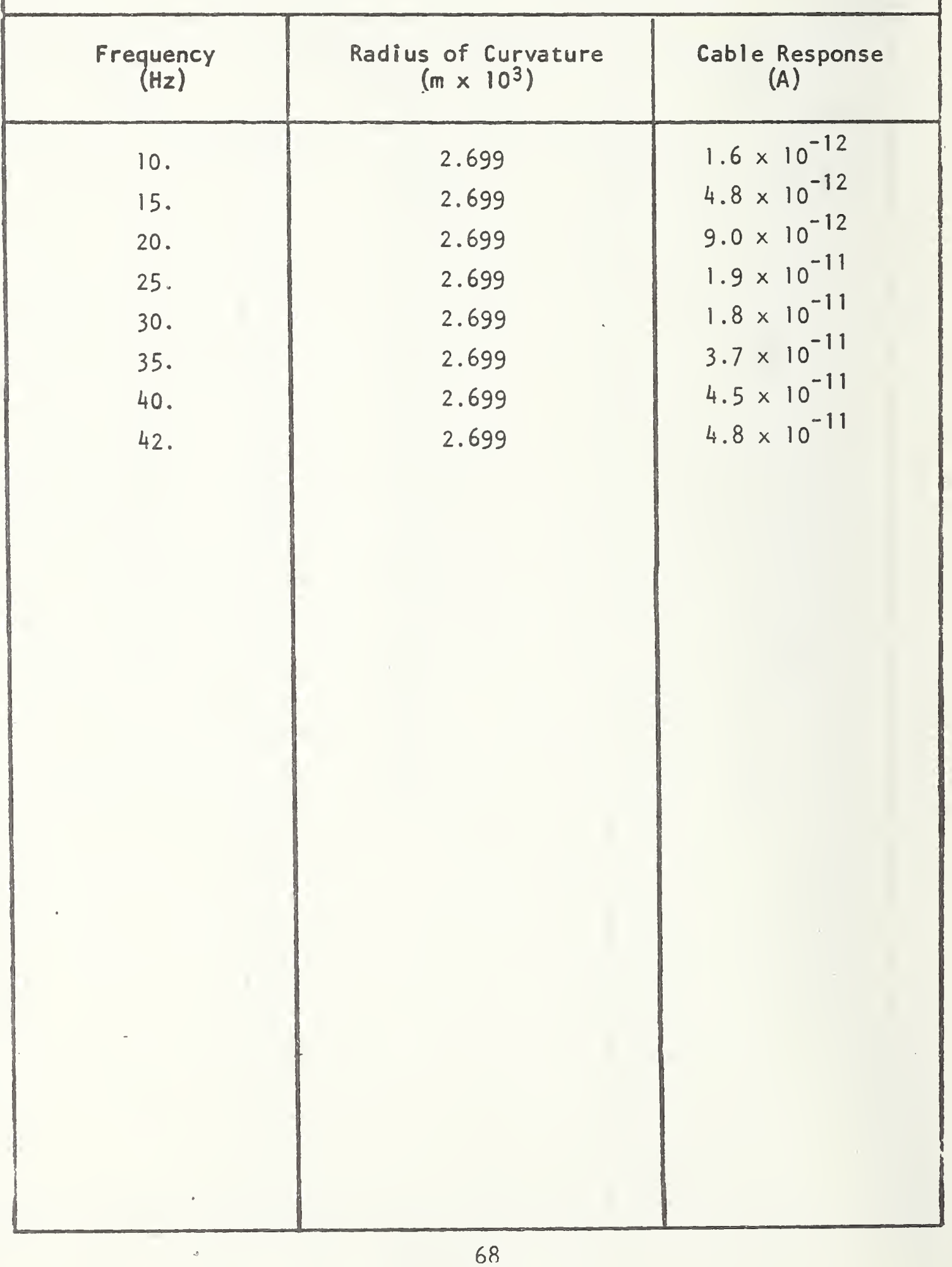


Strain mode: Bending

Cable type: D-250-4214 unpoled (with moisture)

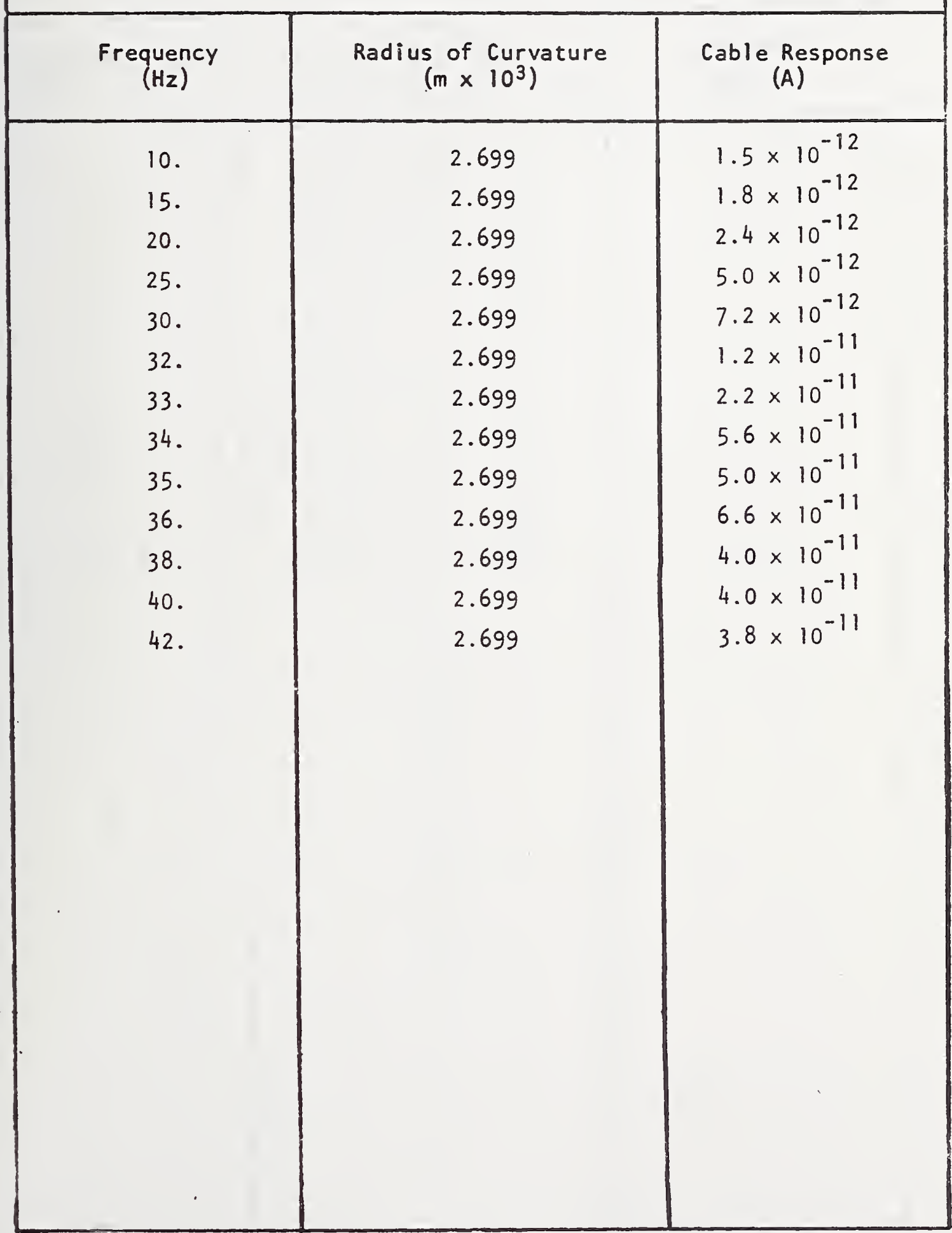


Strain mode: Bending

Cable type: D-250-4214 unpoled

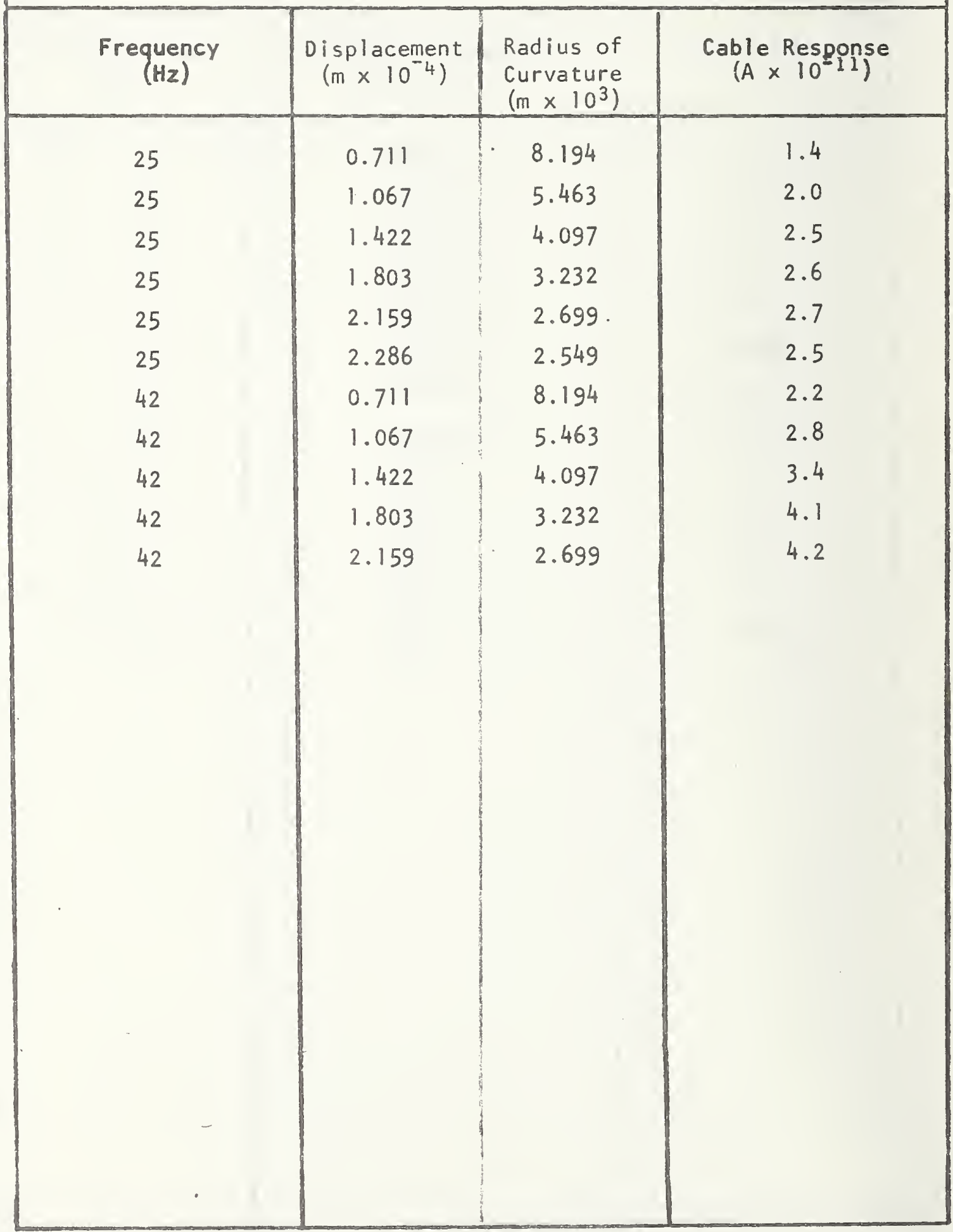




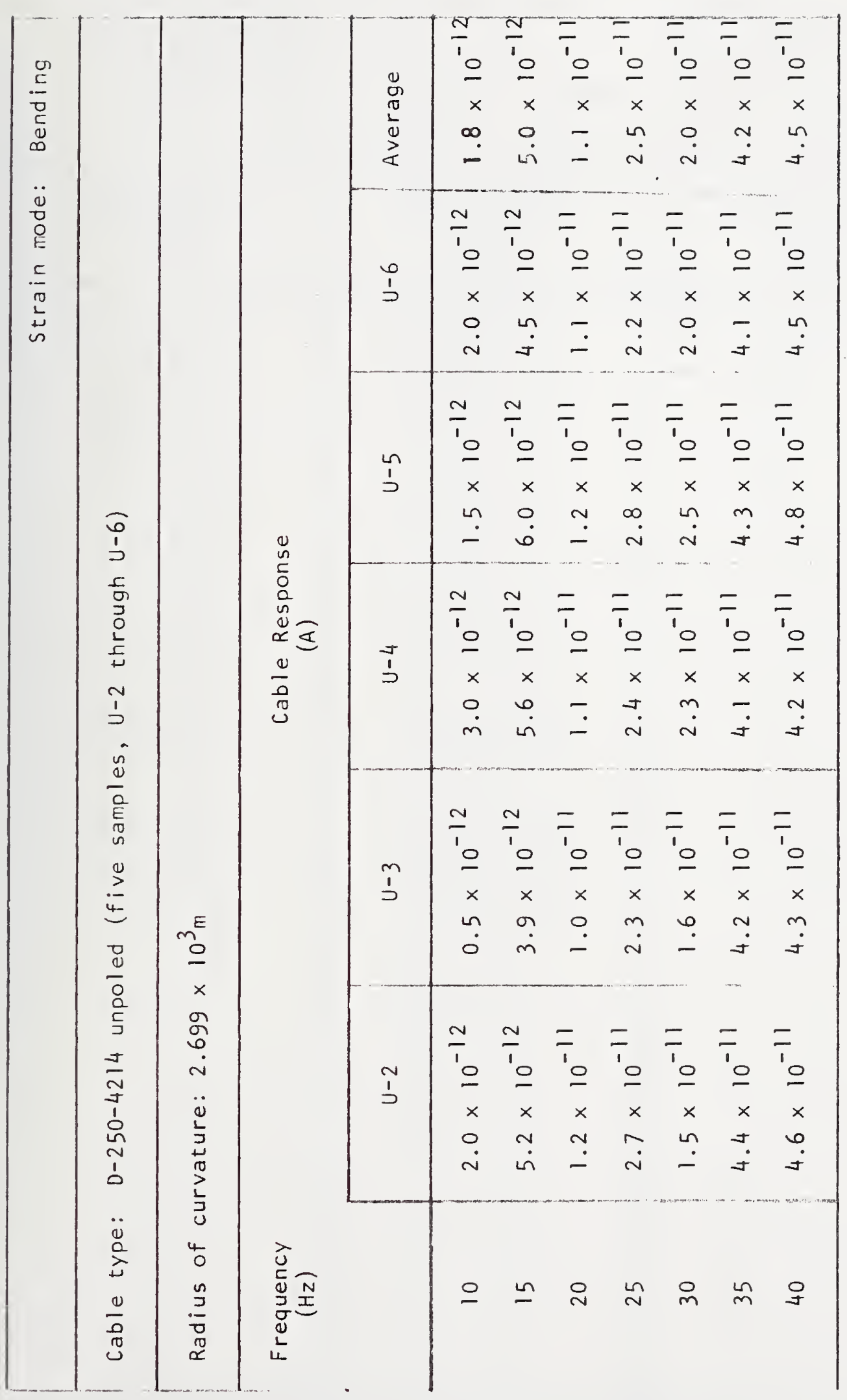




\section{Strain mode: Axial}

Cable type: D-250-4214 poled

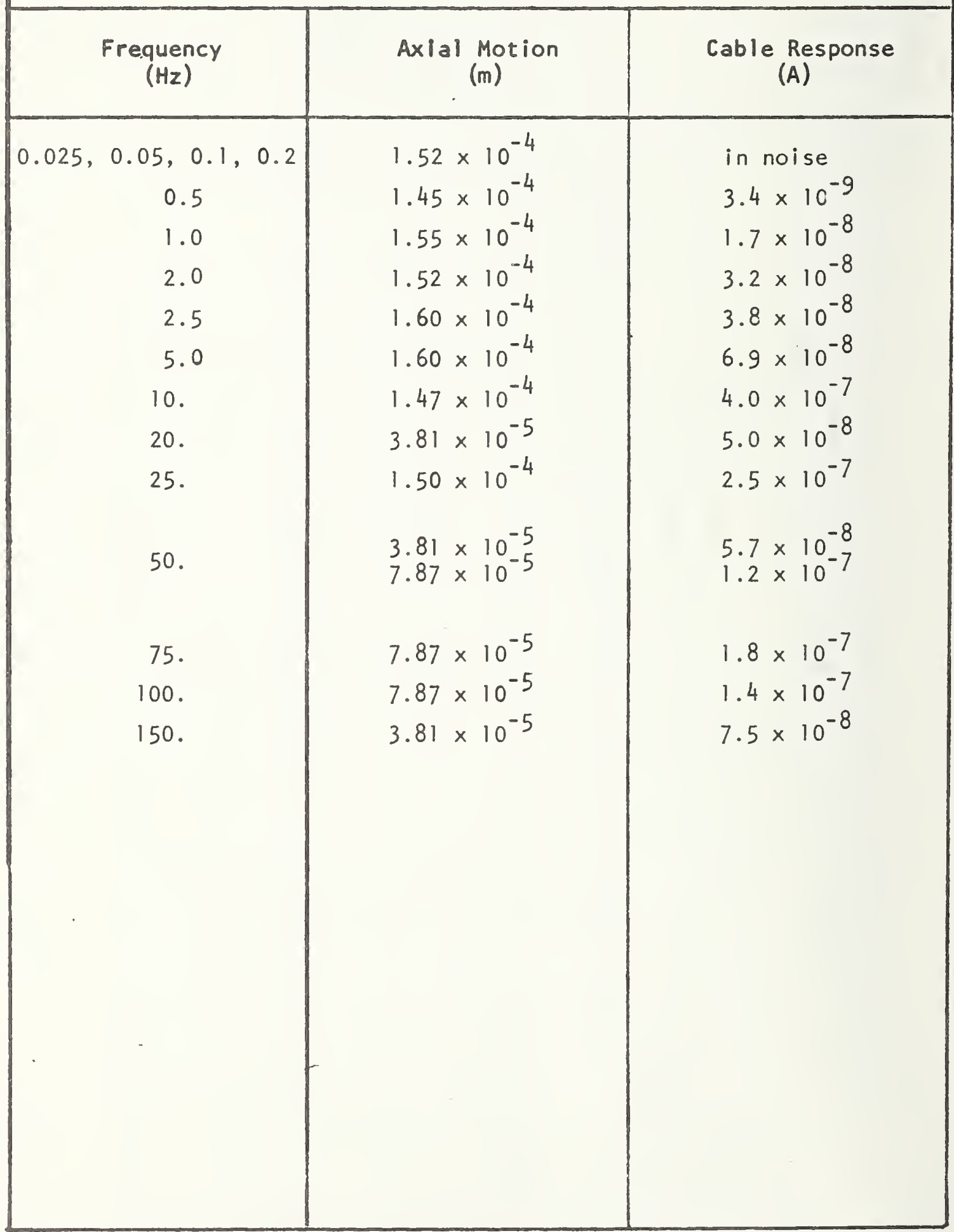


Strain mode: Axial

Cable type: D-250-4214 unpoled

\begin{tabular}{|c|c|c|}
\hline $\begin{array}{l}\text { Frequency } \\
\qquad(\mathrm{Hz})\end{array}$ & $\begin{array}{c}\text { Axial Motion } \\
(\mathrm{m})\end{array}$ & $\begin{array}{l}\text { Cable Response } \\
\text { (A) }\end{array}$ \\
\hline $\begin{array}{c}0.02,0.025,0.03 \\
0.02,0.025,0.03 \\
0.05,0.10 \\
0.05,0.10 \\
0.15 \\
0.15 \\
0.20 \\
0.20 \\
0.25 \\
0.25 \\
0.30 \\
0.30 \\
0.35 \\
0.40 \\
0.40 \\
0.50 \\
0.50 \\
1.0 \\
1.0 \\
2.0 \\
2.0 \\
3.0 \\
3.0 \\
4.0 \\
4.0 \\
5.0 \\
5.0\end{array}$ & $\begin{array}{l}1.52 \times 10^{-4} \\
3.05 \times 10^{-4} \\
1.52 \times 10^{-4} \\
3.05 \times 10^{-4} \\
1.52 \times 10^{-4} \\
3.05 \times 10^{-4} \\
1.52 \times 10^{-4} \\
3.05 \times 10^{-4} \\
1.52 \times 10^{-4} \\
3.05 \times 10^{-4} \\
1.52 \times 10^{-4} \\
3.02 \times 10^{-4} \\
3.02 \times 10^{-4} \\
1.52 \times 10^{-4} \\
3.05 \times 10^{-4} \\
1.52 \times 10^{-4} \\
3.05 \times 10^{-4} \\
1.52 \times 10^{-4} \\
3.05 \times 10^{-4} \\
1.52 \times 10^{-4} \\
3.05 \times 10^{-4} \\
1.52 \times 10^{-4} \\
3.00 \times 10^{-4} \\
1.52 \times 10^{-4} \\
3.02 \times 10^{-4} \\
1.52 \times 10^{-4} \\
2.46 \times 10^{-4}\end{array}$ & $\begin{array}{l}\text { in noise } \\
\text { in noise } \\
\text { in noise } \\
\text { in noise } \\
4.8 \times 10^{-10} \\
1.2 \times 10^{-9} \\
7.2 \times 10^{-10} \\
9.0 \times 10^{-10} \\
8.4 \times 10^{-10} \\
1.0 \times 10^{-9} \\
1.2 \times 10^{-9} \\
2.1 \times 10^{-9} \\
2.6 \times 10^{-9} \\
2.6 \times 10^{-9} \\
2.9 \times 10^{-9} \\
3.4 \times 10^{-9} \\
4.6 \times 10^{-9} \\
2.5 \times 10^{-8} \\
3.4 \times 10^{-8} \\
4.6 \times 10^{-8} \\
6.1 \times 10^{-8} \\
6.0 \times 10^{-8} \\
7.8 \times 10^{-8} \\
1.1 \times 10^{-7} \\
1.2 \times 10^{-7} \\
1.1 \times 10^{-7} \\
1.5 \times 10^{-7}\end{array}$ \\
\hline
\end{tabular}


Cable type: D-250-4214 unpoled

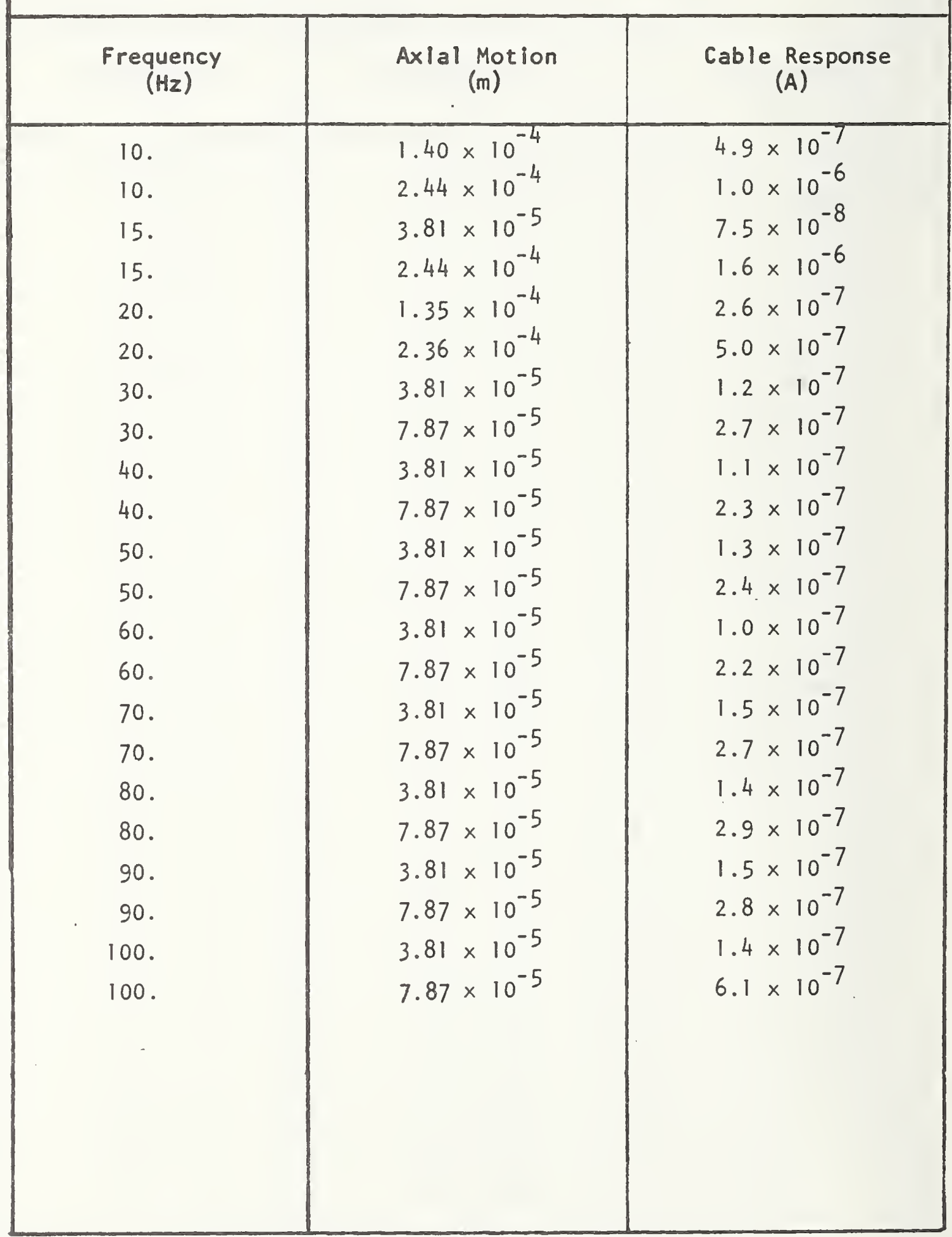


Strain mode: Torsional

Cable type: D-250-4214 poled

\begin{tabular}{|c|c|c|}
\hline $\begin{array}{l}\text { Frequency } \\
\qquad(\mathrm{Hz})\end{array}$ & $\begin{array}{l}\text { Angle } \\
\text { (rad) }\end{array}$ & $\begin{array}{c}\text { Cable Response } \\
\text { (A) }\end{array}$ \\
\hline $\begin{array}{c}0.05,0.5,1.0 \\
2.0 \\
3.0 \\
5.0 \\
15 . \\
22 . \\
36 . \\
42 . \\
43 . \\
50 . \\
85 . \\
100 . \\
110 . \\
155 .\end{array}$ & $\begin{array}{l}8.0 \times 10^{-6} \\
8.0 \times 10^{-6} \\
8.1 \times 10^{-6} \\
8.4 \times 10^{-6} \\
5.6 \times 10^{-6} \\
4.5 \times 10^{-6} \\
2.0 \times 10^{-6} \\
1.4 \times 10^{-6} \\
1.4 \times 10^{-6} \\
1.3 \times 10^{-6} \\
4.0 \times 10^{-7} \\
2.2 \times 10^{-7} \\
1.6 \times 10^{-7} \\
8.0 \times 10^{-8}\end{array}$ & $\begin{array}{l}\text { in noise } \\
\text { in noise } \\
6.0 \times 10^{-11} \\
5.0 \times 10^{-11} \\
2.0 \times 10^{-10} \\
4.2 \times 10^{-10} \\
1.2 \times 10^{-9} \\
1.5 \times 10^{-9} \\
6.0 \times 10^{-9} \\
1.2 \times 10^{-9} \\
3.5 \times 10^{-9} \\
1.8 \times 10^{-9} \\
8.0 \times 10^{-9} \\
6.5 \times 10^{-9}\end{array}$ \\
\hline
\end{tabular}




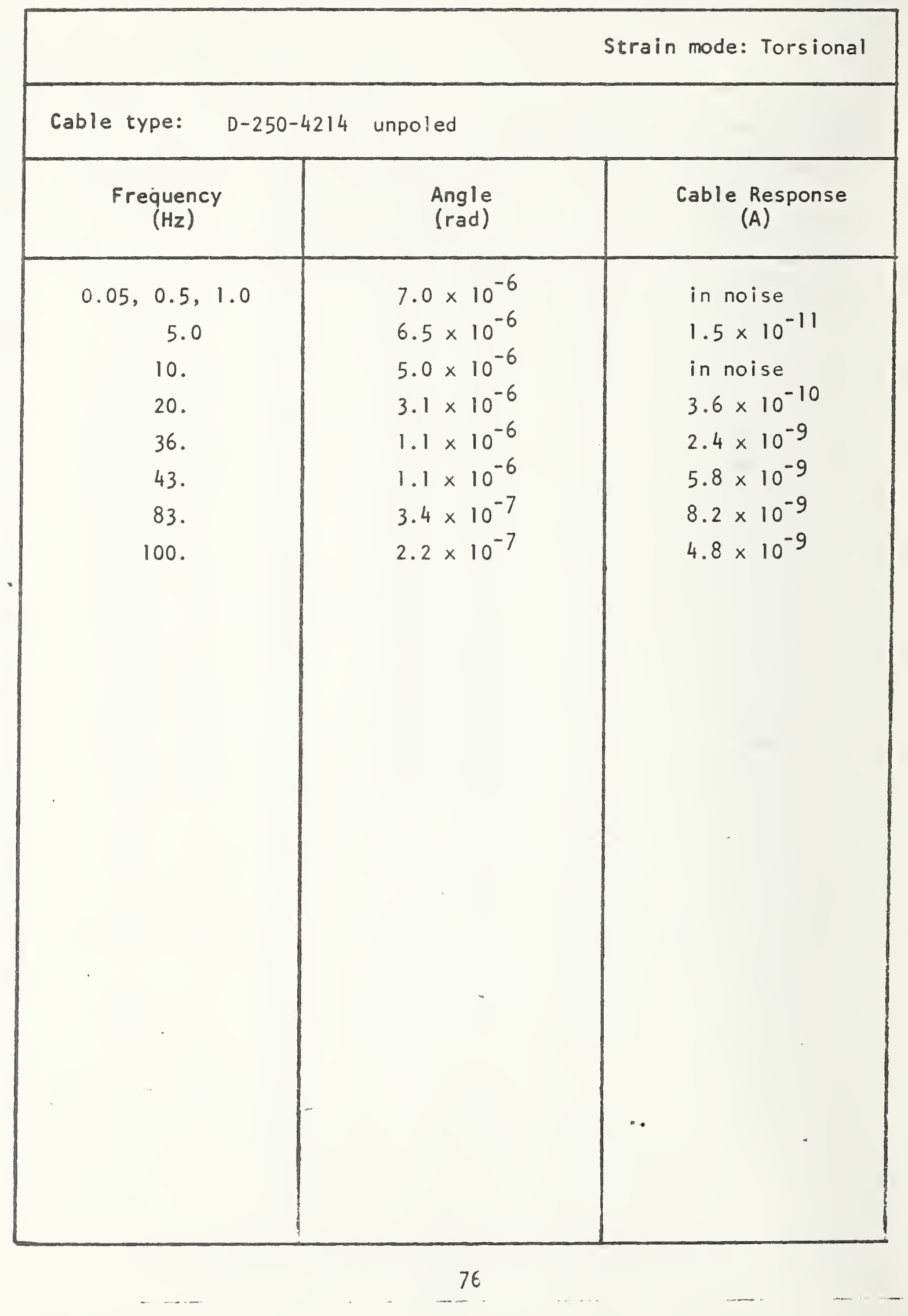


Strain mode: Hydrostatic pressure (bulk compression)

Cable type: D-260-3905 poled

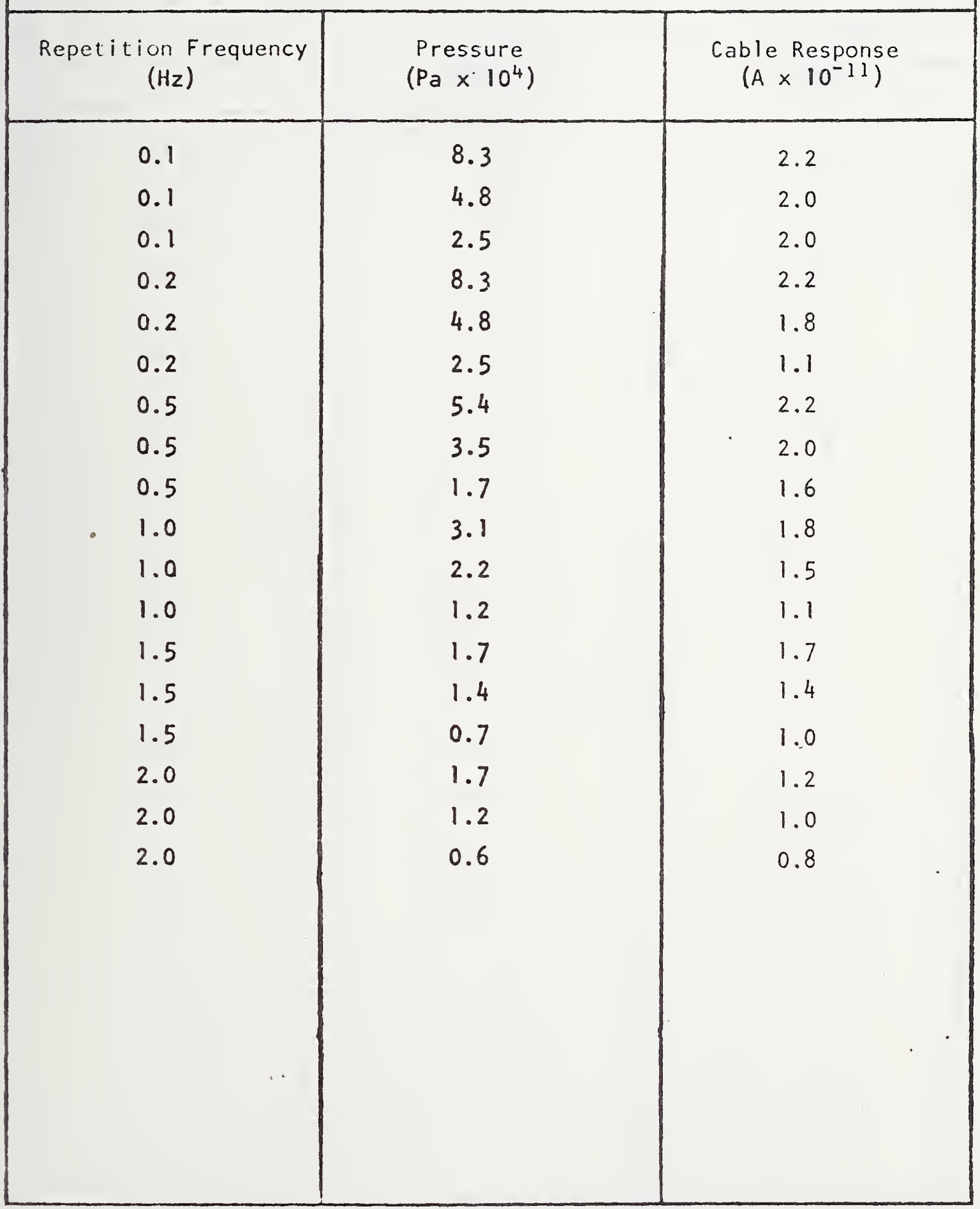


Strain mode: Hydrostatic pressure (bulk compression)

Cable type: D-260-3905 poled

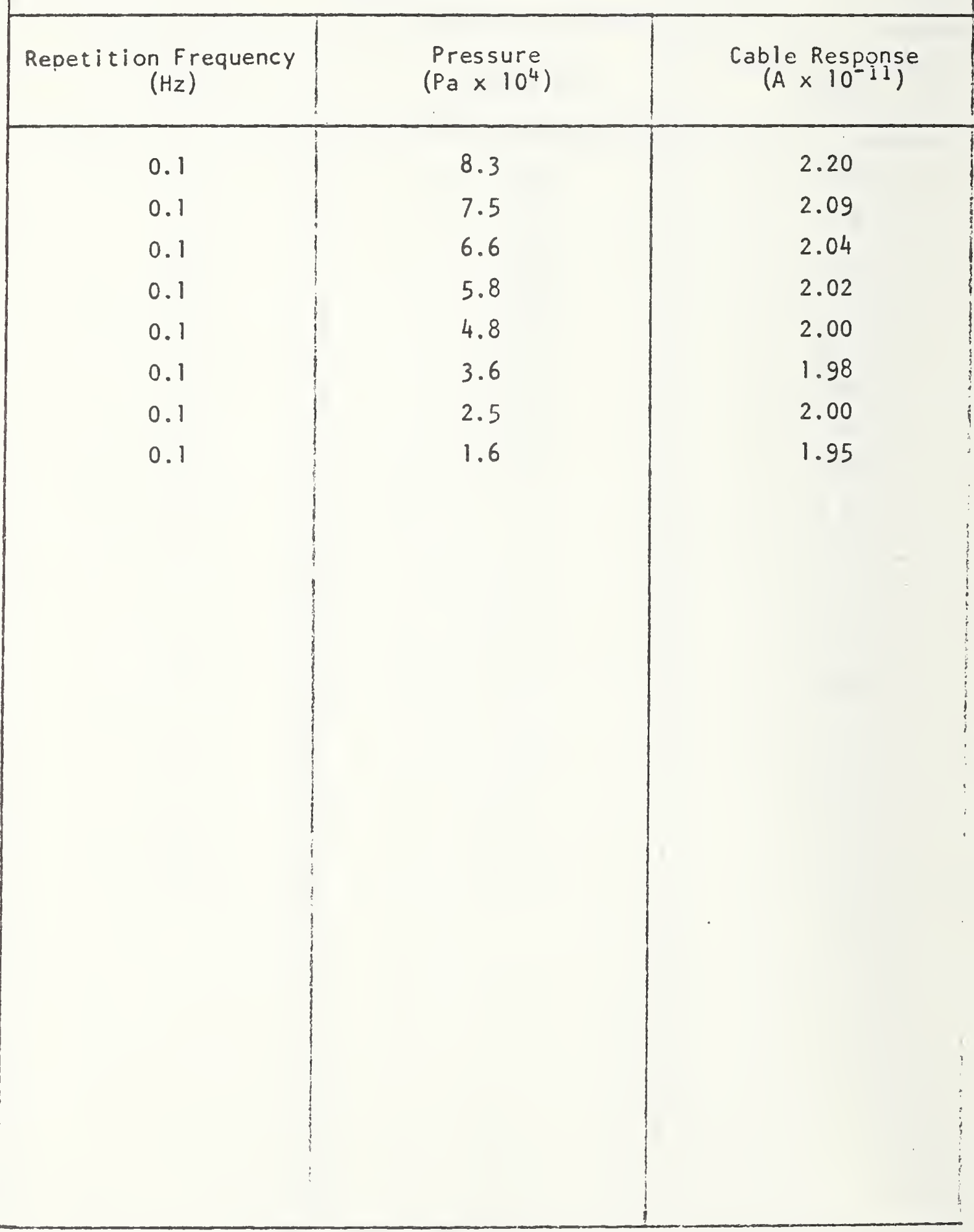


Strain mode: Hydrostatic pressure (bulk compression)

Cable type: 0-260-3905 unpoled

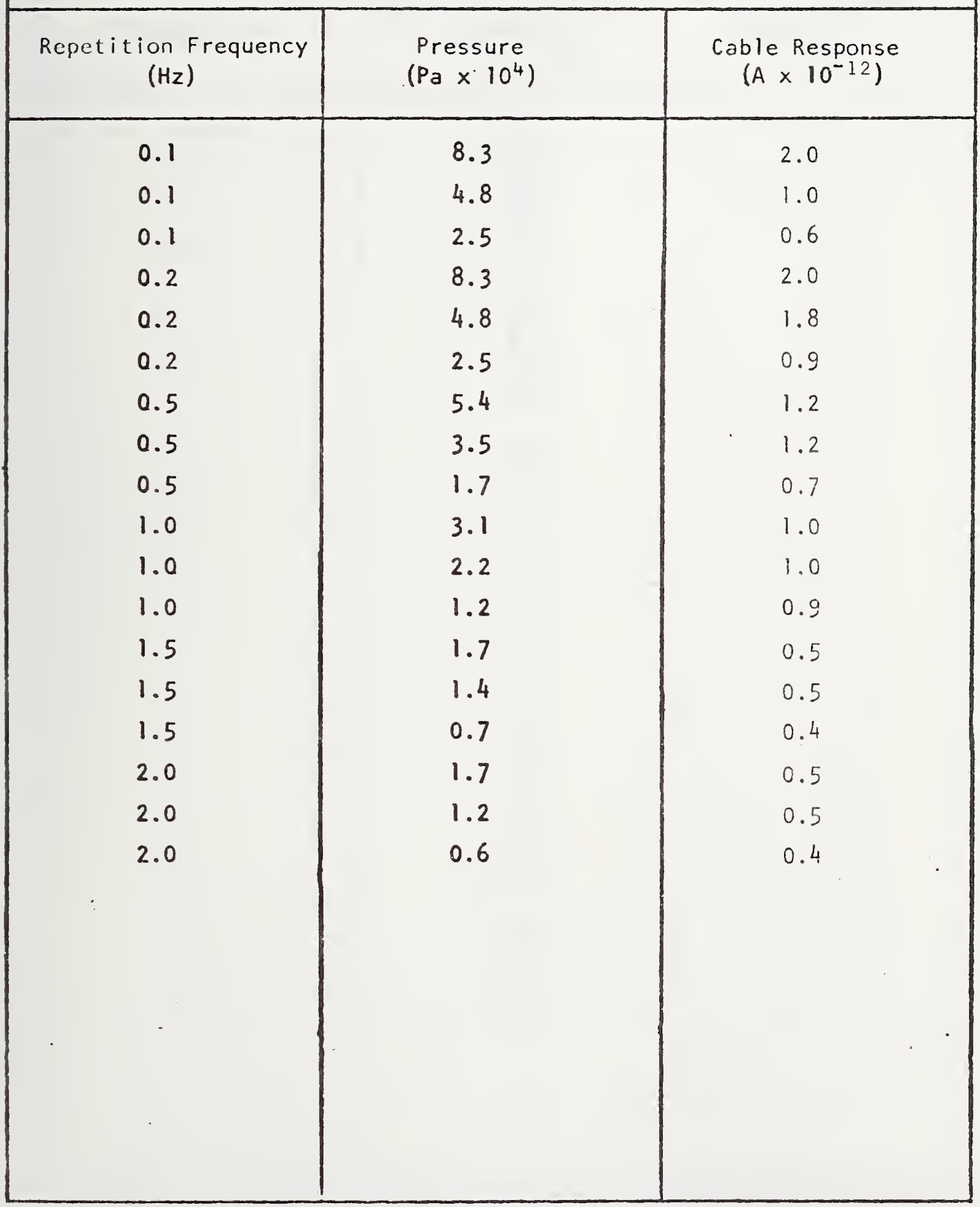




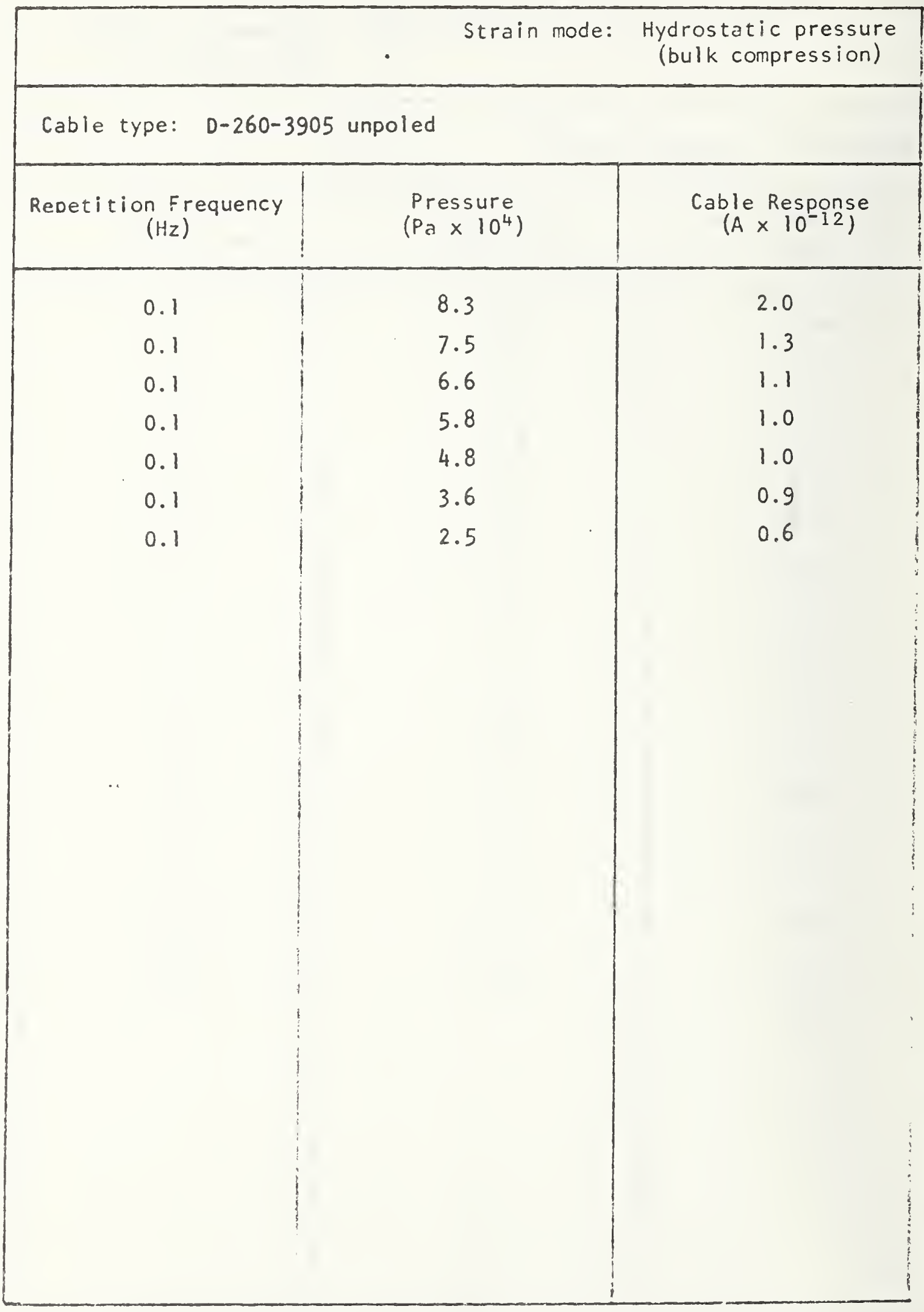


Cable type: D-260-3905 poled

\begin{tabular}{|c|c|c|}
\hline $\begin{array}{c}\text { Frequency } \\
(\mathrm{Hz})\end{array}$ & $\begin{array}{c}\text { Radius of Curvature } \\
\left(m \times 10^{3}\right)\end{array}$ & $\begin{array}{c}\text { Cable Response } \\
\text { (A) }\end{array}$ \\
\hline $\begin{array}{l}1.0,2.0,5.0,10 . \\
20 . \\
22 . \\
24 . \\
26 . \\
28 . \\
30 . \\
32 . \\
34 . \\
36 . \\
38 . \\
40 . \\
42 . \\
44 . \\
46 . \\
48 . \\
50 . \\
52 . \\
54 . \\
56 . \\
58 . \\
60 . \\
62 .\end{array}$ & $\begin{array}{l}2.699 \\
2.699 \\
2.699 \\
2.699 \\
2.699 \\
2.699 \\
2.699 \\
2.699 \\
2.699 \\
2.699 \\
2.699 \\
2.699 \\
2.699 \\
2.699 \\
2.699 \\
2.699 \\
2.699 \\
2.699 \\
2.699 \\
2.699 \\
2.699 \\
2.699 \\
2.699\end{array}$ & $\begin{array}{l}\text { in noise } \\
1.0 \times 10^{-12} \\
2.0 \times 10^{-12} \\
1.0 \times 10^{-12} \\
2.5 \times 10^{-12} \\
3.0 \times 10^{-12} \\
5.0 \times 10^{-12} \\
6.0 \times 10^{-12} \\
5.0 \times 10^{-11} \\
8.0 \times 10^{-11} \\
8.0 \times 10^{-11} \\
7.0 \times 10^{-11} \\
4.5 \times 10^{-11} \\
5.0 \times 10^{-11} \\
5.0 \times 10^{-11} \\
5.0 \times 10^{-11} \\
3.0 \times 10^{-11} \\
2.8 \times 10^{-11} \\
2.6 \times 10^{-11} \\
2.4 \times 10^{-11} \\
2.4 \times 10^{-11} \\
6.4 \times 10^{-11} \\
7.5 \times 10^{-11}\end{array}$ \\
\hline
\end{tabular}




\section{Strain mode: Bending}

Cable type: D-260-3905 unpoled

\begin{tabular}{|c|c|c|}
\hline $\begin{array}{c}\text { Frequency } \\
(\mathrm{Hz})\end{array}$ & $\begin{array}{l}\text { Radius of Curvature } \\
\qquad\left(\mathrm{m} \times 10^{3}\right)\end{array}$ & $\begin{array}{l}\text { Cable Response } \\
\text { (A) }\end{array}$ \\
\hline $\begin{array}{c}0.05,0.1,0.2,0.4 \\
0.5,1.0,5.0,10 \\
20 . \\
25 . \\
30 . \\
35 . \\
40 . \\
50 . \\
60 . \\
70 . \\
80 . \\
90 . \\
100 .\end{array}$ & $\begin{array}{l}2.699 \\
2.699 \\
2.699 \\
2.699 \\
2.699 \\
2.699 \\
2.699 \\
2.699 \\
2.699 \\
4.172 \\
2.699 \\
2.699 \\
2.699\end{array}$ & $\begin{array}{l}\text { in noise } \\
\text { in noise } \\
2.0 \times 10^{-13} \\
3.0 \times 10^{-13} \\
1.2 \times 10^{-12} \\
7.0 \times 10^{-13} \\
5.0 \times 10^{-13} \\
5.0 \times 10^{-13} \\
2.2 \times 10^{-12} \\
3.3 \times 10^{-12} \\
3.1 \times 10^{-12} \\
2.6 \times 10^{-12} \\
5.0 \times 10^{-13}\end{array}$ \\
\hline
\end{tabular}


Strain mode: Axial

Cable type: D-260-3905 poled

\begin{tabular}{|c|c|c|}
\hline $\begin{array}{l}\text { Frequency } \\
\qquad(\mathrm{Hz})\end{array}$ & $\begin{array}{c}\text { Axlal Motion } \\
\left(m \times 10^{-4}\right)\end{array}$ & $\begin{array}{c}\text { Cable Response } \\
(A)\end{array}$ \\
\hline $\begin{array}{cc}0.02,0.025,0.03 \\
0.035,0.04,0.045 \\
0.05,0.10,0.15,0.20 \\
0.25 \\
0.25 \\
0.30 \\
0.30 \\
0.35 \\
0.35 \\
0.40 \\
0.40 \\
0.45 \\
0.45 \\
0.50 \\
0.50 \\
1.0 \\
1.0 \\
2.0 \\
2.0 \\
3.0 \\
3.0 \\
4.0 \\
4.0 \\
5.0 \\
5.0 \\
10 . \\
10 .\end{array}$ & $\begin{array}{l}1.52 \\
1.52 \\
1.52 \\
1.52 \\
3.05 \\
1.52 \\
3.05 \\
1.52 \\
3.05 \\
1.52 \\
3.07 \\
1.52 \\
3.05 \\
1.52 \\
3.05 \\
1.52 \\
3.05 \\
1.50 \\
3.05 \\
1.50 \\
3.05 \\
1.50 \\
3.07 \\
1.50 \\
3.07 \\
1.50 \\
3.07\end{array}$ & $\begin{array}{l}\text { in noise } \\
\text { in noise } \\
\text { in noise } \\
\text { in noise } \\
5.2 \times 10^{-10} \\
\text { in noise } \\
6.0 \times 10^{-10} \\
\text { in noise } \\
9.6 \times 10^{-10} \\
\text { in noise } \\
9.6 \times 10^{-10} \\
9.6 \times 10^{-10} \\
1.3 \times 10^{-9} \\
1.2 \times 10^{-9} \\
1.4 \times 10^{-9} \\
4.1 \times 10^{-9} \\
7.9 \times 10^{-9} \\
7.4 \times 10^{-9} \\
1.4 \times 10^{-8} \\
7.0 \times 10^{-9} \\
1.8 \times 10^{-8} \\
1.5 \times 10^{-8} \\
2.5 \times 10^{-8} \\
1.7 \times 10^{-8} \\
3.2 \times 10^{-8} \\
3.2 \times 10^{-8} \\
1.1 \times 10^{-7}\end{array}$ \\
\hline
\end{tabular}


Strain mode: Axial

Cable type: D-260-3905 poled

\begin{tabular}{|c|c|c|}
\hline $\begin{array}{l}\text { Frequency } \\
\qquad(\mathrm{Hz})\end{array}$ & $\begin{array}{c}\text { Axial Motion } \\
\left(\mathrm{m} \times 10^{-4}\right)\end{array}$ & $\begin{array}{c}\text { Cable Response } \\
\text { (A) }\end{array}$ \\
\hline $\begin{array}{l}15 . \\
15 . \\
20 . \\
20 . \\
30 . \\
30 . \\
40 . \\
40 . \\
50 . \\
50 . \\
60 . \\
60 . \\
70 . \\
70 . \\
80 . \\
80 . \\
90 . \\
90 . \\
100 . \\
100 .\end{array}$ & $\begin{array}{l}1.50 \\
3.05 \\
1.52 \\
2.97 \\
0.38 \\
0.79 \\
0.38 \\
0.79 \\
0.38 \\
0.79 \\
0.38 \\
0.79 \\
0.38 \\
0.79 \\
0.38 \\
0.79 \\
0.38 \\
0.79 \\
0.38 \\
0.79\end{array}$ & $\begin{array}{l}6.4 \times 10^{-8} \\
1.5 \times 10^{-7} \\
2.8 \times 10^{-8} \\
4.6 \times 10^{-8} \\
1.0 \times 10^{-8} \\
1.7 \times 10^{-8} \\
7.6 \times 10^{-9} \\
1.7 \times 10^{-8} \\
9.0 \times 10^{-9} \\
1.5 \times 10^{-8} \\
7.6 \times 10^{-9} \\
1.7 \times 10^{-8} \\
1.0 \times 10^{-8} \\
1.8 \times 10^{-8} \\
1.0 \times 10^{-8} \\
2.1 \times 10^{-8} \\
1.0 \times 10^{-8} \\
1.9 \times 10^{-8} \\
7.6 \times 10^{-9} \\
1.9 \times 10^{-8}\end{array}$ \\
\hline \multicolumn{3}{|c|}{ D-260-3905 unpoled } \\
\hline $\begin{array}{l}\text { Frequency } \\
\qquad(\mathrm{Hz})\end{array}$ & Axial Motion & $\begin{array}{c}\text { Cable Response } \\
\text { (A) }\end{array}$ \\
\hline $0.1-60$ & $2.03 \times 10^{-4}$ & $\begin{array}{l}\text { This cable type produced } \\
\text { no measurable response } \\
\text { above noise to axial } \\
\text { strain. }\end{array}$ \\
\hline
\end{tabular}


Strain mode: Torsional

Cable type: $260-3905$ poled

\begin{tabular}{|c|c|c|}
\hline $\begin{array}{l}\text { Frequency } \\
\qquad(\mathrm{Hz})\end{array}$ & $\begin{array}{l}\text { Angle } \\
\text { (rad) }\end{array}$ & $\begin{array}{c}\text { Cable Response } \\
\text { (A) }\end{array}$ \\
\hline $\begin{array}{c}0.05,0.5,1.0 \\
5.0 \\
10 . \\
20 . \\
30 . \\
40 . \\
50 . \\
60 . \\
70 . \\
80 . \\
90 . \\
100 .\end{array}$ & $\begin{array}{l}7.0 \times 10^{-6} \\
7.0 \times 10^{-6} \\
7.0 \times 10^{-6} \\
4.8 \times 10^{-6} \\
2.8 \times 10^{-6} \\
1.7 \times 10^{-6} \\
1.3 \times 10^{-6} \\
7.6 \times 10^{-7} \\
5.6 \times 10^{-7} \\
5.2 \times 10^{-7} \\
3.0 \times 10^{-7} \\
2.6 \times 10^{-7}\end{array}$ & $\begin{array}{l}\text { in noise } \\
\text { in noise } \\
\text { in noise } \\
1.2 \times 10^{-10} \\
1.6 \times 10^{-10} \\
6.8 \times 10^{-10} \\
7.0 \times 10^{-10} \\
7.5 \times 10^{-10} \\
5.5 \times 10^{-10} \\
5.0 \times 10^{-10} \\
1.0 \times 10^{-10} \\
1.0 \times 10^{-9}\end{array}$ \\
\hline
\end{tabular}


Strain mode: Torsional

Cable type: D-260-3905 unpoled

\begin{tabular}{|c|c|c|}
\hline $\begin{array}{l}\text { Frequency } \\
\qquad(\mathrm{Hz})\end{array}$ & $\begin{array}{l}\text { Angle } \\
\text { (rad) }\end{array}$ & $\begin{array}{c}\text { Cable Response } \\
\text { (A) }\end{array}$ \\
\hline $\begin{array}{c}0.05,0.5,2.0 \\
3.0,4.0,5.0 \\
10 . \\
20 . \\
42 . \\
50 . \\
72 . \\
100 .\end{array}$ & $\begin{array}{l}8.0 \times 10^{-6} \\
8.0 \times 10^{-6} \\
7.8 \times 10^{-6} \\
4.4 \times 10^{-6} \\
1.1 \times 10^{-6} \\
9.6 \times 10^{-7} \\
3.4 \times 10^{-7} \\
2.2 \times 10^{-7}\end{array}$ & $\begin{array}{l}\text { in noise } \\
\text { in noise } \\
4.0 \times 10^{-11} \\
5.0 \times 10^{-12} \\
9.5 \times 10^{-11} \\
3.0 \times 10^{-11} \\
3.2 \times 10^{-10} \\
8.0 \times 10^{-11}\end{array}$ \\
\hline
\end{tabular}


Strain mode: Hydrostatic pressure

(bulk compression)

Cable type: D-270-3953 poled

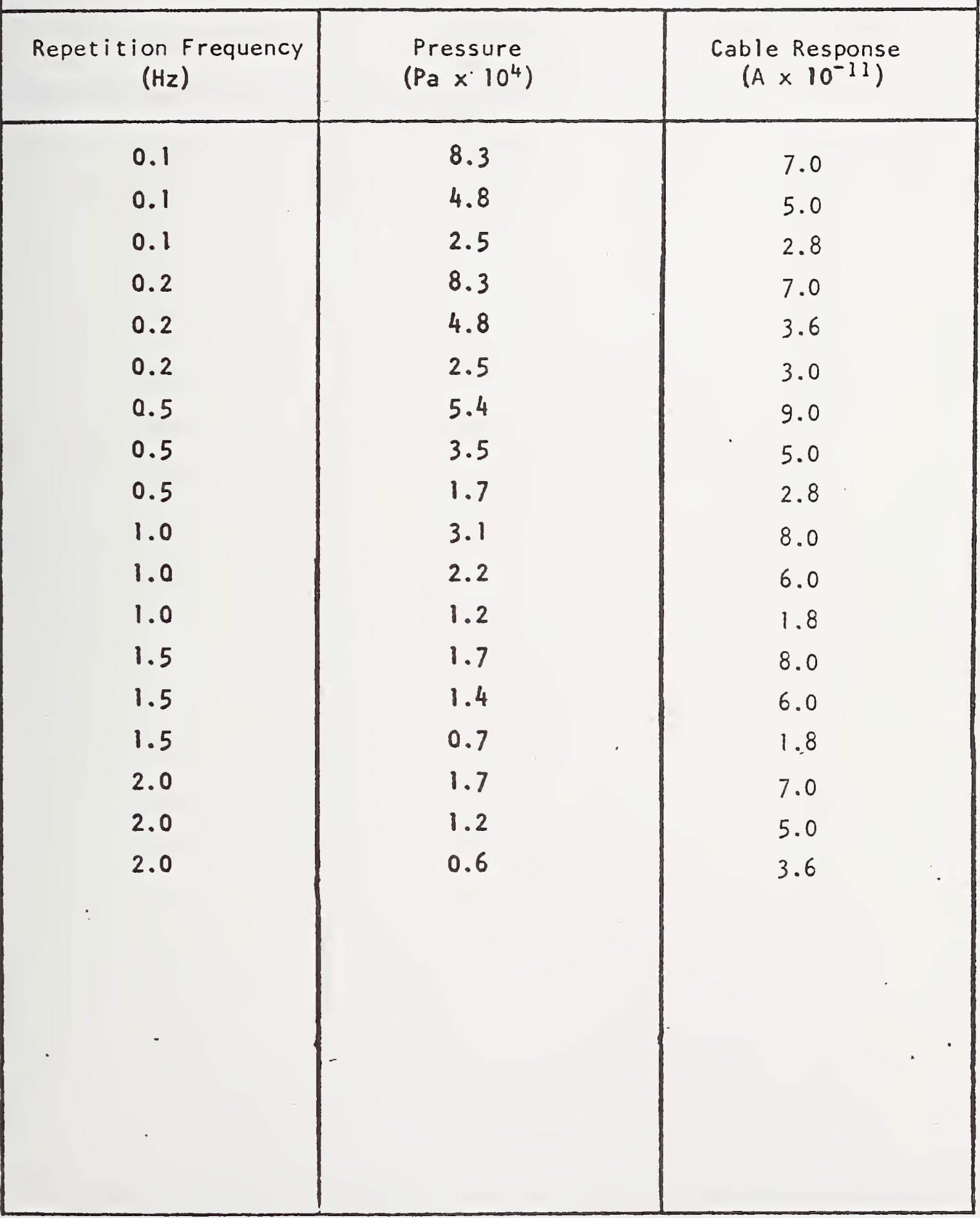


Strain mode: Hydrostatic pressure (bulk compression)

Cable type: D-270-3953-P-1 poled (before water soak)

\section{Redetition Frequency}

$(\mathrm{Hz})$

0.1

0.1

0.1

0.5

0.5

0.5

2.0

2.0

2.0
Pressure

$\left(P a \times 10^{4}\right)$

8.3

4.8

2.5

5.4

3.5

1.7

1.7

1.2

0.6
Cable Response

$\left(A \times 10^{-11}\right)$

6.9

5.0

2.7

8.8

5.0

2.8

6.4

5.2

3.5 
Strain mode: Hydrostatic pressure

(bulk compression)

Cable type: D-270-3953-P-1 poled (after water soak of 24 hours)

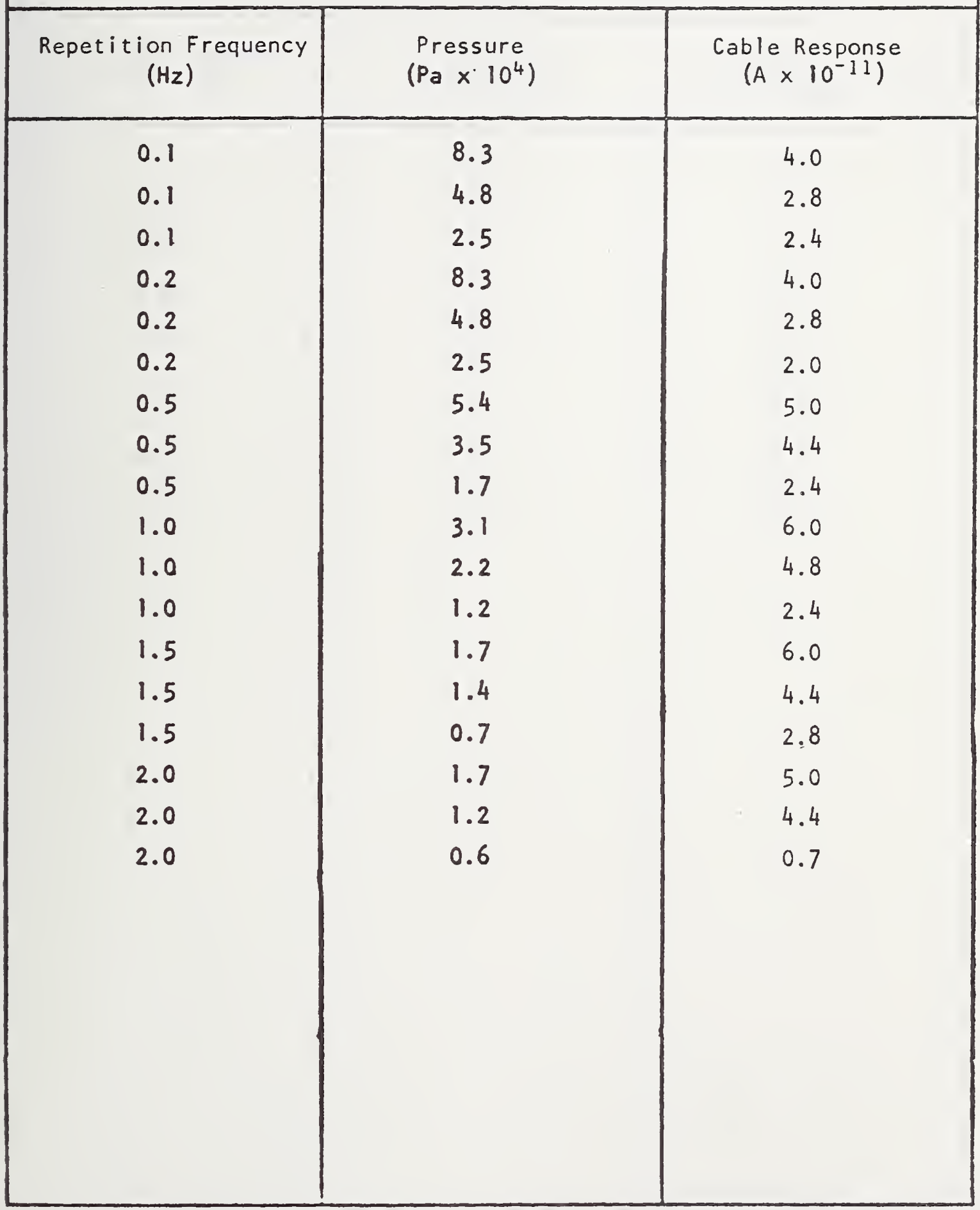




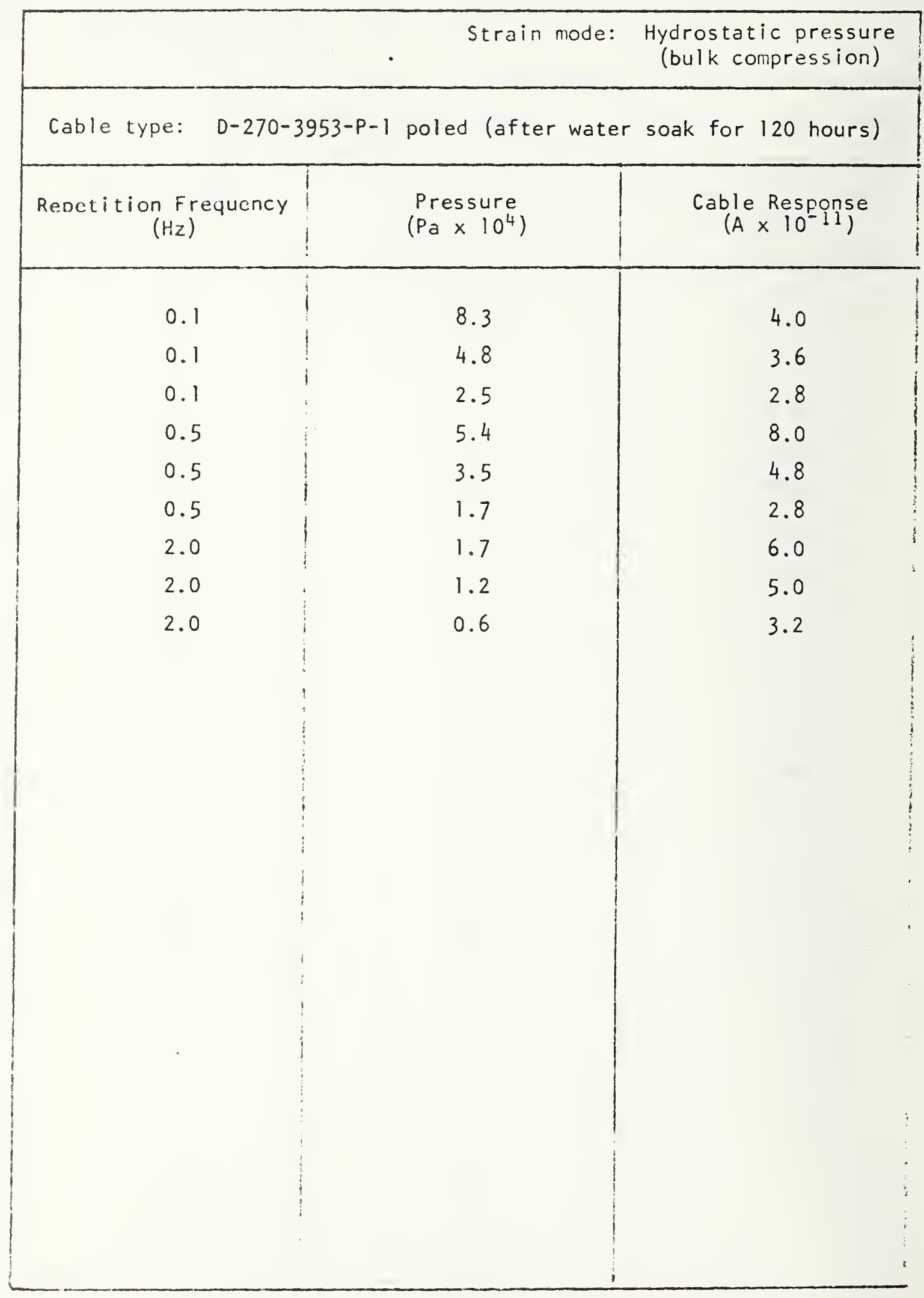


Strain mode: Hydrostatic pressure (bulk compression)

Cable type: D-270-3953 unpoled

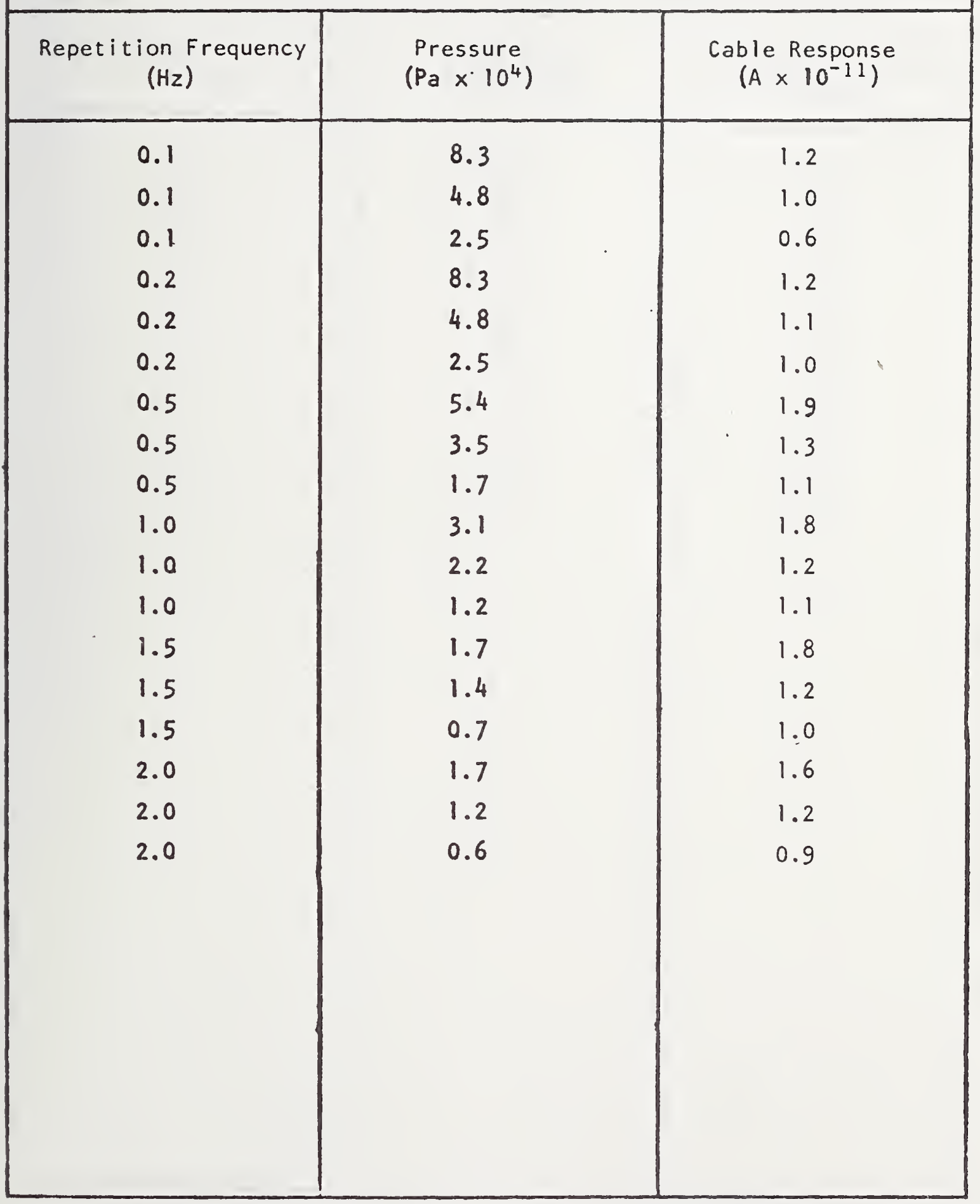




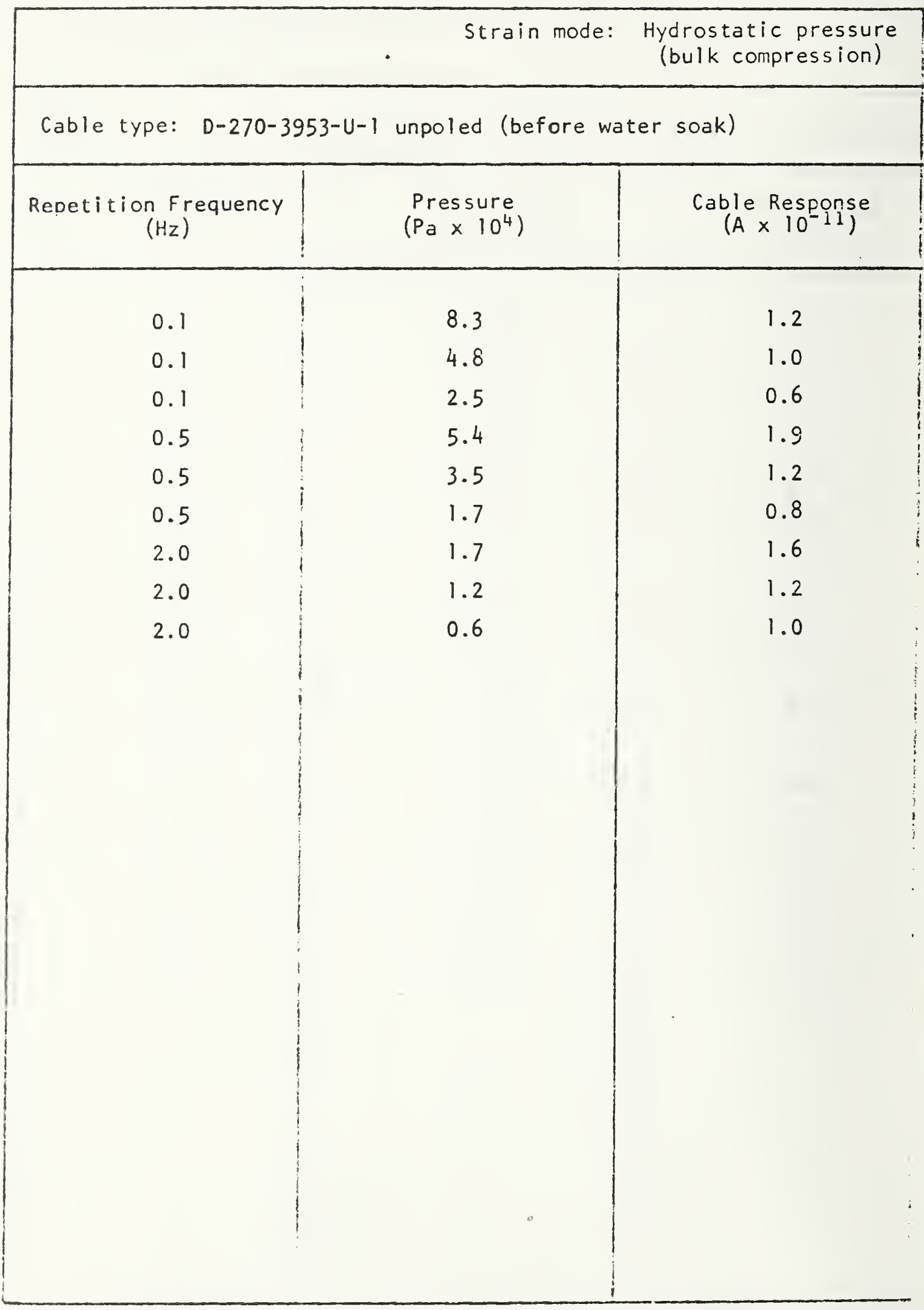


Strain mode: Hydrostatic pressure (bulk compression)

Cable type: D-270-3953-U-1 unpoled (after water soak of 24 hours)

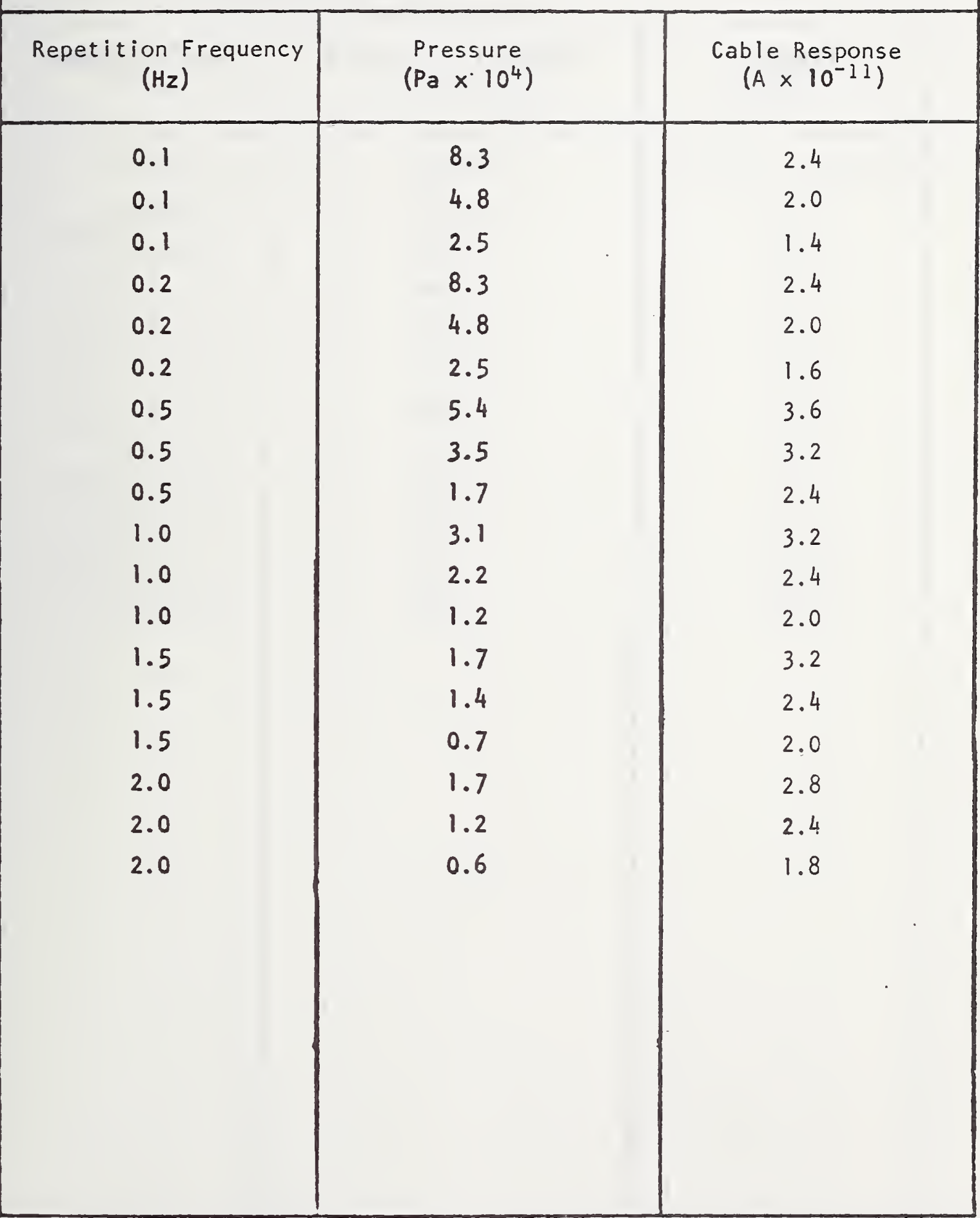


Strain mode: Bending

Cable type: D-270-3953 unpoled

\begin{tabular}{|c|c|c|}
\hline $\begin{array}{l}\text { Frequency } \\
\qquad(\mathrm{Hz})\end{array}$ & $\begin{array}{l}\text { Radius of Curvature } \\
\left(\mathrm{m} \times 10^{3}\right)\end{array}$ & $\begin{array}{c}\text { Cable Response } \\
\text { (A) }\end{array}$ \\
\hline $\begin{array}{c}0.02,0.2,0.4,1.0 \\
5.0 \\
10 . \\
15 . \\
20 . \\
25 . \\
30 . \\
38 . \\
40 . \\
42 . \\
45 . \\
50 .\end{array}$ & $\begin{array}{l}2.868 \\
2.868 \\
2.699 \\
2.699 \\
2.699 \\
2.699 \\
2.699 \\
2.699 \\
2.699 \\
2.699 \\
2.699 \\
2.699\end{array}$ & $\begin{array}{l}\text { in noise } \\
\text { in noise } \\
2.0 \times 10^{-12} \\
5.2 \times 10^{-12} \\
2.0 \times 10^{-12} \\
8.0 \times 10^{-12} \\
1.7 \times 10^{-11} \\
1.1 \times 10^{-11} \\
8.0 \times 10^{-13} \\
5.4 \times 10^{-11} \\
5.2 \times 10^{-11} \\
5.0 \times 10^{-11}\end{array}$ \\
\hline
\end{tabular}


Strain mode: Hydrostatic pressure (bulk compression)

Cable type: D-275-3933 poled

Repetition Frequency

$(\mathrm{Hz})$
Pressure

$\left(\mathrm{Pa} \times 10^{4}\right)$
Cable Response

$\left(A \times 10^{-11}\right)$

\begin{tabular}{l|l|l}
\hline 0.1 & 8.3 & 4.0 \\
0.1 & 4.8 & 3.0 \\
0.1 & 2.5 & 2.0 \\
0.2 & 8.3 & 4.0 \\
0.2 & 4.8 & 3.0 \\
0.2 & 2.5 & 2.0 \\
0.5 & 5.4 & 4.8 \\
0.5 & 3.5 & 4.0 \\
0.5 & 1.7 & 2.0 \\
1.0 & 3.1 & 5.0 \\
1.0 & 2.2 & 3.0 \\
1.0 & 1.2 & 2.5 \\
1.5 & 1.7 & 5.0 \\
1.5 & 1.4 & 5.0 \\
1.5 & 0.7 & 2.0 \\
2.0 & 1.7 & 2.0 \\
2.0 & 1.2 & 2.0 \\
2.0 & 0.6 & 2.0 \\
& &
\end{tabular}

4.0

3.0

.0

4.0

3.0

.0

.8

.0

2.0

5.0

3.0

2.5

5.0

5.0

2.0

2.0

2.0

2.0 


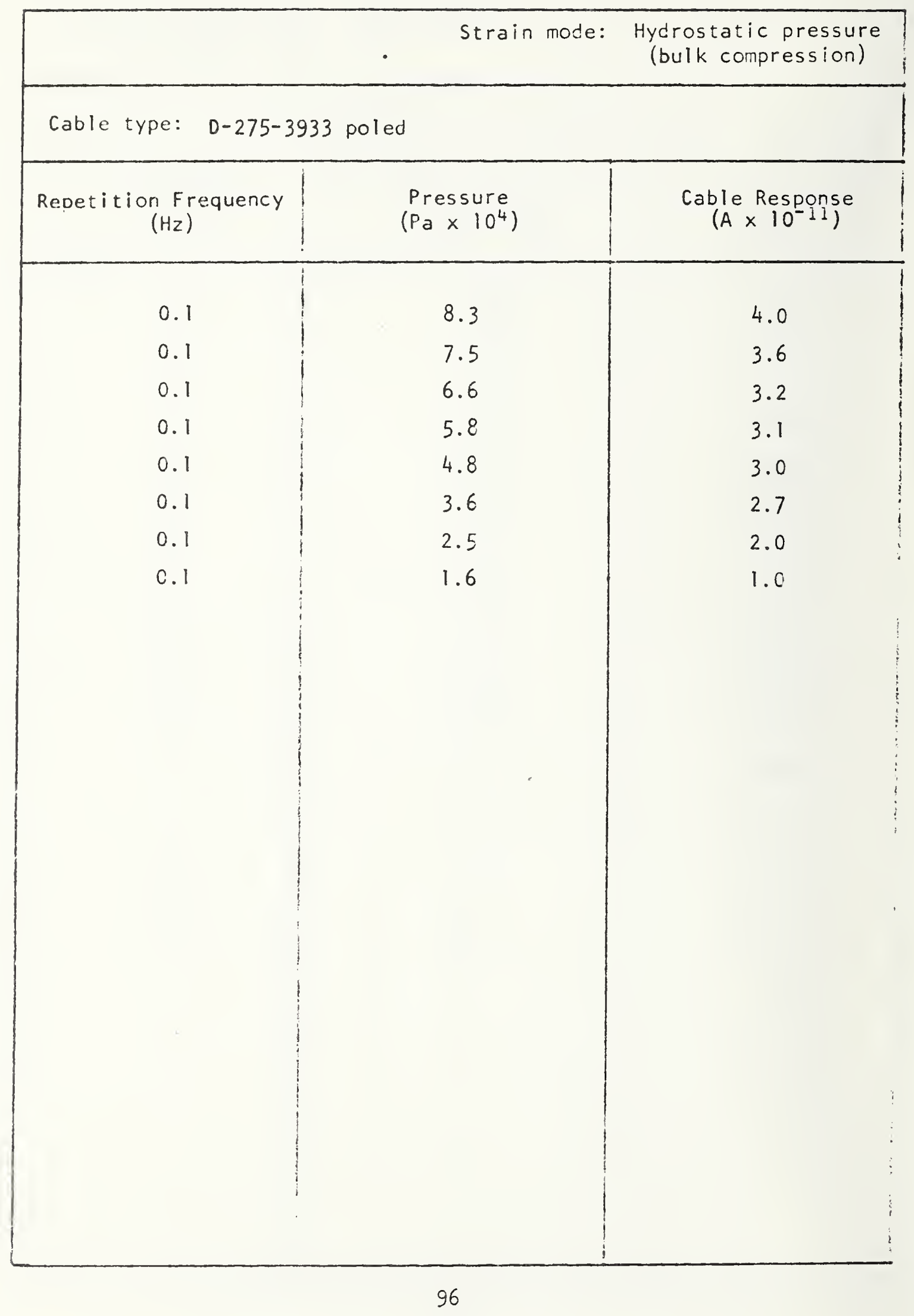


Strain mode: Hydrostatic pressure (bulk compression)

Cable type: D-275-3933 unpoled

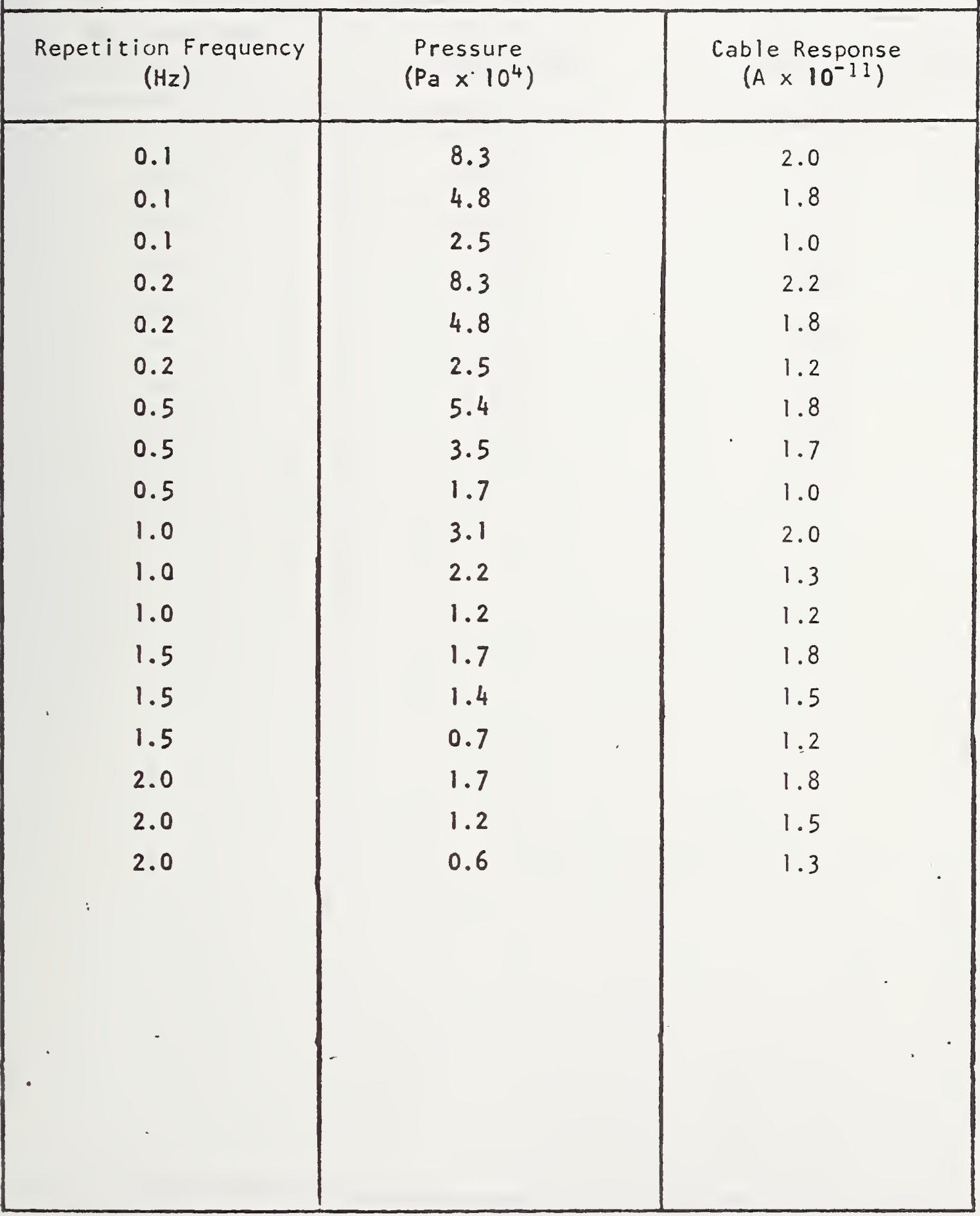




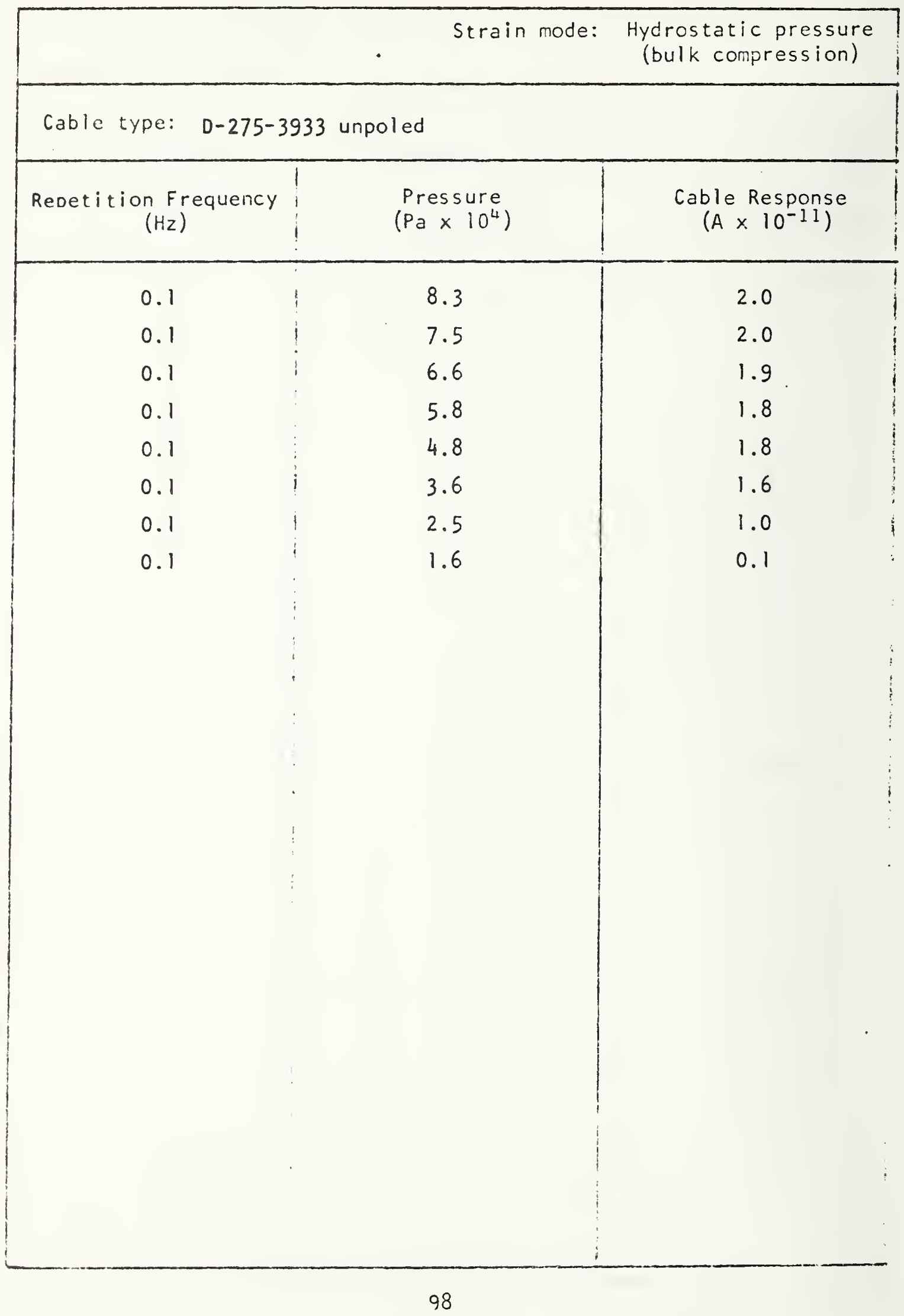




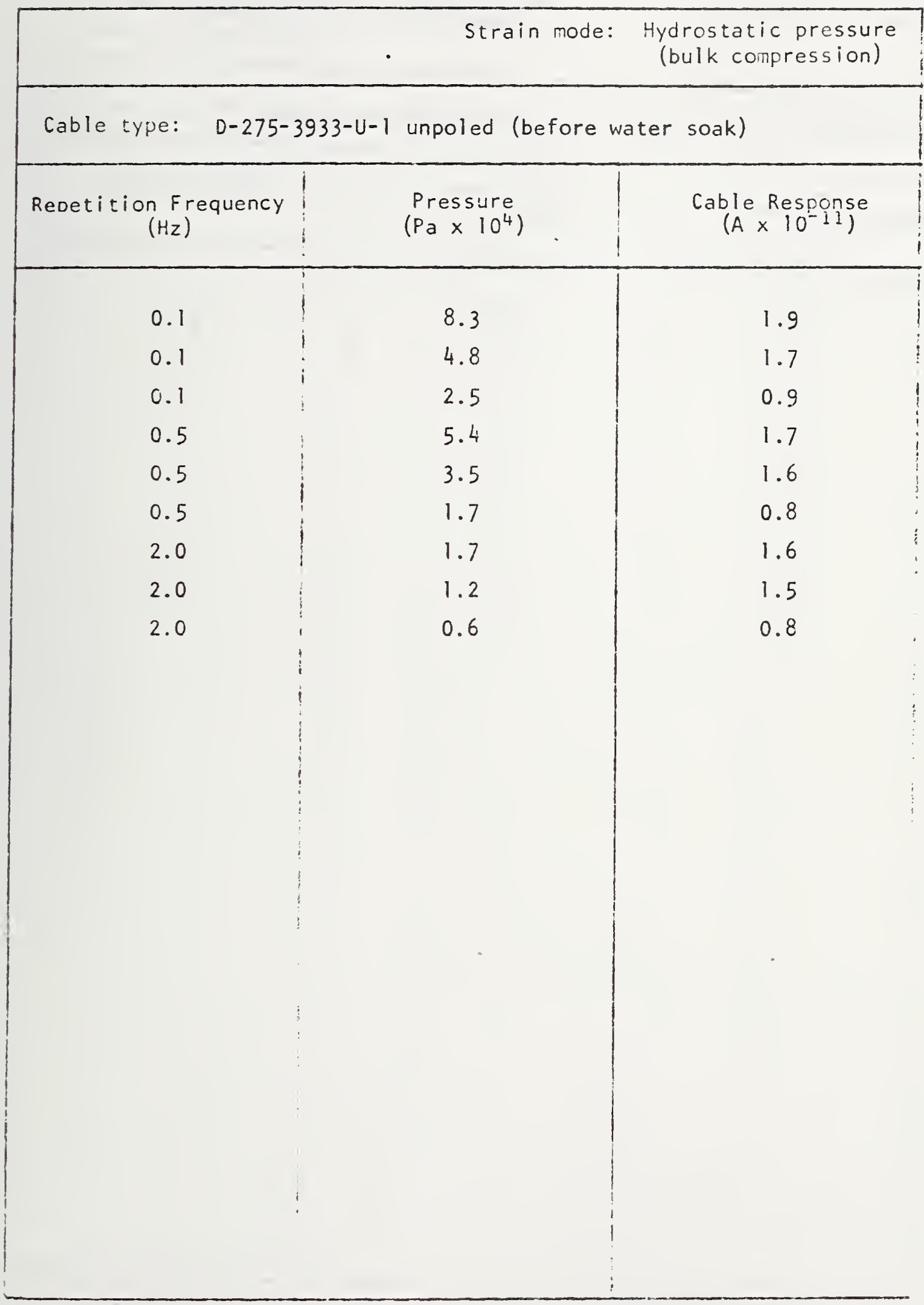




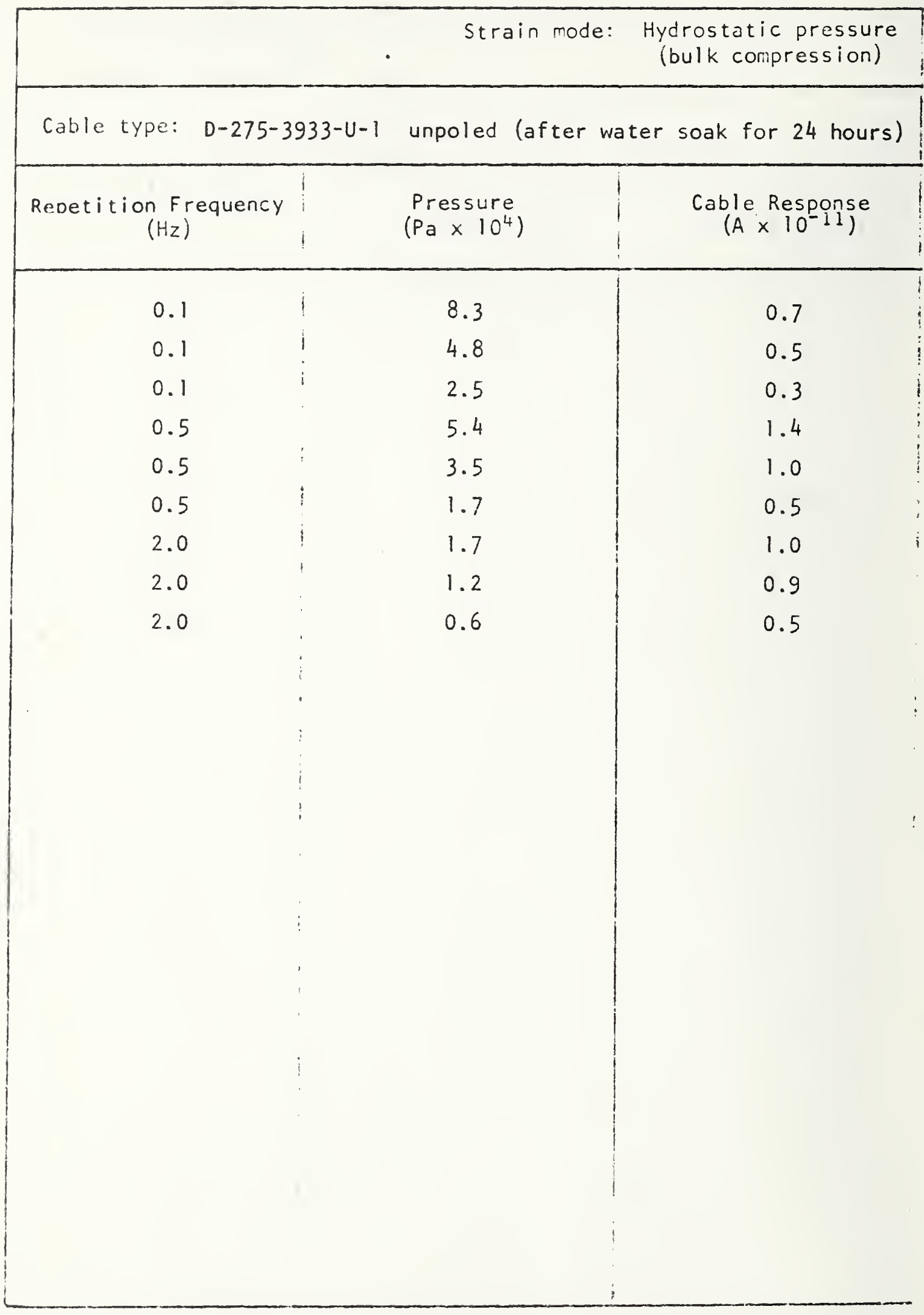


Strain mode: Hydrostatic pressure (bulk compression)

Cable type: D-275-3933-U-1 unpoled (after water soak for 48 hours)

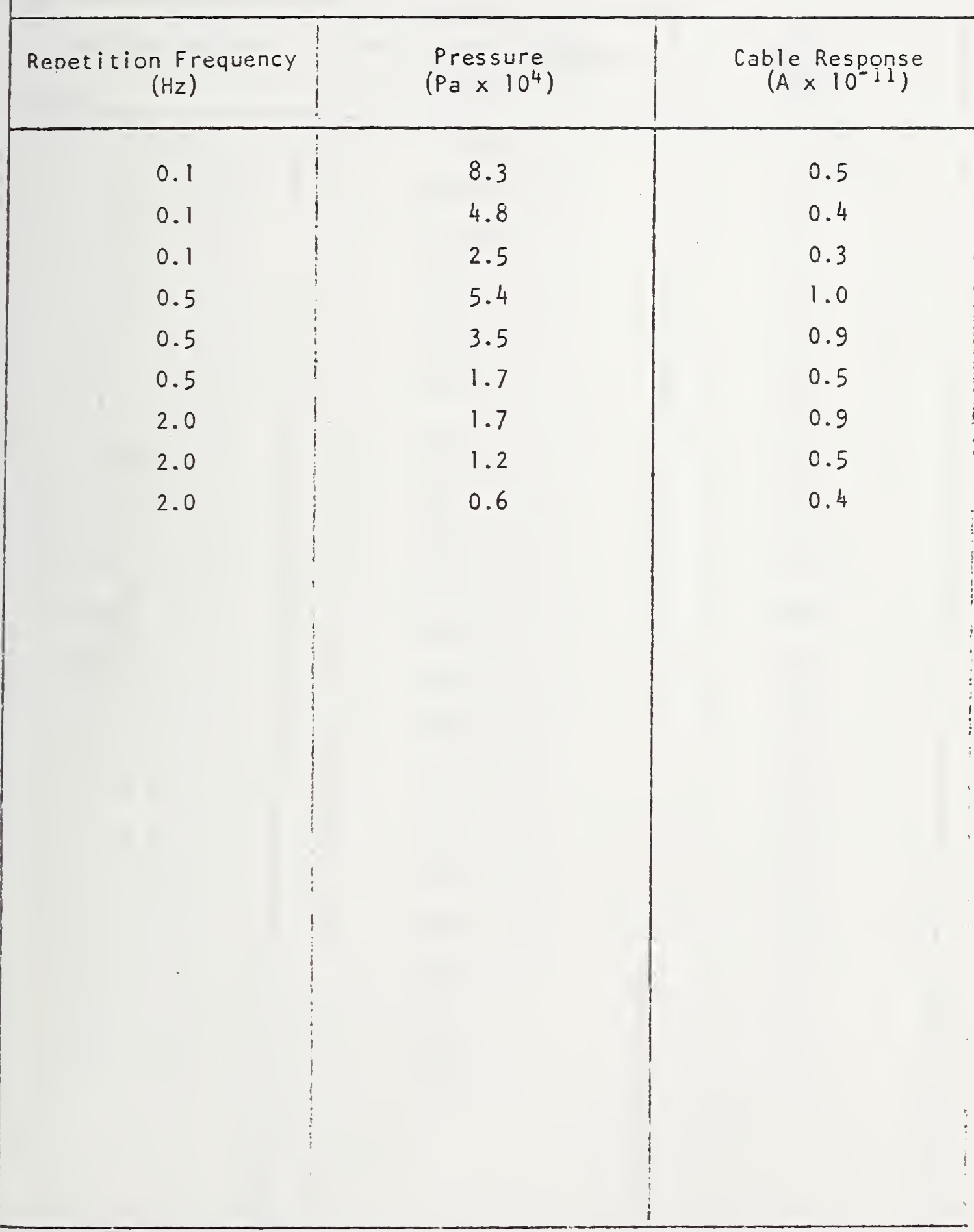




\section{Strain mode: Bending}

Cable type: D-275-3933 poled

\begin{tabular}{|c|c|c|}
\hline $\begin{array}{l}\text { Frequency } \\
\qquad(\mathrm{Hz})\end{array}$ & $\begin{array}{l}\text { Radius of Curvature } \\
\qquad\left(\mathrm{m} \times 10^{3}\right)\end{array}$ & $\begin{array}{l}\text { Cable Response } \\
\text { (A) }\end{array}$ \\
\hline $\begin{array}{l}1.0,0 \\
5.0 \\
10 . \\
12 . \\
14 . \\
16 . \\
18 . \\
20 . \\
22 . \\
24 . \\
26 . \\
28 . \\
30 . \\
32 . \\
34 . \\
36 . \\
38 . \\
40 . \\
45 . \\
50 . \\
55 . \\
60 . \\
65 . \\
70 .\end{array}$ & $\begin{array}{l}2.822 \\
2.699 \\
2.699 \\
2.699 \\
2.699 \\
2.699 \\
2.699 \\
2.699 \\
2.699 \\
2.699 \\
2.699 \\
2.699 \\
2.699 \\
2.699 \\
2.699 \\
2.699 \\
2.699 \\
2.699 \\
2.699 \\
2.699 \\
2.549 \\
2.515 \\
2.699 \\
15.30\end{array}$ & $\begin{array}{l}\text { in noise } \\
2.0 \times 10^{-12} \\
3.0 \times 10^{-12} \\
6.0 \times 10^{-12} \\
6.5 \times 10^{-12} \\
6.5 \times 10^{-12} \\
7.0 \times 10^{-12} \\
8.5 \times 10^{-12} \\
1.0 \times 10^{-11} \\
1.2 \times 10^{-11} \\
1.3 \times 10^{-11} \\
1.5 \times 10^{-11} \\
1.7 \times 10^{-11} \\
2.2 \times 10^{-11} \\
3.0 \times 10^{-11} \\
2.3 \times 10^{-11} \\
2.9 \times 10^{-11} \\
3.3 \times 10^{-11} \\
4.6 \times 10^{-11} \\
6.6 \times 10^{-11} \\
1.2 \times 10^{-10} \\
2.0 \times 10^{-10} \\
2.6 \times 10^{-10} \\
5.0 \times 10^{-10}\end{array}$ \\
\hline
\end{tabular}


Strain mode: Bending

Cable type: D-275-3933 unpoled

\begin{tabular}{|c|c|c|}
\hline $\begin{array}{l}\text { Frequency } \\
\qquad(\mathrm{Hz})\end{array}$ & $\begin{array}{l}\text { Radius of Curvature } \\
\qquad\left(\mathrm{m} \times 10^{3}\right)\end{array}$ & $\begin{array}{l}\text { Cable Response } \\
\text { (A) }\end{array}$ \\
\hline $\begin{array}{l}0.2,0.5,1.0 \\
5.0 \\
6.0 \\
7.0 \\
8.0 \\
10 . \\
15 . \\
20 . \\
22 . \\
24 . \\
26 . \\
28 . \\
30 . \\
32 . \\
34 . \\
36 . \\
38 . \\
55 . \\
60 . \\
65 .\end{array}$ & $\begin{array}{l}3.824 \\
3.824 \\
3.824 \\
3.824 \\
3.824 \\
3.824 \\
2.699 \\
2.699 \\
2.699 \\
2.699 \\
2.699 \\
2.699 \\
2.699 \\
2.699 \\
2.699 \\
2.699 \\
2.699 \\
2.699 \\
2.699 \\
2.699\end{array}$ & $\begin{array}{l}\text { in noise } \\
1.2 \times 10^{-12} \\
1.3 \times 10^{-12} \\
1.2 \times 10^{-12} \\
1.4 \times 10^{-12} \\
1.2 \times 10^{-12} \\
1.4 \times 10^{-12} \\
1.6 \times 10^{-12} \\
1.8 \times 10^{-12} \\
2.1 \times 10^{-12} \\
2.3 \times 10^{-12} \\
2.5 \times 10^{-12} \\
2.9 \times 10^{-12} \\
3.6 \times 10^{-12} \\
2.2 \times 10^{-11} \\
1.2 \times 10^{-11} \\
8.0 \times 10^{-12} \\
1.1 \times 10^{-11} \\
7.0 \times 10^{-12} \\
2.3 \times 10^{-11}\end{array}$ \\
\hline
\end{tabular}


Strain mode: Axial

Cable type: D-275-3933 poled

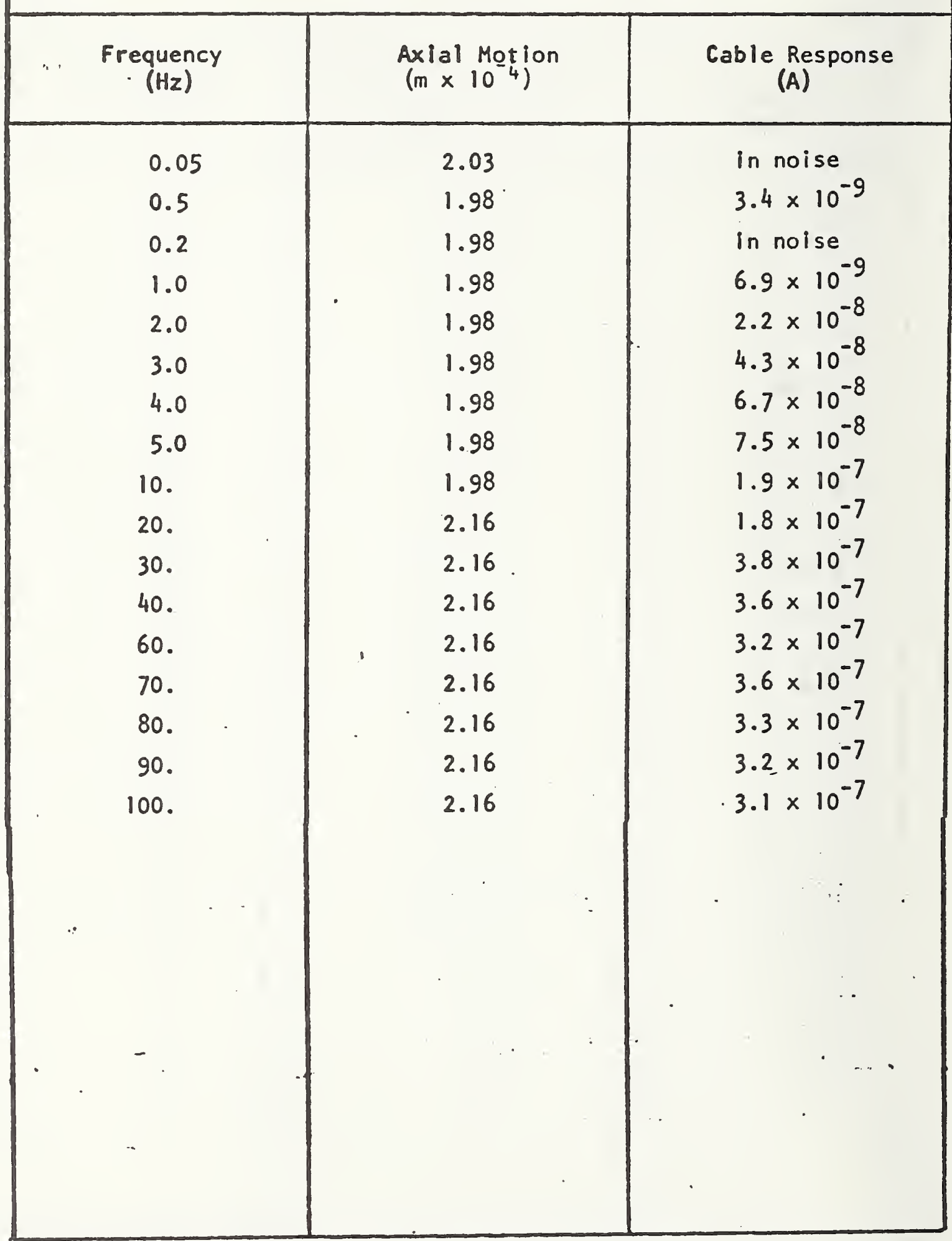


Strain mode: Axial

Cable type: D-275-3933 unpoled

\begin{tabular}{|c|c|c|}
\hline $\begin{array}{c}\text { Frequency } \\
\qquad(\mathrm{Hz})\end{array}$ & $\begin{array}{c}\text { Axlal Motion } \\
\left(m \times 10^{-4}\right)\end{array}$ & $\begin{array}{c}\text { Cable Response } \\
\text { (A) }\end{array}$ \\
\hline $\begin{array}{c}0.02,0.025,0.05,0.1 \\
0.02,0.025,0.05,0.1 \\
0.25 \\
0.25 \\
0.50 \\
0.50 \\
0.75 \\
0.75 \\
1.0 \\
1.0 \\
2.0 \\
3.0 \\
3.0 \\
4.0 \\
4.0 \\
5.0 \\
5.0 \\
10 . \\
10 . \\
15 . \\
15 . \\
20 . \\
20 .\end{array}$ & $\begin{array}{l}1.52 \\
3.05 \\
1.52 \\
3.10 \\
1.52 \\
3.05 \\
1.52 \\
3.05 \\
1.50 \\
3.07 \\
1.50 \\
1.50 \\
3.05 \\
1.52 \\
3.05 \\
1.52 \\
3.05 \\
1.52 \\
3.05 \\
1.52 \\
3.05 \\
1.52 \\
3.05\end{array}$ & $\begin{array}{l}\text { in noise } \\
\text { in noise } \\
\text { in noise } \\
4.2 \times 10^{-10} \\
\text { in noise } \\
1.0 \times 10^{-9} \\
\text { in noise } \\
2.4 \times 10^{-9} \\
4.3 \times 10^{-9} \\
8.6 \times 10^{-9} \\
6.4 \times 10^{-9} \\
1.1 \times 10^{-8} \\
2.3 \times 10^{-8} \\
1.5 \times 10^{-8} \\
3.4 \times 10^{-8} \\
2.0 \times 10^{-8} \\
5.0 \times 10^{-8} \\
8.6 \times 10^{-8} \\
1.7 \times 10^{-7} \\
1.3 \times 10^{-7} \\
2.3 \times 10^{-7} \\
4.6 \times 10^{-7} \\
9.2 \times 10^{-7}\end{array}$ \\
\hline
\end{tabular}


Strain mode: Axial

Cable type: D-275-3933 unpoled

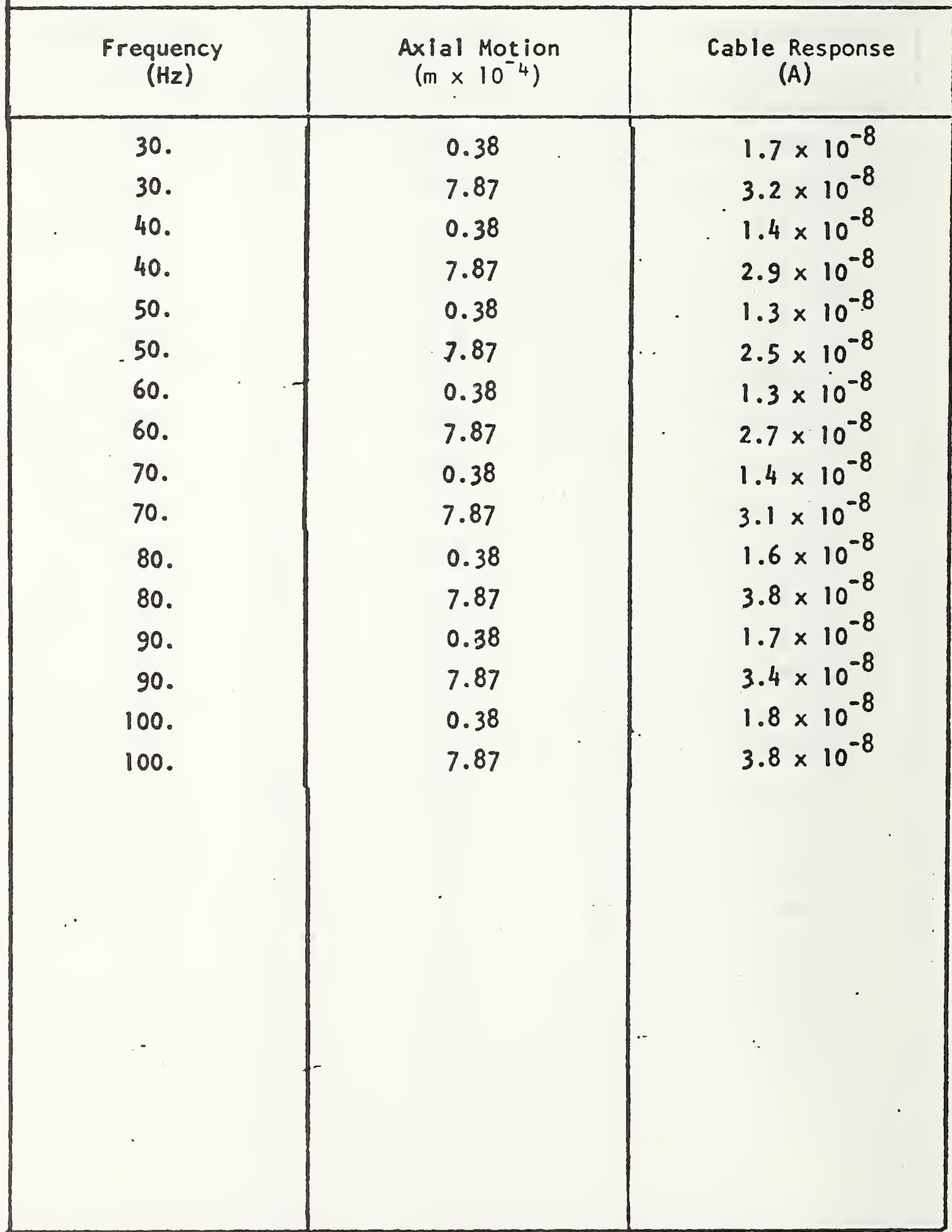


Strain mode: Torsional

Cable type: D-275-3933 poled

\begin{tabular}{|c|c|c|}
\hline $\begin{array}{l}\text { Frequency } \\
\qquad(\mathrm{Hz})\end{array}$ & $\begin{array}{l}\text { Angle } \\
\text { (rad) }\end{array}$ & $\begin{array}{c}\text { Cable Response } \\
\text { (A) }\end{array}$ \\
\hline $\begin{array}{c}0.02,0.05,0.5,1.0 \\
5.0 \\
13 . \\
15 . \\
30 . \\
42 . \\
50 . \\
84 . \\
90 . \\
110 . \\
170 .\end{array}$ & $\begin{array}{l}8.0 \times 10^{-6} \\
8.3 \times 10^{-6} \\
8.1 \times 10^{-6} \\
8.1 \times 10^{-6} \\
2.8 \times 10^{-6} \\
1.2 \times 10^{-6} \\
8.4 \times 10^{-7} \\
4.0 \times 10^{-7} \\
3.4 \times 10^{-7} \\
1.6 \times 10^{-7} \\
6.0 \times 10^{-8}\end{array}$ & $\begin{array}{l}\text { in noise } \\
2.0 \times 10^{-11} \\
1.0 \times 10^{-11} \\
5.0 \times 10^{-10} \\
2.4 \times 10^{-9} \\
6.8 \times 10^{-9} \\
5.0 \times 10^{-10} \\
5.0 \times 10^{-9} \\
7.0 \times 10^{-10} \\
6.4 \times 10^{-9} \\
4.4 \times 10^{-9}\end{array}$ \\
\hline Cable type: D-275-39 & 33 unpoled & \\
\hline $\begin{array}{l}\text { Frequency } \\
\qquad(\mathrm{Hz})\end{array}$ & $\begin{array}{l}\text { Angle } \\
\text { (rad) }\end{array}$ & $\begin{array}{c}\text { Cable Response } \\
\text { (A) }\end{array}$ \\
\hline $0.05-80$ & $8.0 \times 10^{-7}-2.6 \times 10^{-6}$ & $\begin{array}{l}\text { This cable type pro- } \\
\text { duced no measurable re } \\
\text { sponse above noise to } \\
\text { torsional strain. }\end{array}$ \\
\hline
\end{tabular}


Strain mode: Hydrostatic pressure (bulk compression)

Cable type: NBS-made FEP poled

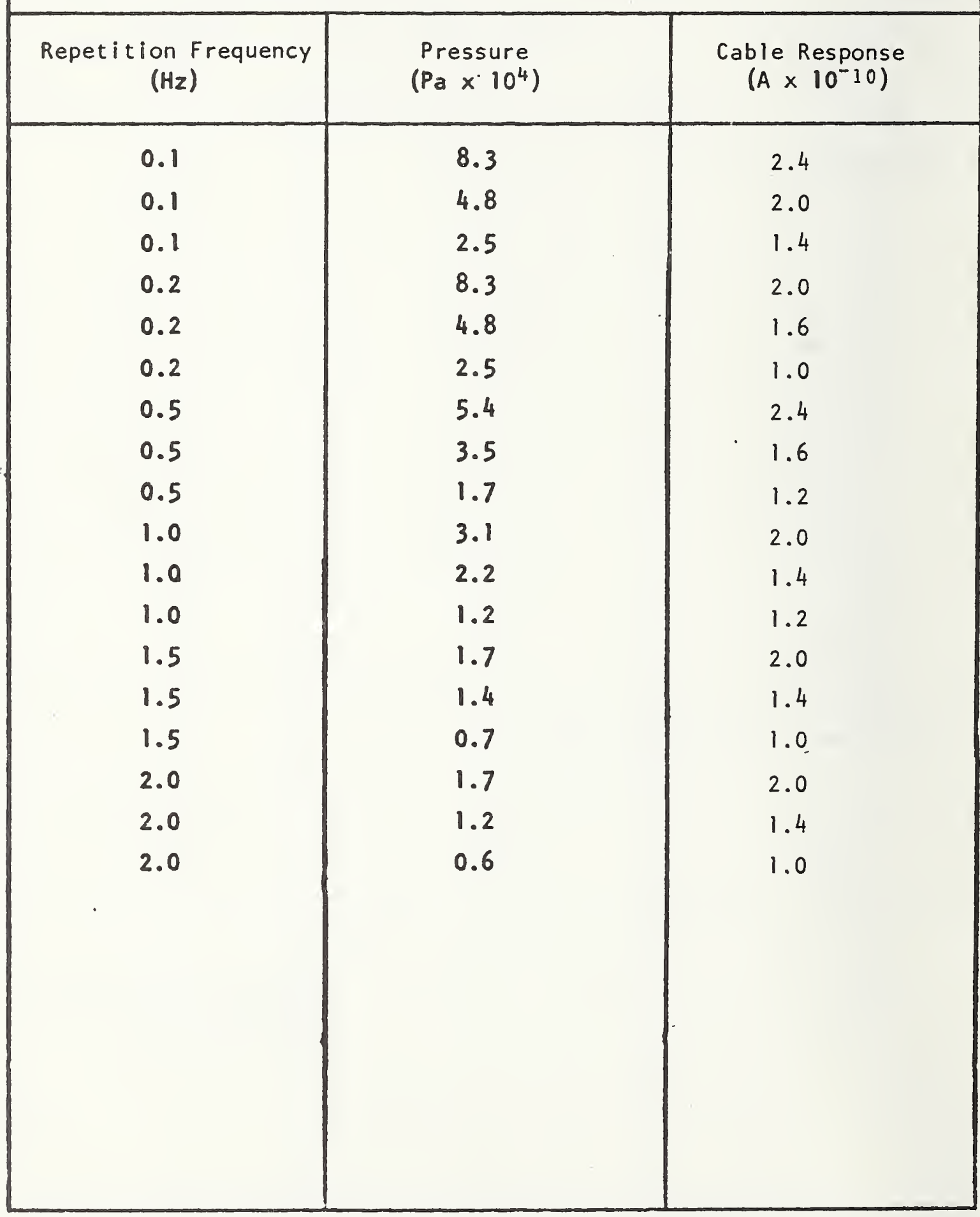


Strain mode: Hydrostatic pressure (bulk compression)

Cable type: NBS-made FEP unpoled

Repetition Frequency

$(\mathrm{Hz})$

$$
\text { Pressure }
$$

$\left(\mathrm{Pa} \times 10^{4}\right)$
Cable Response

$\left(A \times 10^{-11}\right)$
0.1
0.1
0.1
0.2
0.2
0.2
0.5
0.5
0.5
1.0
1. 0
1.0
1.5
1. 5
1.5
2.0
2. 0

8. 3

4.8

2.5

8.3

4.8

2.5

5.4

3.5

1. 7

3.1

2.2

I. 2

1.7

1.4

0.7

1.7

1. 2

0.6

1. 4

1. 4

0.6

1.4

1.4

0.8

1.4

1.0

0.7

1. 5

1.2

1.0

1. 5

1. 2

0.8

1. 4

1.0

0.8 
Strain mode: Hydrostatic pressure (bulk compression)

Cable type: NBS-made FEP unpoled (with polyolefin jacket)

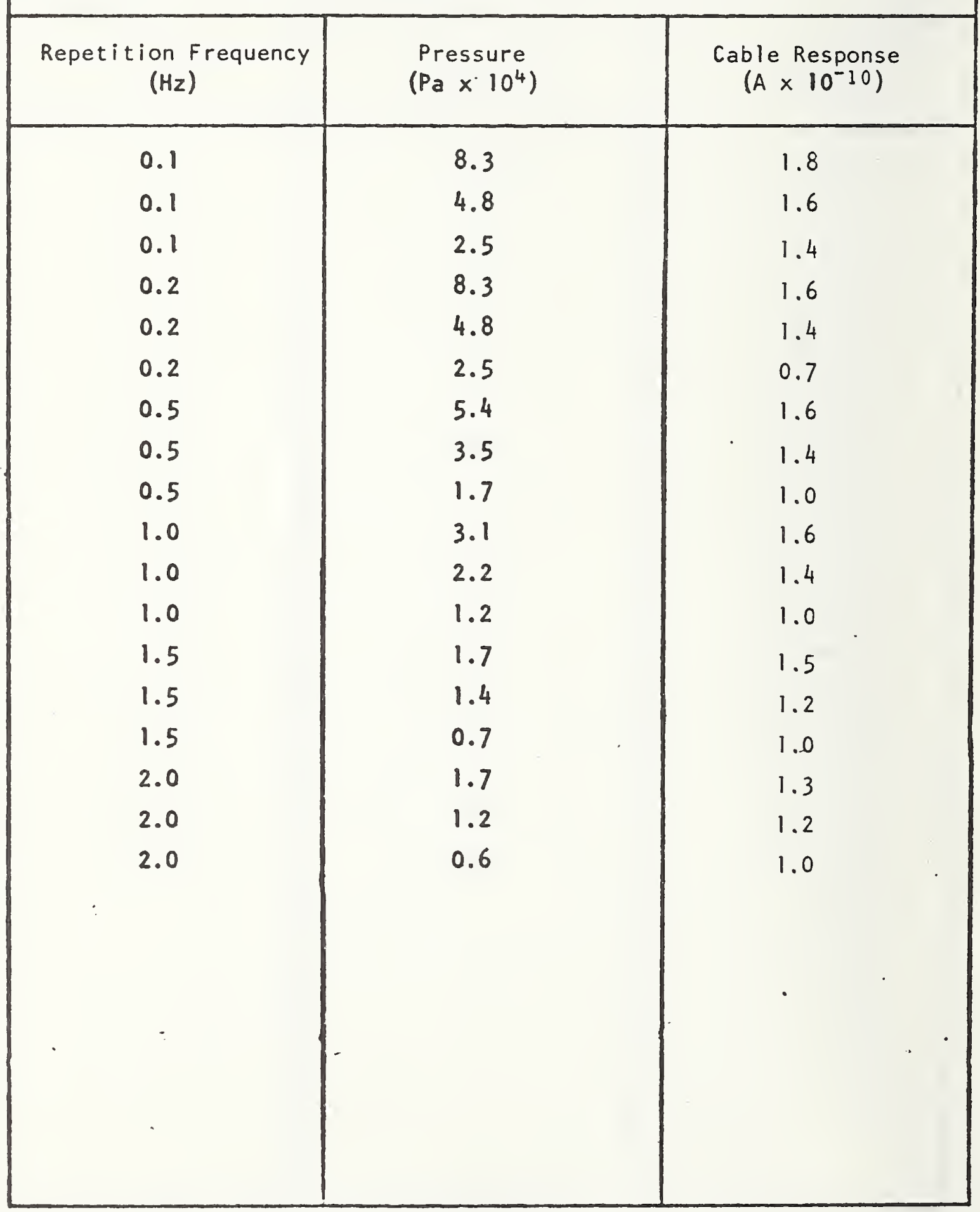


Strain mode: Axial

Cable type: NBS-made FEP poled

\begin{tabular}{|c|c|c|}
\hline $\begin{array}{c}\text { Frequency } \\
(\mathrm{Hz})\end{array}$ & $\begin{array}{c}\text { Axial Motion } \\
\left(\mathrm{m} \times 10^{-4}\right)\end{array}$ & $\begin{array}{c}\text { Cable Response } \\
(\mathrm{A})\end{array}$ \\
\hline 0.05 & 1.52 & in noise \\
0.5 & 1.47 & $6.8 \times 10^{-10}$ \\
1.0 & 1.50 & $5.3 \times 10^{-9}$ \\
2.5 & 1.55 & $1.0 \times 10^{-8}$ \\
5.0 & 1.37 & $2.0 \times 10^{-8}$ \\
10. & 1.27 & $7.6 \times 10^{-8}$ \\
25. & 1.52 & $5.0 \times 10^{-8}$ \\
50. & 0.76 & $2.5 \times 10^{-8}$ \\
75. & 0.76 & $2.1 \times 10^{-8}$ \\
100. & 0.76 & $1.1 \times 10^{-8}$ \\
\hline
\end{tabular}

Cable type: NBS-made FEP unpoled

\begin{tabular}{|c|c|c|}
\hline $\begin{array}{c}\text { Frequency } \\
(\mathrm{Hz})\end{array}$ & $\begin{array}{c}\text { Axial Motion } \\
\left(\mathrm{m} \times 10^{-4}\right)\end{array}$ & $\begin{array}{c}\text { Cable Response } \\
\left(\mathrm{A} \times 10^{-8}\right)\end{array}$ \\
\hline $0.05,0.1,0.2,0.25$ & 3.05 & in noise \\
0.5 & 3.10 & 0.1 \\
1.0 & 3.10 & 0.5 \\
2.5 & 3.10 & 0.91 \\
5.0 & 3.15 & 2.0 \\
10. & 3.15 & 7.2 \\
25. & 3.20 & 5.9 \\
50. & 0.38 & 0.5 \\
70. & 0.38 & 1.6 \\
90. & 0.38 & 1.1 \\
100. & 0.38 & 0.76 \\
\hline
\end{tabular}


Strain mode: Torsional

Cable type: NBS-made FEP poled

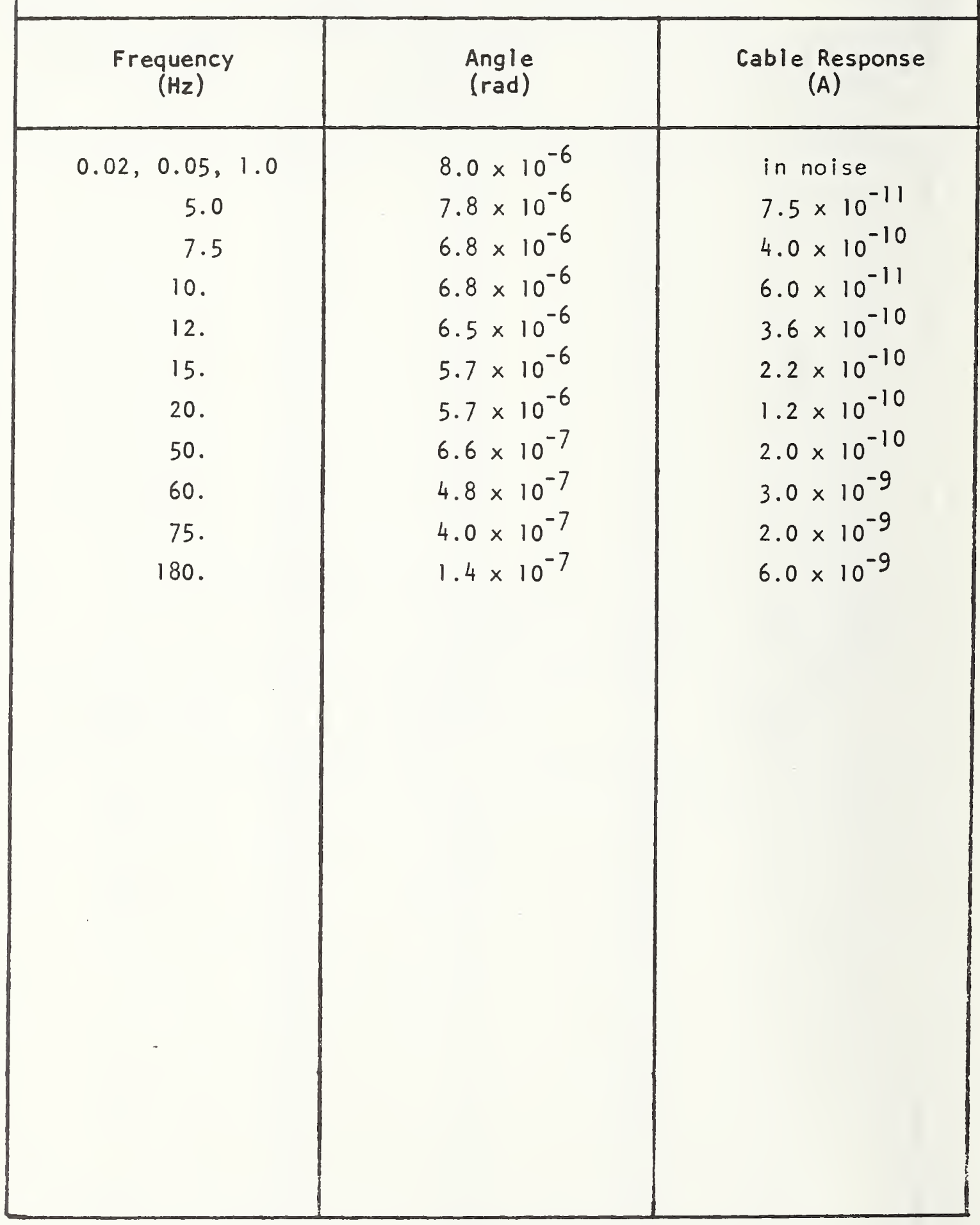


Cable type: NBS-made FEP unpoled

\begin{tabular}{|c|c|l|}
\hline $\begin{array}{c}\text { Frequency } \\
(\mathrm{Hz})\end{array}$ & $\begin{array}{c}\text { Angle } \\
\text { (rad) }\end{array}$ & $\begin{array}{l}\text { Cable Response } \\
(\mathrm{A})\end{array}$ \\
\hline $0.02,0.05,0.5,1.0$ & $8.0 \times 10^{-6}$ & in noise \\
2.0 & $8.1 \times 10^{-6}$ & $4.0 \times 10^{-12}$ \\
4.0 & $8.0 \times 10^{-6}$ & $1.4 \times 10^{-11}$ \\
5.0 & $8.2 \times 10^{-6}$ & $2.4 \times 10^{-11}$ \\
10,30 & $8.0 \times 10^{-6}$ & in noise \\
42. & $1.1 \times 10^{-6}$ & $8.0 \times 10^{-10}$ \\
50. & $8.4 \times 10^{-7}$ & $1.5 \times 10^{-11}$ \\
74. & $4.0 \times 10^{-7}$ & $3.0 \times 10^{-10}$ \\
80. & $3.4 \times 10^{-7}$ & $3.5 \times 10^{-10}$ \\
85. & $3.0 \times 10^{-7}$ & $3.0 \times 10^{-11}$ \\
90. & $2.8 \times 10^{-7}$ & \\
100. & & \\
& &
\end{tabular}




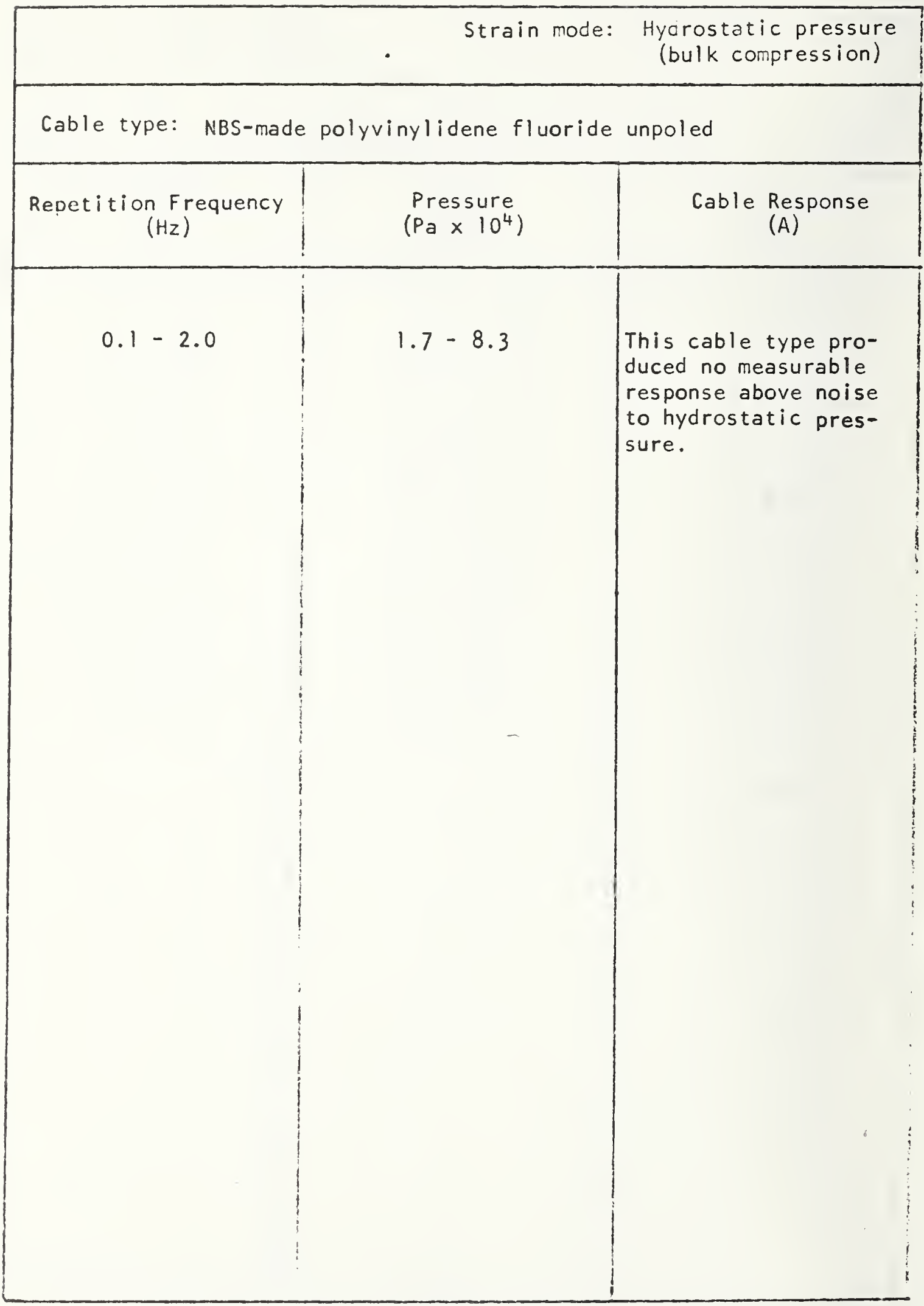




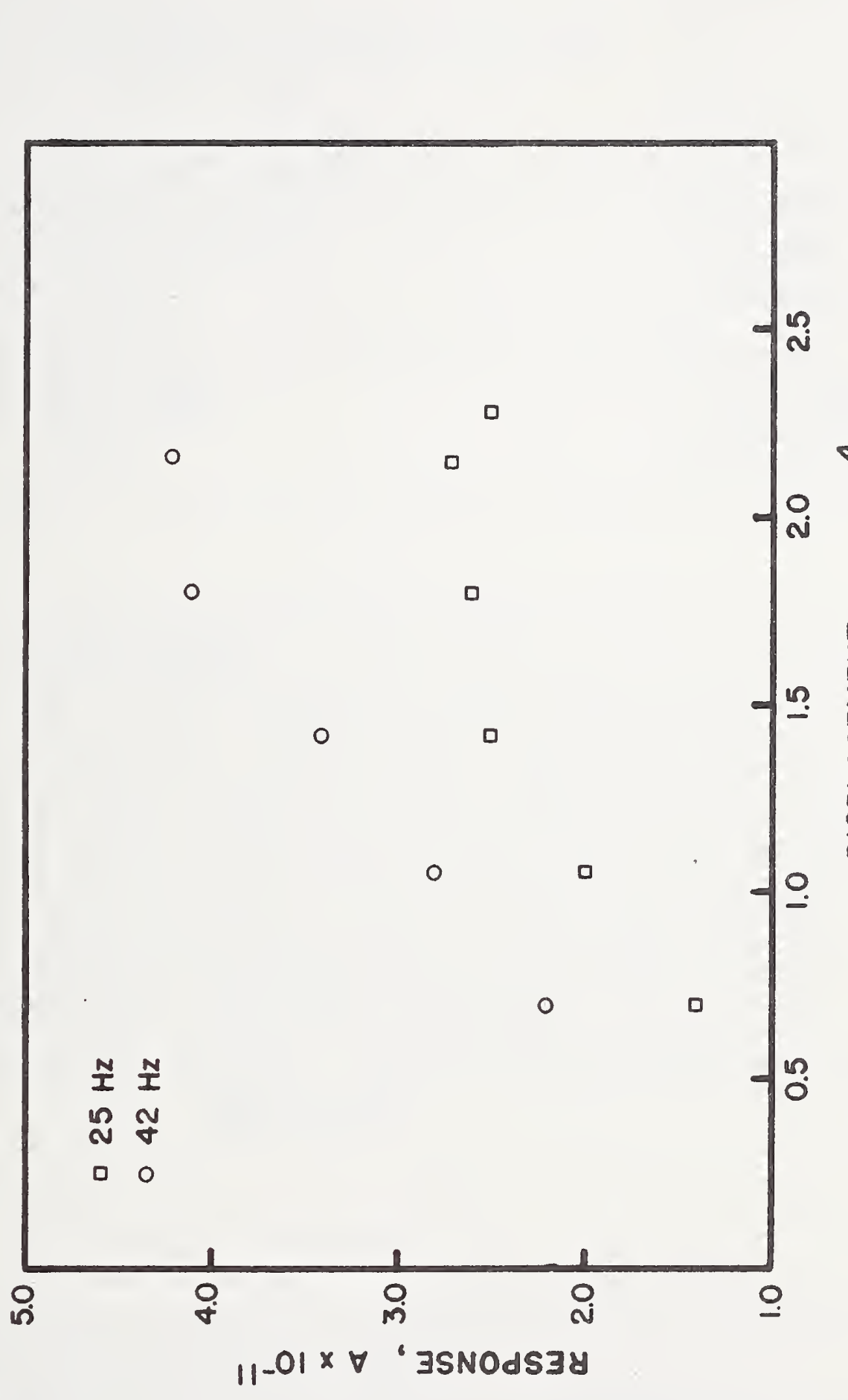

is

山Ш

₹

山

ल

过 㟧

岁

2

崖

뭉

w?

* w

으 붕 뭉

E 눌

넘
울

- z

$\sum_{11}<\frac{1}{4}$

$\frac{d}{d}$

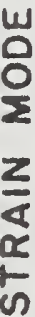

\& 


1. PUBLICATION OR REPORT NO.
NBSIR $73-41 \%$

Test Methods for Determining Coaxial Cable Response to Bending Strain, Bulk Compression (Hydrostatic Pressure), Axial Tension, and Torsional Strain

\section{AUTHOR(S)}

J.F. Mayo-Wells, S. Edelman, and J. Jacobs

9. PERF ORMING ORGANIZATION NAME AND ADDRESS

NATIONAL BUREAU OF STANDARDS

DEPARTMENT OF COMMERCE

W'ASHINGTON, D.C. 20234
2. Gov't Accession
No.

3. Recipient's Accession No.

5. Publication Date

D. Hertorming urganization code

8. Performing Organization

10. Project/Task/W'ork Unit No. 4253445

11. Contract/Grant No. UN CLAS/711A2167

13. Tune of Renner \& Pariod Final Report July, 1972

14. Sponsoring Agency Code

15. SUPPLEMENTARY NOTES

16. ABSTRACT (A 200-word or less factual summary of most significant information. If document includes a significant bibliography or literature survey, mention it here.)

Test methods have been developed for measuring the response of specimen one-meter lengths of coaxial cables, considered as sensing elements, to four separate types of strain: bending strain, bulk compression, axial tension, and torsional strain. Measurements were made on commercially available coaxial cables and on coaxial cables made in the laboratory from insulated wire and wire braid. Cable dielectric materials investigated include tetrafluoroethylene (TFE), fluorinated ethylene propylene (FEP), cellular FEP, polyethylene, cellular polyethylene, and polyvinyl chloride. Data from the measuremerts are included in appendipes.

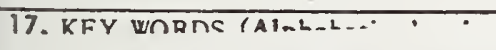

Cable; coaxial; mechanical; response; strain

18. AVAILABILITY STATEMENT

UNL IMIT ED.

FOR OFFICIAL DISTRIBUTION. DO NOT RELEASE TO NTIS.

\begin{tabular}{|l|l|}
\hline $\begin{array}{l}\text { 19. SECURITY CLASS } \\
\text { (THIS REPORT) }\end{array}$ & 21. NO. OF PAGES \\
UNCL ASSIFIED & \\
\hline $\begin{array}{l}\text { 20. SECUR ITY CLASS } \\
\text { (THIS PAGE) }\end{array}$ & 22. Price \\
UNCLASSIFIED & \\
\hline
\end{tabular}





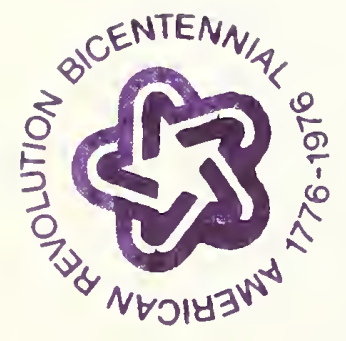

